WORKING PAPER $\cdot$ NO. 2020-38

\title{
In Living Color: Does In-Person Screening Affect Who Gets Hired?
}

John M. Barrios, Laura Giuliano, and Andrew J. Leone MARCH 2020

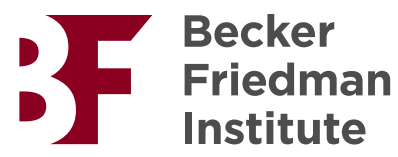




\title{
In Living Color: Does In-Person Screening Affect Who Gets Hired?*
}

\author{
John M. Barrios, Laura Giuliano and Andrew J. Leone ${ }^{\dagger}$
}

March 2020

\begin{abstract}
When hiring new workers, employers often screen large numbers of written applications before selecting a subset for more costly, in-person interviews. A large literature suggests that information frictions lead to screening on imperfect quality signals-e.g., educational pedigree and network-based referrals-and that these practices can perpetuate labor-market inequities. In theory, a reduction in the cost of in-person screening could lead to improvements in both efficiency and equity by reducing the use of blunt signals that disadvantage certain groups. We test this hypothesis by studying the introduction of a labor-market intermediary, the Accounting Rookie Camp (ARC), that greatly facilitated in-person screening in the labor market for $\mathrm{PhD}$ accountants. Using a novel data set with information on new PhDs, recruiters and market outcomes over 11 years, we estimate difference-in-difference models that leverage variation in the timing of ARC adoption. We find that degree program rank and adviser connectedness are strong predictors of initial job placements, but that their impacts are significantly reduced by participation in ARC. The results suggest that the historical returns to program reputation and adviser networks were driven partly by their signaling values, which were reduced by new the information channels created by ARC. They also indicate that in some respects, ARC adoption helped foster greater diversity in hiring. At the same time, we find no evidence that ARC reduced existing disparities in placements by gender and only weak evidence that it benefited under-represented minorities. Finally, using names to predict nationality and native language, we find that ARC led to worse placements for candidates whose native language is very different from English.
\end{abstract}

Keywords: Job Matching, Screening, Signaling, Hiring, Networks, Imperfect Information, In-Person Interview, Academic Labor Market.

JEL Classification Numbers: D83,J7,J23, J44, M510.

${ }^{*}$ We thank Micheal Gibbs, Abbie Smith, Jack Mountjoy, Thomas Wollmann, and workshop participants at INSEAD, National University of Singapore, Pomona College, University of Chicago Booth, UC Santa Cruz, Georgia State University, and Yale SOM. We thank Jin Deng for outstanding research assistance.

${ }^{\dagger}$ Barrios: University of Chicago, john.barrios@chicagobooth.edu. Giuliano: UC Santa Cruz, lgiulian@ucsc.edu. Leone: Northwestern, andrew.leone@kellogg.northwestern.edu. 


\section{Introduction}

When hiring new workers, employers often care about qualities that are hard to ascertain or verify from written application materials. In-person interviews can be more informative, but due to their high cost, they tend to be limited to a subset of pre-screened applicants. Research suggests that in the initial screening process, employers often rely on educational pedigree, network-based referrals, or group membership (e.g., race or gender) as signals of applicant quality or fit. However, to the extent these signals correlate with socioeconomic advantage and not ability, they will yield relatively small efficiency gains and will instead have distributional effects Arrow, 1973; Montgomery, 1991) that may perpetuate inequalities (Calvo-Armengol and Jackson, 2004).

In theory, an innovation that reduces the cost of in-person screening could lead to improvements in both efficiency and equity by reducing information asymmetries and the need to rely on blunt signals that disadvantage certain groups. However, increasing the role of personal interactions in the screening process could also give way to greater influence for bias or errors in judgment (Hoffman et al., 2018). More generally, it could increase the weight placed on any candidate characteristic that is easier to observe in person. Despite a large body of empirical research aimed at understanding the practical importance and distributional consequences of job market screening, there is little rigorous evidence on the role of in-person evaluations.

We address this gap by studying the introduction of a labor-market intermediary that dramatically changed the hiring process in the academic labor market for $\mathrm{PhD}$ accountants. Before 2010, universities seeking to hire PhD accountants for research-oriented positions typically did not meet with applicants in person before selecting a short list of candidates to invite for campus interviews. However, in 2010, a two-day meeting known as the Accounting Rookie Camp (ARC) was created to facilitate in-person screening. Its stated purpose is to provide a forum for faculty and recruiters to meet and network with $\mathrm{PhD}$ candidates, attend 15-minute research presentations by job-seeking candidates, and interview job-market 
candidates before making decisions about recruiting 'fly-outs.1

If the Rookie Camp provided new information about candidates that recruiters used to update their assessments and inform their fly-out decisions, then we should expect to see less weight placed on other imperfect proxies that were previously used by recruiters to screen applicants. To test this prediction, we assemble 11 years of data on new $\mathrm{PhD}$ job candidates, recruiters, and market outcomes. We then leverage the staggered adoption of ARC by institutions on both sides of the market to examine how the determinants of job-market matches changed as institutions began participating in the Rookie Camp.

We begin by focusing on a well-known correlate of job outcomes in academia: the research rank of one's $\mathrm{PhD}$ program. Consistent with prior research, we find there is a high degree of assortative matching in the labor market for new PhDs in Accounting: degree program reputation is a strong predictor of a candidate's initial success, as measured by the rank of the hiring institution. We then estimate difference-in-difference models that allow this relationship to change after institutions begin participating in the Rookie Camp. We find that the impact of program rank is significantly reduced by participation. This result is robust to models that use variation from both sides of the market, and it does not appear to be driven either by pre-existing trends or by selection in the timing of adoption.

We interpret this result as implying that the historical return to program reputation was driven partly by its signaling value to employers, which is diminished by the new information channels created by the Rookie Camp. We also conclude that by reducing the influence of program reputation, the $\mathrm{ARC}$ helped foster greater diversity in hiring, at least on one key dimension.

Next, we investigate the role of personal connections by examining the coauthor networks of a candidate's PhD thesis adviser. We find that even when controlling for assortative matching based on institution rank, the presence of a coauthor connection between a candidate's adviser and a hiring school greatly increases the likelihood of that particular

\footnotetext{
${ }^{1}$ http://aaahq.org/Meetings/2018/Accounting-Rookie-Camp.
} 
job match being realized. Again, however, the impact of adviser connections is significantly reduced after ARC adoption. Moreover, we find a similar reduction in the importance of geographic proximity in determining which job matches are realized in the market. These findings lend further support to our conclusion that when the cost of in-person screening was lowered by ARC, recruiters reduced their reliance on traditional screening mechanisms and information channels.

Turning to candidate-level characteristics, we first explore changes in the role of premarket publications-arguably one of the best and most easily verifiable signals of future productivity. We distinguish between the importance of having any publication prior to graduation and having a "top-5" publication (a strong and relatively rare signal). We find that prior to ARC, having a top- 5 was was especially important for candidates for lowerranked schools, carrying almost twice as much weight as for candidates from higher-ranked schools, but that the opposite was true for other publications. Interestingly, ARC appears to have helped level the playing field by reducing disparities in the weights of both signals. Thus for candidates from lower-ranked schools, ARC participation reduced the importance of having a top-5, but increased their relative return to publications in general, possibly by improving the odds that their application materials would be carefully reviewed.

If the impact of $\mathrm{ARC}$ on hiring patterns was driven primarily by employers ability to make more informed decisions, then its introduction should have led to better hires by the earlier adopters and more efficient matches generally. Consistent with this prediction, we find significant positive effects of ARC adoption by recruiters on both the quantity and quality of publications authored by their new hires within the first three years of employment.2

Finally, we also test for differential effects of the new screening process by the gender, race, or nationality of the candidate (as inferred from names or photographs). If the ARC helped level the playing field in the job market by reducing the role of educational pedigree and personal connections, a natural question is whether ARC also helped foster diversity

\footnotetext{
${ }^{2}$ In future work, we will examine ARC's effect on match quality as measured by turnover and likelihood of tenure with the initial employer.
} 
with regard to gender, race, or nationality. Our findings suggest that it did not. We find no evidence that ARC participation reduced existing disparities in placements by gender and only weak evidence that it benefited under-represented minorities.3

Perhaps our most striking finding pertains to candidates whose undergraduate degrees were from outside the U.S.--and especially those with Chinese surnames. We find that Rookie Camp participation resulted in a penalty for such individuals, as measured by a decline in the probability of placing at a highly ranked university (relative to candidates with domestic undergraduate degrees or English-sounding surnames). If we interpret this result in a framework of statistical discrimination (Arrow, 1973), it might suggest that the new information gleaned from the Rookie Camp led employers to update their prior beliefs about the research productivity in a negative direction for Chinese candidates. An alternate interpretation is that the increased role of interpersonal interaction may have caused factors like language or culture to become more salient or to carry more weight in the overall evaluation of candidates. We find some evidence of an increased role for language when we characterize candidates by the distance between their (predicted) native language and English (though this is highly correlated with Chinese nationality).

To further probe the finding for candidates with Chinese surnames, we focus attention on a subset of these individuals who have what might be considered a signal of their English fluency and/or assimilation with American culture: an English or white-sounding first name $4^{4}$ We find that these candidates historically obtained relatively high-ranked jobs, but that they perform significantly worse in the years following ARC adoption, with negative impacts that are much larger than those for Chinese overall. Estimates from models of pre-market quality

\footnotetext{
${ }^{3}$ Moreover, when we estimate ARC's impact on the role of program reputation separately by gender, we find that the diversifying effect is driven mainly by improved placements for male candidates from lowerranked programs. With regard to under-represented minorities (Blacks and Hispanics), our estimates suggest that like female candidates, these groups also tend to be under-placed, but unlike female candidates, minority candidates appear to benefit from ARC participation. However, the estimated impact is imprecise due to the small numbers of minorities in our sample.

${ }^{4}$ We include both individuals whose only first name is white and those who list a white-sounding name in parenthesis after their Chinese name. Roughly 13 percent (50 out of 396) individuals with Chinese surnames have a white-sounding first name.
} 
signals, including measures of written English proficiency derived from textual analysis of PhD dissertations, help to rule out differential changes in the quality of candidates' written application materials as driver of our results.

In future work, we will supplement our analysis of job placements with an analysis of flyout data constructed from CVs and an email survey. This will allow us to test whether the effects we find on hiring were mediated through changes in who received flyout invitations, as would be expected if our findings indeed reflect changes in the initial screening process. We will also examine whether recruiter attendance at a candidates research presentation, which we will proxy from the randomly assigned time slot, moderates ARC's impact. Because the presentation schedule was determined randomly, a moderating effect of a good time slot on the importance of other signals could be interpreted as evidence that recruiters relied on information garnered from the presentations when making flyout decisions.

A large body of research has been devoted to understanding the theoretical implications of informational asymmetries in the hiring process as well as the practical importance and distributional consequences of various signaling and screening mechanisms. Empirical studies often focus on identifying the role for signaling or screening through a particular mechanism such as educational attainment, network-based referrals, or statistical discrimination based on group membership (e.g., race or gender). A common challenge in this literature is how to credibly distinguish these mechanisms from other channels linking applicant characteristics to labor market outcomes.

Methodologically, our study complements a strand of literature that identifies the presence of screening or signaling by asking how employers respond to a sharp change in the cost or availability of information on applicant quality. Two recent examples are MacLeod et al. (2017), who find that employer access to a new measure of individual skill reduces the return to college reputation in Colombia, and Agan and Starr (2018), who find that a ban on the use of criminal background checks in New Jersey led to a higher penalty for black males in the screening process for job interviews. 
More generally, our study builds on three specific strands in the literature:

1. Signaling value of education. We provide new evidence on the long-standing question of whether the returns to education reflect a signaling value (Spence, 1973) in addition to a human capital effect on productivity (Becker, 1964). Distinguishing between these two channels is difficult because individuals rarely differ in the educational credentials that might signal their ability to employers without also differing their accumulated human capital (Clark and Martorell, 2014). Early work by Farber and Gibbons (1996) and Altonji and Pierret (2001) proposed testing the prediction that if signaling is important, the return to education should diminish with job tenure as employers learn about worker ability. In this vein, Oyer and Schaefer (2019) find that the return to an elite law-school education is large and relatively stable over time, and interpret this as suggesting a small role for signaling. However, as these authors acknowledge, the persistence in earnings variation could be caused partly by variation in the quality of first jobs rather than individual earnings potential (Oyer, 2006; Oreopoulos et al., 2012; Kahn, 2010).

Our approach circumvents these issues by asking how informational frictions affect the return to educational reputation in initial job placements. This approach is most similar to MacLeod et al. (2017) who study the returns to college reputation in the Colombian labor market and find that the introduction of a college exit exam, which provides employers new information about the skills of college graduates, leads to a reduction in the effect of college reputation on earnings. Aside from a different context, our study differs in several key ways. One is that we can distinguish empirically between the reputation of one's degree program and the connections of one's adviser; our results point to the independent effects of program reputation and networks. Another crucial difference is that in our context, the new information available to employers is obtained from in-person interactions rather than an objective measure of skill.

2. Networks and employee referrals. Theory suggests that among other reasons, firms may use referrals as a screening mechanism to reduce asymmetric information (Montgomery, 
1991). In our context, an adviser's professional and social connections to faculty at other institutions may impact her students' placements because it enhances her ability to provide credible signals about match quality. Other possible channels include reciprocity and favoritism. The empirical literature on hiring networks has produced substantial credible evidence that networks and referrals influence labor market outcomes Kramarz and Skans, 2014); however, less is known about the reasons why network-based hiring is so common. Support for the screening explanation has been found in the context of ethnicity-based networks in Germany (Dustmann et al., 2016) and in a selection of large U.S. firms (Burks et al., 2015; Brown et al., 2016). But in a field experiment in India, Beaman and Magruder (2012) find that network-based hiring can lead to favoritism and reduced productivity. We extend this body of evidence to the context of academic labor markets.

3. Statistical discrimination. Our study is also related to the literature on race and gender-based statistical discrimination. A key challenge in this literature is the difficulty of distinguishing between statistical discrimination-e.g., the use of race as a proxy for some other quality the employer cares about-and discrimination due to implicit bias or prejudice of the hiring agent. An established literature uses correspondence studies that randomly assign names to fictitious resumes as a means of testing for hiring discrimination. In their seminal paper, Bertrand and Mullainathan (2004) find that resumes with "white" names receive roughly $50 \%$ more call-backs than those with "black" names, and this gap is robust to the inclusion of additional information that could signal productivity. The authors cautiously interpret this evidence as being more consistent with employer bias than with statistical discrimination. However, recent work by Agan and Starr (2018) find strong evidence of racebased statistical discrimination by showing that so-called "ban-the-box" policies, which limit employers use of criminal background checks to screen job applicants, reduce the call-back success rates for resumes of black men.

Understanding the motivations and mechanisms underlying name-based discrepancies in call back rates is key for understanding the policy implications. For example, if discrimi- 
nation is statistical and if an applicant's race is a coarse proxy for productivity, then racial disparities might be addressed by changes in sequencing or screening technology. Under this scenario, individuals from "out" groups might also improve their own outcomes by adopting names that signal in-group status (Biavaschi et al., 2017; Oreopoulos et al., 2012; Arai and Skogman Thoursie, 2009). On the other hand, in the presence of a strong racial bias or preference for a characteristic that is highly correlated with race, disparities are likely to persist under any screening technology in which race is observed prior to the final hiring decision.

Interestingly, advocates for ban-the-box policies have stressed the importance of rapport building for overcoming stereotypes that lead to statistical discrimination. Support for this view comes from audit studies that use individuals rather than resumes and conclude, for example, that personal contact plays an essential role in mediating the effects of criminal stigma (e.g., Pager et al. 2009). While ban-the-box policies appear to have reduced interview opportunities for black men because they increased employer screening costs, the question remains whether a reduction in interview costs could have led to the intended benefits. While our study focuses on a more specialized market, it provides some of the first rigorous evidence, using data on actual job seekers, on the broader question of how increasing personal contact in the early stages of the job screening process affects labor market outcomes.

Finally, this study complements prior work on academic labor markets in economics, accounting and other related fields. Several studies find that degree school reputation and advisor connections are both strong predictors of job market success $!^{5}$ However, to the extent that a candidate's research potential is improved by attending a higher-quality $\mathrm{PhD}$ program and having an adviser with better networks, these patterns of assortative matching

\footnotetext{
${ }^{5}$ The importance of attending an elite graduate or undergraduate institution has been documented in the markets for economists (Athey et al., 2007, Smeets et al., 2006); financial economists (Chan et al. 2009); lawyers (Oyer and Schaefer, 2019); and accountants (Fogarty et al., 2011). Others have found that adviser connections play a significant role. For example, see Rose and Shekhar (2018) and Krueger and Wu (2000) on the market for economists; and Hadlock and Pierce (2018) on financial economists. School-based networks have also been studied in the markets for lawyers (Oyer and Schaefer, 2016, 2019) and for PhDs in political science (Fowler et al., 2007)
} 
would be expected even if future research productivity were perfectly observed 6 As such, most of the prior research does not speak to the importance of school reputation or adviser connections as screening devices. Our finding that the returns to these established predictors of job-market success are diminished when informational frictions are reduced allows us to conclude that their value to recruiters is derived partly from the difficulty of assessing application quality. This conclusion is consistent with that of Conley and Onder (2014) who study the determinants of research productivity of new PhDs in Economics and conclude that there is substantial noise in identifying research talent at the time the doctoral degree is granted. Importantly, our study goes beyond descriptive evidence and provides causal evidence that labor market institutions like ARC can reduce informational frictions.7

\section{Setting}

\subsection{The Academic Labor Market for Ph.D. Accountants}

Like most other academic job markets, the academic market for $\mathrm{PhDs}$ in accounting is characterized by a decentralized search and matching process, with timing that is driven by the academic calendar. Because skills and personal qualities that are highly valued are also hard to convey credibly in writing, campus interviews ("flyouts")-in which candidates give a formal presentation of their research and have individual meetings with current faculty-are an essential part of the process. But because they typically include only a small fraction of applicants, the screening process used to narrow the applicant pool is also critical. Studies examining the determinants of placements in accounting and related academic fields have found that both adviser connectedness and reputation of degree-granting institutions play

\footnotetext{
${ }^{6}$ Another link between credentialing and labor market outcomes is through rents. Barrios (2019) finds that adoption of the 150-hour rule which increased the educational requirements for a CPA license led to a reduced supply of new CPAs and increased rents to the profession with little impact on quality.

${ }^{7}$ Two recent studies find evidence that in-person meetings have significant positive effects on the formation and dissemination of knowledge among researchers (Leite Lopez de Leon and McQuillin, 2020, Catalini et al. 2020). However, we know of no studies that examine impacts on hiring.
} 
important roles (Krueger and Wu, 2000; Baruffaldi et al., 2016; Rose and Shekhar, 2018). However, prior to 2010, universities seeking to hire $\mathrm{PhD}$ accountants for research-oriented positions typically did not meet with candidates in person before selecting their fly-out list.

The annual job market for new accounting PhDs typically starts in September of the year before the job begins. Most degrees are awarded in May or June and academic jobs typically begin in July or August of the following year. Job openings for accounting PhDs are listed through the Accounting Research Network, the American Accounting Association (AAA), and HigherEd Jobs, although a small number of schools post solely on their own websites. Schools require candidates to submit applications and advisors to submit letters of reference through a number of modalities, including mail, e-mail, university-specific web servers, and third-party web servers. Traditionally, employers would review applications throughout the fall and in January invite some applicants to on campus interviews. Flyouts occur from late January to the end of March with the market clearing by April and with most candidates finding positions. Applicants who have not secured a position by late April may seek temporary academic employment as one-year visiting assistant professors or as lecturers; or they may postpone graduation and re-enter the job market the following year.

\subsection{The Accounting Rookie Camp}

In contrast to larger academic fields like economics, the traditional recruiting approach in accounting relied primarily on paper applications and advisor letters as opposed to formal interviews at an annual academic meeting. The lack of an interview market stemmed partly from the mismatch in timing between the annual meeting of the AAA and the academic labor market-especially in the market for research-oriented positions $8^{8}$ In 2010, the University of Miami aimed to address this shortcoming by organizing an Accounting PhD Rookie Recruiting and Research Camp (henceforth ARC or Rookie Camp) that was held in early

\footnotetext{
${ }^{8}$ As discussed in Bergner et al. (2016) and Hunt and Jones (2016), recruiters for teaching-oriented positions in Accounting often set up short interviews at the AAA meeting, which is held in August of each year. However, the early timing of the AAA meeting makes it less useful to recruiters for research-oriented positions since the quality of one's dissertation is easier to assess the closer it is to the final product.
} 
December.

The ARC facilitated in-person screening of candidates in three ways. First, it created a venue where recruiters could set up short interviews with candidates. Second, it provided opportunities for informal meetings among all recruiters and candidates in attendance. Finally, and perhaps most importantly, it organized a series of formal, 15-minute research presentations which were given by participating job candidates and could be attended by any recruiter. The presentation schedule was determined randomly to minimize concerns about favoritism in the allocation of preferred time slots. Beginning in 2013, the Rookie Camp was organized by the AAA and by 2015 it had become an integral feature of the job market for new PhDs in accounting.

\subsection{Other features of the academic labor market}

Beyond the introduction of the Accounting Rookie Camp, several features of the market for new PhDs in Accounting offer practical advantages for studying the screening process. First, academic research position are human-capital intensive and initial contracts for new PhDs are typically written for at least three years, making screening very important. Second, while informational frictions are high for employers, they are relatively low (and arguably much less

relevant) for applicants. In short, all jobs openings are posted in a few places at the same time of year, so the cost of learning about open positions is low; and the application procedure is fairly uniform-making the marginal cost of an application low. Third, there is a fixed supply of newly qualified candidates each year and a relatively small number of research-oriented positions for new PhDs. The combination of a small number of positions and a low marginal cost of an application makes it plausible to assume that candidates who desire a research job apply to most or all positions. Finally, while we lack data on earnings, it is also a reasonable assumption that candidates for research-oriented jobs share a primary objective of placing at the highest-ranked department, subject to some idiosyncratic preferences. Not only do higher-ranked department tend to pay higher salaries and benefits; strong initial placements 
also confer several advantages that impact future productivity and thus future job options (Oyer, 2006).

While our analysis does not require that these assumptions hold exactly, they are useful for interpreting the data. For example, it is very unlikely that the assortative matching of new PhDs to similarly ranked universities reflects preference-based sorting on the part of the job seekers. It is also unlikely that ARC had any significant effect on job matching by informing job-seekers about open positions, although it may have allowed applicants and recruiters to share information about idiosyncratic preferences or features of the job.

\section{Data and Sample Construction}

Our analysis employs a comprehensive new database that contains the names and characteristics of all individuals who received a PhD in accounting from a U.S. institution between 2005 and 2015. This section describes the data sources, sample construction, and key variables in our analysis.

\subsection{Sample of Ph.D. Graduates}

To generate our base sample, we used the most recent 15 volumes of Hasselback's Accounting Directories.9 Graduates and programs were researched to ensure doctorates were earned in accounting. In total, we collected data on the career and educational histories of more than 2,270 graduates from 102 academic institutions in the U.S. with active doctoral programs in Accounting during the sample period. We supplemented the information from the directory with data on new graduates with PhDs in Accounting that we collected from university websites, online vitae, ProQuest's dissertation database, and the official ARC rosters. We then used the information on individual candidates to construct panel data on the schools where they received their degrees and the institutions that hired them.

\footnotetext{
${ }^{9}$ These were downloaded from http://www.jrhasselback.com/FacDir.html
} 
The sample for the primary analysis is restricted to doctoral graduates whose first job was at a four-year academic institution. Because we have relatively little information on individuals employed outside academia, we exclude those with non-academic jobs as well as graduates who obtain visiting or lecturer positions or who are missing placement information altogether ${ }^{10}$ We also exclude a small number graduates with start dates that far pre-date their graduation year or initial placements more than two years after earning the degree ${ }^{11}$ These restrictions leave us with a sample of 1,741 individuals that we use for most of our analysis. To rule out market-driven changes in sample selection as a confounder in our analysis, we use data on the full sample of all $\mathrm{PhDs}$ each year to construct and control for measures of labor market tightness.

\subsubsection{Candidate Publications}

We obtain individuals' publication histories, including publication titles, coauthors, and dates, from several sources: individuals' CVs, the Social Science Research Network (SSRN), google scholar, and the Brigham Young University (BYU) Accounting research ranking site. ${ }_{12}$ We use these sources to generate three separate measures of an individual's productivity before and after graduating: the total number of publications, the number of publications in top-five journals, and the number of coauthored publications. When looking at the relationship between pre-market publications and the first job placement, we include only papers that were published up to and including the year the individual graduated. When modeling post-hire productivity, we include papers published in the first three years of employment.

\footnotetext{
${ }^{10}$ While the Hasselback directories cover all four-year academic institutions, they do not include PhDs who are not employed in academia. We therefore have information on non-academic placements only in cases where we can obtain a CV or LinkedIn profile. Fewer than $1 \%$ of all candidates in our sample take non-tenure track positions in academia.

${ }^{11}$ Graduates with pre-PhD start dates typically held non-research positions before pursuing the doctorate and then returned to those institutions to resume employment. Those with late start dates may have delayed employment due to family or other reasons.

${ }^{12}$ https://www.byuaccounting.net/rankings/univrank/rankings.php
} 


\subsubsection{Candidate Gender, Race and National Origin}

We do not have information on self-reported race, ethnicity, or gender since most individuals do not provide this information on their CVs. However, it is the information available to employers that we are interested in studying, and research based on "correspondence studies" with fictitious resumes has established that employers appear to infer race and gender from applicants' names (Bertrand and Mullainathan, 2004). We therefore use the candidates' names to predict their gender, race, and national origin using a combination of classifying algorithms and APIs. For gender, we use the NamSor Gender API, which infers gender from the combination of characters in individuals' first and last names ${ }^{13}$ For cases where gender is identified with less than $99 \%$ certainty, we assign gender based on assessments made by research assistants using photographs from the professional websites of the candidates.

We assign race and national origin to individuals in our sample by combining predictions using both NamSor and "NamePrism", a non-commercial ethnicity/nationality classification

tool. Specifically, for each candidate, we use both the first and last name to query the NamePrism online tool and obtain baseline probabilities for the 6 ethnic categories defined by the U.S. Census Bureau: hispanic; non-hispanic white, non-hispanic black or African American, non- hispanic asian/Pacific Islander, non-hispanic American Indian and Alaska Native, and non- hispanic Multi-racial. NamePrism employs a training data set of 57 million contact lists from a major Internet company, US census data on the distribution of last names by race, and trains its algorithm using the homophily principle exhibited in communication as the basis for its ethnicity classifier. Each candidate is assigned a probability, ranging from $0 \%$ to $100 \%$, of belonging to each of the six ethnic groups, and the six probabilities sum to 1. We assign the category with the highest probability.

\footnotetext{
${ }^{13}$ This tool was developed by Elian Carsenat: http://www.namsor.com/. It uses classifications algorithms trained on large labeled databases in the census.
} 


\subsection{University Reputation and Chair Connections}

\subsubsection{University Reputation}

Our primary measures of university reputation are based on the BYU rankings for universities and $\mathrm{PhD}$ programs. We use the university rankings to measure the quality of a candidate's initial job placement and the program rankings to measure the reputation of their $\mathrm{PhD}$ program. University rankings are constructed by aggregating the total number of citations for each author and then summing across all authors employed at the university in a given year, excluding those listed as emeritus or retired 14 Universities are rank-ordered based on this total citation count. $\mathrm{PhD}$ programs are ranked similarly by aggregating the citations of all individuals who graduated from a program in the previous six years. In both cases, to avoid concerns about endogenous changes in rankings over time, we measure rank at a fixed point in time, using the three years prior to the Rookie Camp 15 We also convert both rank measures to percentile ranks to facilitate interpretation of the estimated coefficients.

\subsubsection{Adviser Networks}

In addition to information on a candidate's degree program, we also collect information on their primary Ph.D. adviser or dissertation chair. We obtain adviser names from a combination of CVs and dissertation title pages ${ }^{16}$ Our primary interest is in the adviser's network connections to potential employers, which may affect placements either through an information channel or through reciprocity and favoritism. We measure the role of connections using information on advisers' coauthors $[7$ We define an adviser as being connected to an institution in year $t$ if she has ever published a paper with a researcher who is at that institution

\footnotetext{
${ }^{14}$ The authors are not penalized for co-authorship work; however, our results are robust to co-authorship adjustments

${ }^{15}$ The BYU ranking data is not available prior to 2009

${ }^{16} \mathrm{We}$ found adviser names for $86 \%$ of our sample. These were obtained from the candidate's dissertation, published online by ProQuest.

${ }^{17}$ Coauthor information is obtained from individuals publications which were gathered from the sources cited above.
} 
in year $t$

\subsection{Rookie Camp Data}

We obtained information on ARC participants by compiling Rookie Camp programs for the years 2009-2014. The programs provide the names of all individuals participating as job candidates each year, their school affiliations and dissertation titles, and the date and time of each individual's 15-minute presentation. The programs also contain information on the recruiting schools in each of the years.

\subsection{Descriptive statistics}

Figure 1 shows the total numbers of participants in the market each year for new PhDs (panel a), supplying universities (panel b), and hiring universities (panel c). In addition, panel (a) shows the counts of new PhDs who obtained a job at any four-year institution (i.e., the individuals in our analysis sample), and panel (c) shows counts for a subset of highly ranked universities that were likely to eventually recruit at ARC ${ }^{19}$ Finally, the light blue bar in each panel shows the numbers of Rookie Camp participants each year.

In the six years before the Rookie Camp, an average of 69 U.S. PhD programs sent PhDs to the market each year; an average of 140 new $\mathrm{PhDs}$ got jobs each year at an average of 111 hiring universities. The jobs numbers dip somewhat during the recession (2009-2010) and then rise to an average of 180 per year in the post-ARC years (2011-2015).

In 2011 (its first year), ARC was attended by 49 new PhDs (roughly 30\% of all new PhDs in the sample that year), representing 32 of the 70 Ph.D. programs that sent candidates to the market. By 2015, participation in ARC had risen to 128 job-seekers representing nearly

\footnotetext{
${ }^{18}$ Specifically, we consider the advisor's coauthors on all publications between the year 1997 and year $t_{+1}$ (to account for a lag between coauthorship and publication date).

${ }^{19}$ Highly ranked universities are defined as having a research rank above the median in our sample. As discussed further below, these schools were much more likely to ever recruit through ARC, consistent with ARC's focus on the research market. When analyzing the effect of ARC participation by job candidates, we focus on the likelihood of obtaining a first job at a highly ranked school.
} 
two-thirds of all $\mathrm{PhDs}$ and 70 of the $82 \mathrm{PhD}$ programs with students on the market. On the demand side of the market, the number of hiring universities that participated in the ARC rose from 15 in 2011 to 61 in 2015. By 2015, $44 \%$ of hiring universities participated in ARC (panel C), and roughly half of new hires were made by a university that participated in ARC (not shown in the figure).

Because the ARC was intended primarily to facilitate the market for research-oriented jobs, participation rates-especially in the early years-skewed toward more highly-ranked schools. Trends in the composition of participants on both the supply and demand side of the market are shown in Figure 2. Starting with the supply side (panel a) we see that the average rank of degree schools participating in the first year of ARC was around the 65th percentile. However, this was followed by a steady downward trend, and by 2015, the average rank was close to the median (consistent with an $85 \%$ participation rate that year).

Turning to the demand side of the market, panel $b$ of Figure 2 shows that the top-ranked recruiting schools were generally the first to attend the ARC. The participating recruiting schools in the first three years were, on average, ranked at the 80th percentile of all hiring schools in the sample. Schools that began participating in 2014 and 2015 were somewhat lower-ranked, but even by the end of the sample period, the average rank of participating recruiting schools was around the 70th percentile, compared to a mean around the 25th percentile for non-ARC recruiters. When analyzing the impact of ARC participation by recruiters, our preferred models will focus on the set of relatively high-ranked, researchoriented schools that had "adopted" ARC by the end of the sample period.

Descriptive statistics for our analysis samples are shown in Tables 1 and 2 . Table 1 shows average characteristics of the individual job candidates and their degree programs, both for the sample overall, and separately for schools ranked above and below the median and in the years before and after the introduction of ARC. The overall sample is $41 \%$ female, $66 \%$ White, 29\% Asian (or Pacific Islander) and 4.3\% Black or Hispanic (henceforth minority). The two largest groups by predicted national origin are English (44\%) and Chinese (23\%). 
Women, minorities, and Chinese students are all somewhat under-represented at high-ranked schools. Over time, there is a slight increase in the share of English candidates and a decline in the share of Asian candidates at both groups of schools ${ }^{20}$

Looking at program characteristics, we see that the average cohort size in our sample is 3.2 students; higher-ranking programs are roughly $25 \%$ larger than lower-ranking ones, and both groups grow around 15\% over the sample period. Consistent with the research orientation of the ARC, new PhDs from higher-ranking schools participate at $50 \%$ higher rate than those from lower ranking schools (60\% vs. 39\%). Unsurprisingly, they are also much more likely to be hired by top-ranked universities over the sample period. However, while these graduates are more than twice as likely to obtain a "top-ranked" job in 2005-2010, they are only $80 \%$ more likely to do so in the five years after ARC's introduction-suggesting a diminished role for program rank in placement success.

Table 2 provides descriptive statistics for four groups of recruiters in our sample: The "early adopters" who began participating between 2011 and 2013; the "late adopters" who began in 2014 or 2015; the "post-sample" adopters who attend for the first time in 2016 or 2017; and those who had never participated as of 2018. Consistent with Figure 2b, both the average rank and the fraction of schools ranked above the median is higher among the groups that participated earlier (rows $1 \& 2$ ). Row 3 shows the predicted program rank of new PhDs hired by the schools in each groups, based on a regression model that includes various characteristics of the hiring school and estimated using the first three years of the data (2005-2007) ${ }^{21}$ As expected, recruiters that participate in the ARC earlier, being more highly ranked themselves, tend to hire candidates from higher-ranked programs. Employers that participate earlier are also more likely to run one of the $\mathrm{PhD}$ programs that produces the candidates in our sample. Interestingly, however, the "early adopter" group also has

\footnotetext{
${ }^{20}$ Detailed data on the demographic composition of $\mathrm{PhDs}$ each year are provided in Appendix A.2.

${ }^{21}$ The model includes: the school's BYU rank described above; an alternative rank based on UT Dallas; dummies for being in the U.S., for having a PhD program, and for being unranked (and assigned rank of zero) in either ranking measure; the average number of hires in 2005-2007; and the interactions of these variables with each other.
} 
the largest share of non-U.S. schools (15\% of this group), suggesting that non-U.S. schools interested in hiring PhDs from the U.S. viewed Rookie Camp participation as important.

Figure 3 shows a binned scatter plot of the average rank of the hiring school against an individual's degree school rank, along with the fitted line from a quadratic model. The relationship is close to linear with an R-squared of 0.22 . This striking degree of assortative matching on institutional reputation is consistent with prior literature on academic labor markets (see footnote 5).

\section{Empirical Strategy \& Identifying Variation}

The strong relationship between degree program rank and the rank of the university where a new $\mathrm{PhD}$ gets hired suggests that applicants from highly ranked programs tend to have higher research potential on average. But if employers' find it hard to assess individual variation within programs, then the strength of the relationship might be driven partly by employers use of program rank as an imperfect proxy for quality. In turn, if the Rookie Camp allowed recruiters to improve their assessments, we should expect program rank to become less predictive of job placements after recruiters and applicants begin participating in the ARC. This same logic applies to the role of other quality signals and screening devices such as an individual's pre-graduation publication record and the network connections of their advisor.

To test these predictions, we use a difference-in-difference approach that exploits variation in the timing of Rookie Camp adoption by schools. We use three complementary but distinct

approaches that differ in the source of variation in ARC participation (variation across recruiters vs. degree programs) and in the level at which the outcome is measured (candidate, employer, or match). 


\subsection{Models of hiring decisions using recruiter variation}

We begin by using variation among recruiters to estimate models in which the outcome describes the candidate that is hired. Specifically, for recruiter $j$ in year $t$, we model the rank of the new hire's degree program (Degree School Rank $k_{j t}$ ) as:

$$
\begin{aligned}
\text { Degree School Rank } \text { Re }_{j t}= & \beta_{1} * \text { Recruiter Rank } k_{j}+\beta_{2} * \text { Post } A R C_{j t} \\
& +\beta_{3} *(\text { Recruiter Rank } \times \text { Post } A R C)_{j t}+\theta_{t}+\epsilon_{j t}
\end{aligned}
$$

Here, Recruiter Rank $k_{j}$ is the predicted value of Degree School Rank $k_{j t}$ from a model fitted to observed hires in 2005-2007, based on the recruiter's rank and other fixed characteristics prior to 2011 (see footnote 19). It can be thought of as measuring a recruiter's historical ability to attract candidates from highly-ranked programs due to its own research reputation. We estimate equation (1) using the full sample, so in the absence of any changes in reputations or hiring practices over time, we would expect $\beta_{1}=1$. Post $A R C_{j t}$ is a dummy variable that equals one if the employer sent a recruiter to the Rookie Camp in year $t$ or earlier, and Recruiter Rank $\times$ Post $A R C_{j t}$ is the interaction of Recruiter Rank $k_{j}$ and Post $A R C_{j t}$. Equation (1) also includes year fixed effects $\left(\theta_{t}\right)$ to control for overall market conditions in year $t$; we also estimate specifications that replace Recruiter Rank $_{j}$ with recruiter fixed effects.

Our primary interest is in $\beta_{3}$, which tells us how participation in the ARC as a recruiter affects the relationship between the recruiter's reputation and the rank of the degree programs it hires from. In equation (1), $\beta_{3}$ is estimated using variation in ARC adoption among employers with the same predicted hiring patterns (from years prior to the ARC's introduction). A causal interpretation of $\beta_{3}$ requires that there is no selection on unobservables in the decision to begin recruiting at ARC. A second assumption underlying the simple difference-in-difference model is that there are no dynamic effects at the recruiter level; ARC participation changes recruiters' hiring in the year they participate, and not with a lag.

To assess the validity of our research design, we present a number of robustness tests. 
These include: (1) restricting the sample to employers that made at least one hire pre- and post ARC (to improve balance in the composition of hiring schools over time); (2) further restricting the sample to employers that eventually adopted the ARC (to further improve comparability); and (3) adding recruiter fixed effects to the model to control for all variation in hiring patterns due to fixed characteristics of employers. In this last specification, $\beta_{3}$ is identified off of within-employer changes in hiring patterns and differences in the timing of adoption. We also estimate distributed lag models by adding leads and lags of the treatment variable to equation (1). The leads allows us to assess the assumption of no selection on unobservables by testing for differences in hiring patterns prior to ARC's implementation; while the lags allow us to test for dynamic effects.

Finally, we also estimate specifications that control for potentially confounding variation due to differential effects of labor market conditions on different types of recruiters. To do this, we construct two measures of labor market tightness in each year: one based on the share of all new PhDs who obtain any job at a four-year academic institution, and one based on the ratio of the number of jobs at highly ranked universities to jobs at all four-year universities. Figure 4 illustrates the time series pattern in these two measures.

Figure 5 illustrates the research design using variation in ARC adoption among recruiters, and presents visual evidence in support of the key assumptions. The figure uses data on the subset of employers who eventually adopt the ARC during our sample period (henceforth "ever adopters"), and splits them into two groups based on the timing of adoption: the "early adopters" who begin participating between 2011 and 2013 (panel a) and the "late adopters" who begin in 2014 or 2015 (panel b). Within each of these categories, employers are further grouped into "higher-ranked" or "lower-ranked" based on their ranking relative to the median of the "ever-adopter" analysis sample. ${ }^{22}$ The dashed lines plot the average

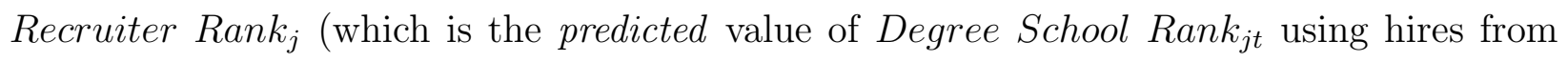
2005-2007) for each of these groups over time. Since Recruiter Rank $k_{j}$ is a fixed characteristic

\footnotetext{
${ }^{22}$ Recall from Table 2 that the ever adopters are generally more highly ranked than non-adopters in our sample.
} 
of each school, these group means will vary over time only if there are compositional changes in the sample that cause the variable to be correlated with changes in hiring patterns over time. The flat trend in these lines is therefore reassuring.

The solid lines in Figure 5 plot the mean values of Degree School Rank $k_{j t}$ for the actual hires made each year. In the years prior to ARC adoption (indicated by the vertical line in each panel), deviation of these lines from the predicted values reflect changes over time in unobserved determinants of hiring patterns. As would be expected, there is some fluctuation around the predicted means. Importantly, however, there is no evidence of differential trends in the years prior to ARC adoption, consistent with the assumption of no selection on timevarying unobservables. Finally, both panels show a similar pattern following ARC adoption: among the higher-ranking employers, the degree school rank of new hires begins to fall relative to its predicted value. By the end of the sample period, the observed gap in average Degree School Rank $k_{j t}$ between higher and lower-ranked employers is effectively eliminated. This indicates that there was a decline in assortative matching with timing that is strongly suggestive of a causal role for the Rookie Camp 23

\subsection{Models of job placements using degree-school variation}

Since the ability to screen through ARC requires participation by job candidates as well as by recruiters, we can also estimate ARC's impact on placements using variation in adoption by degree-granting schools. Here, we estimate linear probability models in which the outcome is defined as whether the initial placement of candidate $i$ with a $\mathrm{PhD}$ from degree school $s$ in year $t$ is at a highly ranked university (i.e., one that is ranked above the median of all

\footnotetext{
${ }^{23}$ Note that while the overall impact of ARC appears to grow over time following adoption, we cannot infer anything about the dynamic effects for individual employers from this figure; a dynamic effect for the market overall could be driven entirely by the increase in ARC participation over time.
} 
employers in our sample). Our estimation equations take the following form:

$$
\begin{aligned}
\text { HighRank F } J_{i s t}= & \beta_{1} * D S \text { Rank }_{s}+\beta_{2} * \text { Post ARC } \\
& +\beta_{3} *(D S \text { Rank } \times \text { Post ARC })_{s t} \\
& +\beta_{4} * \text { Year } 1_{s t}+\beta_{5} *(D S \text { Rank } \times \text { Year } 1)_{s t} \\
& +\beta_{6} * X_{i s t}+\beta_{7} *(X \times \text { Post ARC })_{i s t}+\beta_{8} *(X \times \text { Year } 1)_{i s t} \\
& +\theta_{t}+\epsilon_{i s t}
\end{aligned}
$$

The variable $D S R_{a n k}$ is constructed using observed hires in 2005-2007 and the rank of a candidate's degree school prior to 2011 to predict the probability of HighRank F $J_{i s t}$. Hence it measures the degree program's historical ability to place candidates at highly ranked universities due to the research reputation of its graduates ${ }^{24}$ We also estimate variants of equation (2) that replace $D S \operatorname{Rank}_{s}$ with degree school fixed effects. In some specifications, we also include characteristics $X$ of the individual candidate. These include quality signals that vary at the candidate level such as the number and quality of journal publications before graduation. $X$ also includes the candidate's gender and predicted race and nationality.

While the unit of observation in (2) is a new $\mathrm{PhD}$ candidate, the treatment variable Post $A R C_{s t}$ is defined at the program level: a program is defined as having adopted the ARC in year $t$ if it sent at least one job candidate to the Rookie camp in year $t$ or earlier. Although ARC participation does vary at the individual level even within some program cohorts, an individual's decision to participate is almost certainly endogenous. We therefore instrument the individual's decision with ARC adoption by the degree school. To avoid concerns about selective timing of a school's adoption due to idiosyncratic variation in candidate quality between cohorts, we include a dummy variable, Year $1_{s t}$, to control for the first year of adoption by each degree school. ${ }^{25}$ Thus, the coefficients $\beta_{2}$ and $\beta_{3}$ can be interpreted as the reduced-form effect on candidates' outcome of their degree programs' decision, made in prior years, to begin sending job candidates to the rookie camp. We are particularly

\footnotetext{
${ }^{24}$ Analogous to Recruiter $R a n k_{j}$ in equation (1), the model also includes other fixed school-level characteristics, such as average cohort size, that may affect a program's reputation.

${ }^{25}$ For example, a school's initial decision to participate could be motivated by an unusually promising candidate or by a last-ditch effort to help a weak candidate who has no other prospects by late November.
} 
interested in $\beta_{3}$, the coefficient on the interaction of degree school rank with the post-ARC adoption indicator, as this will tell us whether a candidate's degree-school reputation carries less weight in determining their job market success after the school starts participating in the ARC.

We also use models like (2) to explore whether the effect a degree school's participation in ARC differed by an individual candidate's characteristics $X$, conditional on any differential effects by the rank of the degree school. For example, by defining $X$ as an indicator for having publications prior to the market, we use the coefficient $\beta_{7}$ (on the interaction of $X$ with Post $A R C_{s t}$ ) to test whether this potentially observable signal of research productivity became more or less important in the context of the ARC Similarly, we can test for heterogeneous effects by gender, race and nationality by defining $X$ as a dummy variable for a particular demographic characteristics.

\subsection{Match-level models for the role of networks and proximity}

Our third estimation approach uses variation from both sides of the market to study how adoption of ARC affected the characteristics of job matches. Different from our first two approaches, our unit of analysis is now a potential match between job candidate $i$ and recruiter $j$, and we are interested in match-specific variation in the cost to recruiter $j$ of learning about candidate $i$ through channels other than the ARC. We focus on two proxies for information channels: adviser coauthor networks and geographic proximity $[2]$ We start by showing that both measures have independent effects on the likelihood that a particular match is realized, even when controlling for the effect of rank similarity between schools. We then ask whether the introduction of ARC reduced the importance of network connections and physical distance in determining the matches that are realized.

To proceed, we construct a match-level data set consisting of all possible recruitercandidate pairs that can be formed from the set of all universities that hired in a given

\footnotetext{
${ }^{26}$ In these specifications, we also include the interaction of $X$ with $Y$ ear $1_{s t}$.

${ }^{27}$ Catalini et al. (2020) show that geographic frictions play an important role in research collaborations among scientists.
} 
year and all candidates that graduated and obtained a job in that year. We then estimate the following linear probability model:

$$
\begin{aligned}
\text { Hire }_{i j s t}= & \beta_{1} * \text { Similar Rank School }_{j s}+\beta_{2} * \text { Advisor Connection }_{i j}+\beta_{3} * \text { Log }_{\text {Distance }} \text { Ss } \\
& +\beta_{4} * \text { Post ARC } \text { S }_{j / s t}+\beta_{5} * \text { Post ARC } \text { A }_{j / s t} \times \text { Similar Rank }_{j s} \\
& +\beta_{6} * \text { Post ARC } C_{j / s t} \times \text { Advisor Connection }_{i j} \\
& +\beta_{7} * \text { Post ARC } C_{j / s t} \times \text { Log Distance }_{j s} \\
& +\alpha_{s}+\gamma_{j}+\theta_{t}+\epsilon_{i j s t}
\end{aligned}
$$

The dependent variable Hire $_{i j s t}$ is an indicator variable that takes on a value of one if candidate $i$ from degree school $s$ was hired by university $j$ in year $t$ and is equal to zero otherwise. The variable Similar Rank School, an indicator for whether the degree school and recruiting school are in the same rank decile, captures the effect of assortative matching. The role of networks in the market is captured by Advisor Connection, which takes on a value of one if the candidate's dissertation advisor had a coauthor on the faculty of the recruiting school. And to capture the role of physical distance in the job market, we include Log Distance which is the log distance between the campuses of the degree school and recruiting school. Finally, Post $A R C$ is an indicator variable that takes on the value of one in years after either the recruiting school or the degree school began participating. We estimate the model using each source of variation, and in all specifications we include fixed effects for degree school $\left(\alpha_{s}\right)$, hiring school $\left(\gamma_{j}\right)$, and year $\left(\theta_{t}\right)$. Our coefficients of interest are $\beta_{5}, \beta_{6}$ and $\beta_{7}$, which capture the effect of ARC participation on the importance of rank similarity, chair connections and distance for determining job matches. 


\section{$5 \quad$ ARC's Effect on the Importance of Traditional Qual- ity Signals}

\subsection{The role of degree-school reputation}

\subsubsection{Evidence from variation in recruiter participation}

Table 3 reports the estimates of equation (1), which examines how hiring outcomes are affected when recruiters participate in ARC. Here, the outcome is the percentile rank of the degree school where the hired candidate received their PhD. Column 1 shows the model estimates based on the full sample, while the specifications in columns 2-6 are restricted to recruiters that ever participated in the ARC. In columns 3-6, the sample is further restricted to recruiters that hired in both the pre and post-ARC periods.

To interpret the coefficients, recall that Recruiter Rank is an index of recruiter rank variables in years prior to ARC and constructed from a model predicting DS Rank. Thus, in the absence of any changes in program ranks or hiring practices over time, we would expect $\beta_{1}=1$, and the coefficient of .95 in column 1 suggests that the rank order of universities (with respect to their ability to recruit from top schools) changes little over time. In turn, the coefficient of -0.40 on Post ARC $\times$ Recruiter Rank implies that the effect of recruiter rank on the average program rank of realized hires fell by $40 \%$ when recruiters began participating in the Rookie Camp. The magnitude of this coefficient is reduced somewhat, but remains negative and significant, when estimated using only the "ever adopter" sample (column 2) and when excluding those that did not hire in both the pre- and post-ARC years (column 3). In our preferred specification that includes recruiter fixed effects (column 4), the estimate implies a $27 \%$ reduction in the effect of recruiter rank on degree school rank. This estimate is robust to specifications that include measures of labor market tightness and allow the effects of labor market conditions to vary with the rank of the recruiter (columns 5 and 6).

Further support for a causal interpretation of this result is shown in panel (a) of Figure 
6, which plots the coefficients and 95\% confidence intervals from a distributed lag model with 3 leads and 2 lags. In the 3 years prior to adoption, the coefficients are close to zero with no evidence of a trend. They become negative and significant beginning in the year of adoption 28

\subsubsection{Evidence from variation in degree-school participation}

In Table 4, we examine ARC's effect on job market placements using variation from the supply side of the market. Table 4 reports the estimates of equation (2), in which the outcome is an indicator for placing at a highly ranked university. Consistent with the results of the recruiter-based analysis, the estimates in Table 4 suggest that ARC adoption lead to a statistically significant, $21 \%-23 \%$ reduction in the effect of degree school rank on the probability of obtaining a highly ranked first job. The coefficients are remarkably stable across specifications, including our preferred specification with degree school fixed effects (column 4). Moreover, the insignificant coefficients on Year 1 and its interaction with $D S$ Rank obviate concerns about selection in the timing of ARC adoption.

The coefficients from the distributed lag model for candidate placement are shown in panel (b) of Figure 6. Again, the coefficients are close to zero with no trend in the 3 years prior to ARC adoption by the candidate's degree school, and they are negative and significant in the 3 years beginning with the year of adoption.

In Table 5, we demonstrate the robustness of the inferences in Table 4 to alternative measures of job market outcomes. Column 1 reproduces the estimates from column 4 of Table 4. In column 2, we replace the binary outcome (HighRankFJ) with the percentile rank of the first job. And in column 3, we replace the rank measure with an indicator variable for whether the hiring school ever participated in the ARC. Consistent with our previous results, model 2 shows that $\mathrm{ARC}$ adoption by degree programs led to a diminished association between the rank of one's degree school and the rank of one's first employer. Additionally,

\footnotetext{
${ }^{28}$ The model estimates are shown in Appendix Table A1
} 
the results in column 3 suggest that the effect of ARC participation on placements is indeed driven by changes in the likelihood of being hired by an employer that recruited through ARC.

Overall, these results suggest that the ARC changed the sources of information used by recruiting schools to screen candidates and reduced their reliance on degree programs rank as a signal of candidate quality.

\subsection{The role of candidate-level quality signals}

In Table 6, we examine the role of a previously observable signal of applicant productivity (a pre-graduation publication) and the ARC's effect on the weight placed on this signal in the hiring decision. ${ }^{29}$ Table 6 reports the estimates of a variant of equation (2), defining $X$ as an indicator for having a publication prior to the market. Thus, we use the coefficient $\beta_{7}$ (on the interaction of $X$ with Post $R C_{s t}$ ) to test whether this potentially observable signal of research productivity became more or less important in the context of the ARC. We consider three variations of pre-graduation publications: any publication before graduation (Models 1-3), a top 5 publication before graduation (Models 4-6), and a coauthored publication before graduation (Models 7-9). The models are estimated on the full sample (Models 1, 4, 7) as well as separately for candidates from higher-ranked (Models 2, 5, 8) and lower-ranked (Models 3, 6, 9) degree programs.

In Model 1, we see a clear relation between having a Pre Grad Publication and the likelihood of obtaining a high ranked placement (an increase of 17 percentage points in the likelihood). Moreover, the ARC does not seem to have changed the importance of this signal given the small and insignificant coefficient on Pre Grad Pub SignalXDS Post RC. This inference holds for both top-5 publications as well as coauthored publications (Models 4 and 7). The relation is consistent with pre-graduation publications serving, on average, as a significant signal of individual quality. For example, in the case of a top-5 publication,

\footnotetext{
${ }^{29}$ In Appendix Figure A.6 we plot the percentage of individual who graduate each year with at least one publication.
} 
where quality is even more explicit from the publication, we see the likelihood of placing at a high ranked university increase 24 percentage points.

We go on to examine the potential differential effects of the ARC (based on whether the candidate graduated from a high or low ranked school) on the importance of the pre-grad publication as a signal of quality. Models 2 and 3 shows that before the ARC, PhDs from top schools had a higher return to a pre-graduation publication 30 Specifically, having a publication before graduation increased the likelihood of getting a job at a highly-ranked university by 20 percentage points (on a mean of $63 \%$ ) for graduates of high-ranked schools, and by 14 percentage points (on a mean of 29\%) for graduates of lower-ranked programs. Post ARC, the return is diminished for PhDs at top schools, but not for those from lowerranked schools as can be seen in Figure 7. This differential pattern is more pronounced for the return to coauthored pubs (Models 5 and 6) where the return to a coauthored pub is roughly cut in half for those from top programs, yet doubled for those from lower-ranked programs.

These differential patterns suggest that for students from highly ranked programs, the ARC led to a reduction in the weight placed on the signal-consistent with the predicted effects of reducing the cost of information in a standard signaling/screening model. However, if anything, ARC had the opposite effect for PhDs from lower-ranked institutions, where the results suggest that the ARC may have reduced "attention discrimination" (Bartos et al., 2016)-which previously favored graduates of higher-ranked programs-by lowering the overall cost of screening. In other words, candidates with publications who were previously overlooked because they graduated from a lower-ranked school can now get noticed.

\subsection{The impact of ARC on the role of connections and proximity}

We examine the role of advisor connections and physical distance in academic placements in Table 7, which provides estimates of equation (3). Model 1 reports the baseline estimates

\footnotetext{
${ }^{30}$ Recall that $20 \%$ (33\%) of PhDs from high (low) -ranked schools had a publication before graduating.
} 
of the relation between the likelihood of a candidate being hired and the similarity in the rank of the schools. We find that prior to the ARC, the probability of a match occurring between a candidate from degree school s and a job at school $j$ is 0.6 percentage points higher (relative to all other possible matches) if school $s$ and school $j$ are in the same rank decile. In Model 2, we introduce advisor connections. While the coefficient on rank similarity remains strong and highly significant, we find that conditional on school rank similarity; there is a 5.2 percentage points increase in the hiring probability if the candidates dissertation chair has a coauthor at school $j$. Thus, given that the likelihood of a coauthor connection is higher in similarly ranked schools, the network effect of advisor connections seems to explain about $12 \%$ of the assortative matching by school rank 31 We introduce school distance in Model 3. Consistent with information frictions that increase with distance, we find that increases in the distance between schools are associated with a reduction of $0.7 \%$ in the likelihood of being hired. This estimate translates into a $13 \%$ reduction in the likelihood of being hired for a one standard deviation increase in distance.

The effect of the ARC on these baseline relations is examined in Models 4 and 5. In Model 4, we use variation from the degree school adoption, while Model 5 uses variation from the recruiting school's participation in the ARC. In Model 4, we see that the adoption of the ARC significantly weakens the relationship between placement and chair connections, rank similarity, and distance. Consistent with less reliance on private information and networks, the ARC leads to a quarter reduction in the importance of connections in placement (a reduction of $1.5 \%$ points in the likelihood of placing at a university given a chair's connection to the school). We see a similar reduction in the importance of school rank similarity with a $0.5 \%$ reduction in the likelihood of placing post ARC. Finally, we find a 0.3 percentage point reduction in the coefficient on distance, suggesting that distance-based information frictions became less critical after schools began participating in ARC.

When we examine the ARC from the perspective of the recruiting schools' participation in

\footnotetext{
${ }^{31}$ The conclusions are very similar if we use a continuous measure of rank distance rather than indicators for being in the same rank decile.
} 
Model 5, we again see a reduction in the weight put on the similarity of rank and distance. For example, after participating in the ARC, recruiting schools reduce their hiring from schools within their rank (the interaction of Post ARC Adoption (Recruiter)X Advisor Connection eliminates the association with the similarity of rank. However, we see no significant effect on their reliance on advisor connections in hiring. Finally, hires made after ARC adoption come from degree schools that are further away on average. Overall, the results in Table 7 lend further support to our conclusion that the ARC lowered the cost of in-person screening, which lead recruiters to reduce their reliance on traditional screening mechanisms and channels of information.

\subsection{The impact of ARC on the Productivity of New Hires}

Our results so far indicate that ARC changed the weights on the various signals used by employers in the market and, in turn, changed the composition of who gets hired. To examine whether this change in selection improved the efficiency of the market, we focus on ARC's effect on productivity. Specifically, in Table 8, we examine the impact of ARC on the productivity of new hires in their first three years. We measure productivity as the log number of publications in their first three years (Columns 1 and 3) and the log number of publications in a Top-5 accounting journal (Columns 2 and 4). We estimate specifications based on equation (2) using OLS. Columns one and three are estimated as linear OLS models, while columns two and four are linear probability models. All specifications include year fixed effects, while columns three and four include degree school fixed effects.

Table 8 shows that candidates hired by recruiters during the period of the ARC tend to be more productive. We see that the candidates these ARC participating schools hire have a 10 to $15 \%$ increase in the number of published articles. They also exhibit an increase in the number of articles published in a top-5 journal of around 10\%. Moreover, this improvement in productivity does not seem to vary by the rank of the hiring university, as indicated by the precise zero coefficients on the interaction between Recruiter Rank and the Post ARC 
variable. While these results suggest an improvement in productivity of hires obtained through ARC, the improvement could be driven by either better screening by employers given the in-person elements of $\mathrm{ARC}$ and/or improvements in the match quality of candidates to recruiters 32

\section{ARC's Role in the Evolution of Placement Gaps by Gender, Race and Nationality}

The results presented thus far suggest that the ARC helped level the playing field by reducing the importance of attending a prestigious degree school, network effects (advisor connections), and by drawing attention to graduates of lower-ranked programs who have strong research potential (as measured by pre-market publications). In light of this finding, a natural question is whether ARC also led to greater equality of opportunity in other dimensions. In this section, we examine placement gaps by candidate gender, race and nationality (predicted by their names) and estimate the impact of ARC participation on these gaps.

\subsection{Conditional placement gaps by gender, race \& nationality; evolution over time}

In Figure 8, we examine placement gaps and the evolution of these gaps over the years in our sample period by plotting coefficients from a linear probability model that predicts the likelihood of placing in a top-ranked university, controlling linearly for the rank of the degree school, a dummy for group membership (e.g., gender), and the interactions of these variables with a linear time trend ${ }^{33}$ Even among students who graduate from similarly ranked degree schools; there are significant gaps in placements by gender, race, and national origin.

\footnotetext{
${ }^{32}$ Disentangling these two mechanisms is beyond the scope of the current draft. A potential way forward would be through promotion decisions, which we are currently acquiring to focus more on the match quality dimension.

${ }^{33}$ The full models can be seen in Appendix Table A.2
} 
Panel (a) shows that the placement gap for females relative to males has deteriorated over the period, with women being ten percentage points less likely to place at a highly ranked school by 2015. Panels (b-d) show placement gaps for minorities (defined as Black race or Hispanic origin), Asians and foreign candidates. Here again, we see significant gaps in recent years, and with the exception of the the minority-white gap, all gaps appear to widen in the post-ARC years. Asian and foreign candidates start the sample with 5 to $7 \%$ higher likelihoods of placing at a high-rank school. However, by the end of the period, both groups are less likely to place at a top tier school (9 to $10 \%$ less likely).

\subsection{Candidate Demographics and the ARC}

The placement gaps documented above naturally raise the question of what effect has the ARC had on the gaps. In Figure 9, we turn to answer this question by modeling the effect of the $\mathrm{ARC}$ on the relation between candidate demographics and placement at a highly ranked university. In Panel a, we begin by examining each demographic group's likelihood of participating in the ARC. We then construct the placement gaps for the various characteristics plotted in Panel b by estimating equation1. These models give us the reducedform estimates of the likelihood of a high-ranked placement, using the sample of schools that eventually participated in the rookie camp. The specifications also include year and degree school fixed effects $\sqrt[34]{ }$ We plot each of the coefficients on the demographic characteristics ( i.e., the placement gap) as well as the full effect of the ARC on the placement gap for each group 35

Panel $\mathrm{b}$ of Figure 9 documents a significant gender gap in placements among candidates from similarly ranked programs. Yet, we do not find that ARCs impact differed significantly by the candidates gender. Concerning under-represented minorities (Blacks and Hispanics), our estimates suggest that these groups also tend to be under-placed, but unlike female

\footnotetext{
${ }^{34}$ See Appendix Table A.4 for the full models

${ }^{35}$ The full effect of the ARC on the placement gap is defined as the sum of Dem and DemXPost RC in the estimated models found in Appendix Table A.4
} 
candidates, minority candidates appear to benefit from ARC participation. However, the estimated impact is imprecise due to the small numbers of minorities in our sample. Turning to the larger subgroups of race and nationality in our sample, we find that ARC participation resulted in a significant penalty (measured by a relative decline in the rank of the hiring university) for candidates with Asian last names (relative to whites) and for non-US candidates (relative to candidates whose undergraduate degree is from a U.S. school). This is despite a somewhat higher first stage participation effect for Asian candidates, as seen in Panel a.

The large negative effects documented for those candidates with Asian and foreignsounding names above lead us to investigate potential explanations for this effect. We do so by repeating the analysis (estimate the same models as in Figure 9 ) for the largest subgroup within each of these categories: students with Chinese-sounding names (66\% of Asians, $45 \%$ of foreign students, and $23 \%$ of all PhDs in our sample). Figure 10 provides the first stage participation (Panel a) and the placement effects of the ARC (Panel b).

In Figure 10 we see that despite being no more likely to participate in the ARC (relative to whites), individuals with Chinese surnames suffer a significant penalty on their likelihood of placing at a high-rank school (more than a 36\% decrease in the likelihood) after the ARC. For candidates of other nationalities, the ARC penalty is small and statistically insignificant. These results suggest that the effect for Chinese candidates is not solely driven by their foreign status per se and may instead be driven by some combination of language and cultural differences (Felbermayr and Toubal, 2010; Melitz and Toubal, 2014).

To investigate this possibility, we examine Chinese individuals that use white-sounding first names-a potential signal of the individual's effort to assimilation to U.S. culture. In the pre-ARC period, these individuals were at least as likely as white candidates-and more likely than other Chinese individuals-to obtain a highly-ranked job. But when these individuals begin participating in the ARC, their likelihood of being hired at a highly ranked school declined by nearly 40 percentage points and roughly double the impact on Chinese students as a whole. These estimates are robust to the inclusion of pre-market publications (interacted 
with degree-school rank and the ARC adoption dummy) as controls, and as such, they do not appear to be driven by changes over time in the quality of Chinese candidates.

\subsubsection{Language Differences and Writing Differences}

To further explore the role of language differences in driving the relation, we go on to examine ARC's effect based on how different an individual's native language is from English. Our language distance measure is calculated as the distance between the candidate's native language and English using data from elinguistics.net. We then classify foreign candidates by the similarity of their (predicted) native language to English, and we estimates the impact of $\mathrm{ARC}$ adoption for those with more distant native languages. Figure 11 indicates that the post-ARC penalty is strongest among those whose native language is very different from English. This finding further supports our conclusion that language differences play a role in driving the post-ARC penalty for Chinese candidates.

Potentially, recruiters could have detected language differences prior to ARC from the writing quality of an individual's job market paper. However, given the work and help put into individuals' job market papers (receiving help with the writing from advisors and copy editors), it seems that job market papers would not help distinguish individuals' language ability. Moreover, writing quality and spoken language quality may be distinct (some speak better than they write and vice versa). We formally test this perspective by collecting the dissertations for individuals in our sample. We then perform various natural language processing techniques on the documents to generate two measures of writing quality: one based on the number of grammatical errors in the text and one reflecting the writing richness of the document 36

In Figure 12, we begin by examining the writing gaps for the three demographic groups: Asians, Chinese, and White-named Chinese. These writing gaps constructed by estimating

\footnotetext{
${ }^{36}$ The lexical richness measure of Mass we use is based on a logarithmic function of the relation between the terms (types) and the total number of words in a text (tokens). The measure gives us a measure of the diversity of the writing.
} 
equation 1 replacing the outcome measure with the percentage of grammatical errors in Panel a and the writing richness measure Mass in Panel b. These models give us the reduced-form estimates of writing changes for the groups relative to whites before and after ARC, using the sample of schools that eventually participated in the rookie camp. The specifications also include year and degree school fixed effects. ${ }^{37}$ We plot each of the coefficients on the demographic characteristics (i.e., the writing gap) as well as the full effect of the ARC on the writing gap for each group 38

Panel a of Figure 12, shows that concerning grammatical errors, all three groups had similar percentages of errors in their dissertations as compared white candidates before ARC. Moreover, it seems that after the ARC, all three groups decreased the percent of typographical errors in their job market papers as compared to white candidates. When we look at writing richness in Panel $\mathrm{b}$, we see each of the groups exhibiting a similar richness in writing when compared to white candidates in the pre-ARC period. Similar to the inferences from Panel a, there is a statistically insignificant increase in the richness of the Asian and Chinese groups relative to whites after ARC. Notably, there is no difference in writing richness for Chinese with white first names before and after ARC. Thus, it seems unlikely that job market papers could be used to distinguish the language ability of the candidates before ARC. Overall, these results highlight the importance of the in-person component of ARC in amplifying the prominence of language differences and driving the previously documented changes in placement likelihoods for these groups.

Our results can either be interpreted through the framework of statistical discrimination or from a recruiter bias. From the lens of statistical discrimination, the results would suggest that the new information gleaned from the in-person signals in the ARC led employers to update their prior beliefs about the research productivity in a negative direction for Chinese candidates and a positive direction for Anglo candidates (Arrow, 1973). The alternative

\footnotetext{
${ }^{37}$ See Appendix Table A.8 for the full models

${ }^{38}$ The full effect of the ARC on the writing gap is defined as the sum of Dem and DemX Post ARC in the estimated models found in Appendix Table A.8
} 
interpretation is that the increased role of interpersonal interaction may have caused factors like language to become more salient or to carry more weight in the overall evaluation of candidates. This would be consistent with the evidence from the Chinese candidates with white first names, for whom recruiters' perception of their English-speaking ability may have changed substantially.

\section{Conclusion}

We study the effects of a labor market intermediary that reduced the cost of in-person job screening on the determinants and distribution of job-market placements for new PhDs. We find strong evidence that the increase in in-person screening led recruiters to place less weight on imperfect quality signals-including degree school reputation and referrals from connected advisers-that were previously used to screen applicants. We go on to examine how these changes in the screening process affected the ultimate productivity new hires and the quality of job matches (Smeets et al. (2006)). We document an increase in the number and quality of papers produced by individuals hired through ARC. We conclude that the historical returns to program reputation and adviser connections were driven partly by their signaling and screening values, and that the ability to screen candidates in person at a lower cost led employers to update their assessments and change their hiring decisions. They also indicate that by one measure, the ARC helped foster greater diversity in hiring and increased productivity. With respect to candidate demographics, however, we find that rookie camp participation resulted in a penalty (measured by a decline in the rank of the hiring university) for candidates with Chinese names relative to those with English-sounding names. Our findings are consistent with an increase in the weight of English speaking ability in the screening process, though cultural differences and bias may also play a role.

The study makes several contributions to the literature on the academic labor market as well as to the general literature on hiring. Our findings are especially relevant for under- 
standing the determinants of initial placement of graduate students, which are key to shaping academic careers $(\mathrm{Oyer}(2006))$. In the broader literature on employment and hiring, a large body of research has explored the theoretical implications or informational asymmetries in the hiring process as well as the practical importance and distributional consequences of various signaling and screening mechanisms. The literature, however, has suffered from its inability to credibly distinguish these mechanisms from other channels linking applicant characteristics to labor market outcomes. Methodologically, our study credibly identifies the importance of screening and signaling by asking how employers respond to a sharp change in the cost of information on applicant quality. Finally, our study provides some of the first rigorous evidence, using actual job seekers, that increased personal contact affects labor market screening and hiring outcomes. 


\section{References}

Agan, A. and S. Starr (2018). Ban the box, criminal records, and racial discrimination: A field experiment. The Quarterly Journal of Economics 133(1), 191-235.

Altonji, J. G. and C. R. Pierret (2001). Employer learning and statistical discrimination. The Quarterly Journal of Economics 116(1), 313-350.

Arai, M. and P. Skogman Thoursie (2009, Jan). Renouncing personal names: An empirical examination of surname change and earnings. Journal of Labor Economics 27(1), 127-147.

Arrow, K. J. (1973). The theory of discrimination. Discrimination in labor markets 3(10), $3-33$.

Athey, S., L. F. Katz, A. B. Krueger, S. Levitt, and J. Poterba (2007). What does performance in graduate school predict? graduate economics education and student outcomes. American Economic Review 97(2), 512-520.

Barrios, J. M. (2019). Occupational licensing and accountant quality: Evidence from the 150-hour rule. Becker Friedman Institute for Research in Economics Working Paper (2018$32)$.

Bartos, V., M. Bauer, J. Chytilova, and F. Matejka (2016). Attention discrimination: Theory and field experiments with monitoring information acquisition. American Economic Review 106(6), 1437-1475.

Baruffaldi, S., F. Visentin, and A. Conti (2016). The productivity of science \& engineering phd students hired from supervisors' networks. Research Policy 45(4), 785-796.

Beaman, L. and J. Magruder (2012). Who gets the job referral? evidence from a social networks experiment. American Economic Review 102(7), 3574-93.

Becker, G. S. (1964). Human capital. The University of Chicago Press.

Bergner, J. M., J. J. Filzen, and J. A. Wong (2016). Navigating the accounting academic job market and related advice. In Advances in Accounting Education: Teaching and Curriculum Innovations, pp. 147-176.

Bertrand, M. and S. Mullainathan (2004). Are emily and greg more employable than lakisha and jamal? a field experiment on labor market discrimination. American Economic Review 94(4), 991-1013. 
Biavaschi, C., C. Giulietti, and Z. Siddique (2017). The economic payoff of name americanization. Journal of Labor Economics 35(4), 1089-1116.

Brown, M., E. Setren, and G. Topa (2016). Do informal referrals lead to better matches? evidence from a firm's employee referral system. Journal of Labor Economics 34(1), 161209.

Burks, S. V., B. Cowgill, M. Hoffman, and M. Housman (2015). The value of hiring through employee referrals. The Quarterly Journal of Economics 130(2), 805-839.

Calvo-Armengol, A. and M. O. Jackson (2004). The effects of social networks on employment and inequality. American Economic Review 94(3), 426-454.

Catalini, C., C. Fons-Rosen, and P. Gaule (2020). How do travel costs shape collaboration? Management Science forthcoming.

Chan, K. C., C. R. Chen, and H.-G. Fung (2009). Pedigree or placement? an analysis of research productivity in finance. Financial Review 44(1), 87-111.

Clark, D. and P. Martorell (2014). The signaling value of a high school diploma. Journal of Political Economy 122(2), 282-318.

Conley, J. P. and A. S. Onder (2014). The research productivity of new phds in economics: the surprisingly high non-success of the successful. Journal of Economic Perspectives 28(3), 205-16.

Dustmann, C., A. Glitz, U. Schönberg, and H. Brücker (2016). Referral-based job search networks. The Review of Economic Studies 83(2), 514-546.

Farber, H. S. and R. Gibbons (1996). Learning and wage dynamics. The Quarterly Journal of Economics 111(4), 1007-1047.

Felbermayr, G. J. and F. Toubal (2010). Cultural proximity and trade. European Economic Review 54(2), 279-293.

Fogarty, T. J., D. V. Saftner, and J. R. Hasselback (2011). Knowing one's place: The distribution of new accounting academics into a segmented labor market. Journal of Accounting Education 29(2-3), 89-99.

Fowler, J. H., B. Grofman, and N. Masuoka (2007). Social networks in political science: Hiring and placement of ph.ds, 1960-2002. PS: Political Science \& Politics 40(4), 729739 . 
Hadlock, C. J. and J. R. Pierce (2018). Hiring your friends: Evidence from the market for financial economists. Industrial and Labor Relations Review forthcoming.

Hoffman, M., L. B. Kahn, and D. Li (2018). Discretion in hiring. The Quarterly Journal of Economics 133(2), 765-800.

Hunt, S. and K. T. Jones (2016). Interviewing potential accounting faculty at the aaa national meeting and rookie camp: Surveys of schools'experiences and impressions. Academy of Educational Leadership Journal 20(1), 65-84.

Kahn, L. B. (2010). The long-term labor market consequences of graduating from college in a bad economy. Labour Economics 17(2), 303-316.

Kramarz, F. and O. N. Skans (2014). When strong ties are strong: Networks and youth labour market entry. Review of Economic Studies 81(3), 1164-1200.

Krueger, A. B. and S. Wu (2000). Forecasting job placements of economics graduate students. The Journal of Economic Education 31(1), 81-94.

Leite Lopez de Leon, F. and B. McQuillin (2020). The role of conferences on the pathway to academic impact: Evidence from a natural experiment. Journal of Human Resources 55(1), 164-193.

MacLeod, W. B., E. Riehl, J. E. Saavedra, and M. Urquiola (2017). The big sort: College reputation and labor market outcomes. American Economic Journal: Applied Economics 9(3), 223-61.

Melitz, J. and F. Toubal (2014). Native language, spoken language, translation and trade. Journal of International Economics 93(2), 351-363.

Montgomery, J. D. (1991). Social networks and labor-market outcomes: Toward an economic analysis. The American Economic Review 81(5), 1408-1418.

Oreopoulos, P., T. Von Wachter, and A. Heisz (2012). The short-and long-term career effects of graduating in a recession. American Economic Journal: Applied Economics 4(1), 1-29.

Oyer, P. (2006). Initial labor market conditions and long-term outcomes for economists. Journal of Economic Perspectives 20(3), 143-160.

Oyer, P. and S. Schaefer (2016). Firm/employee matching: An industry study of us lawyers. ILR Review 69(2), 378-404. 
Oyer, P. and S. Schaefer (2019). The returns to elite degrees: The case of american lawyers. ILR Review 72(2), 446-479.

Pager, D., B. Western, and N. Sugie (2009). Sequencing disadvantage: Barriers to employment facing young black and white men with criminal records. The Annals of the American Academy of Political and Social Science 623(1), 195-213.

Rose, M. E. and S. Shekhar (2018). Informal contacts in hiring: The economics job market. Max Planck Institute for Innovation 6 Competition Research Paper No. 18-12.

Smeets, V., F. Warzynski, and T. Coupé (2006). Does the academic labor market initially allocate new graduates efficiently? Journal of Economic Perspectives 20(3), 161-172.

Spence, M. (1973). Job market signaling. The Quarterly Journal of Economics 87(3), $355-374$. 


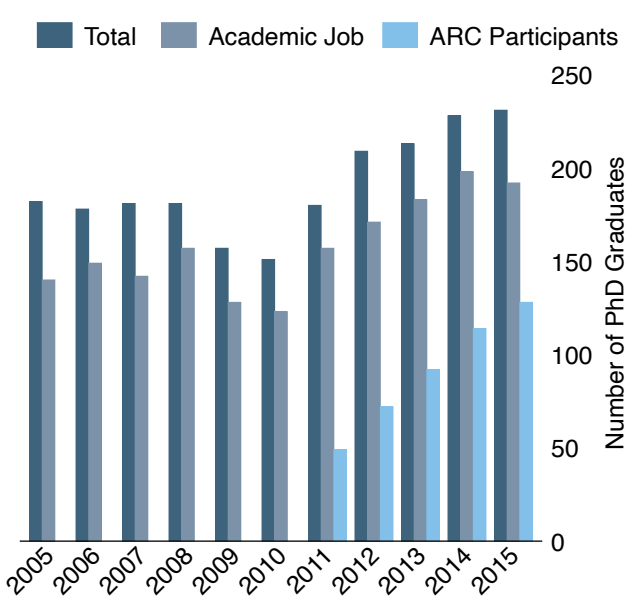

(a) Supply - Ph.D. Graduates

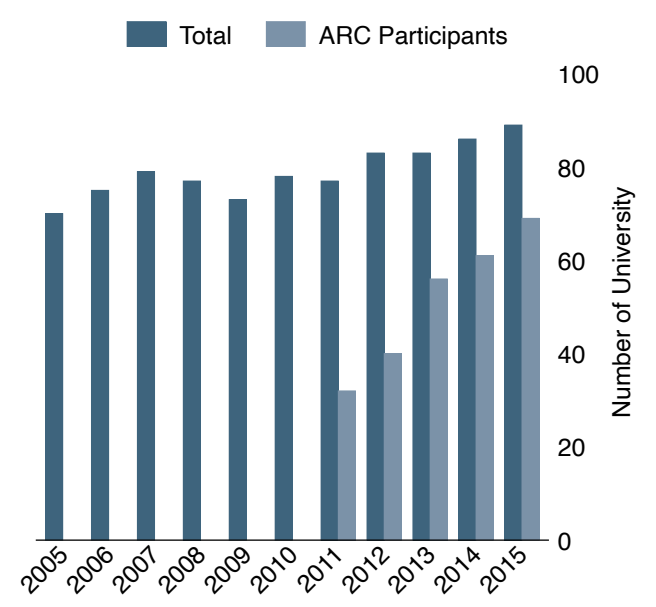

(b) Supply - Ph.D. Granting Universities

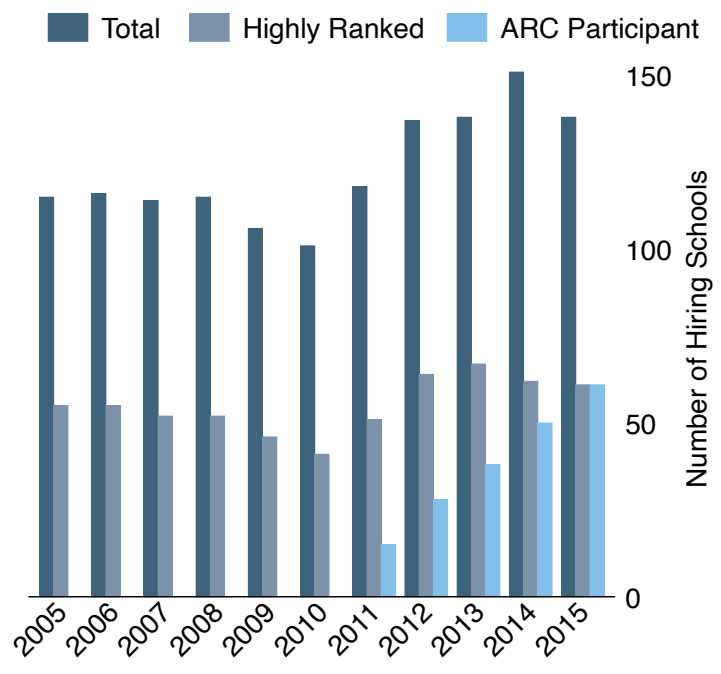

(c) Hiring Universities (Recruiters)

Figure 1: This figure plots the numbers of individual and institutional participants in the U.S. academic labor market for Ph.D. accountants by year. Panel (a) graphs the number of new Ph.D.s who graduated from one of 102 accredited U.S. Ph.D. programs and were hired by an academic institution. Panel (b) shows the number of U.S. universities producing Ph.D.s each year while panel (c) plots the number of hiring universities. Each panel also shows the number of Rookie Camp participants in each year. 

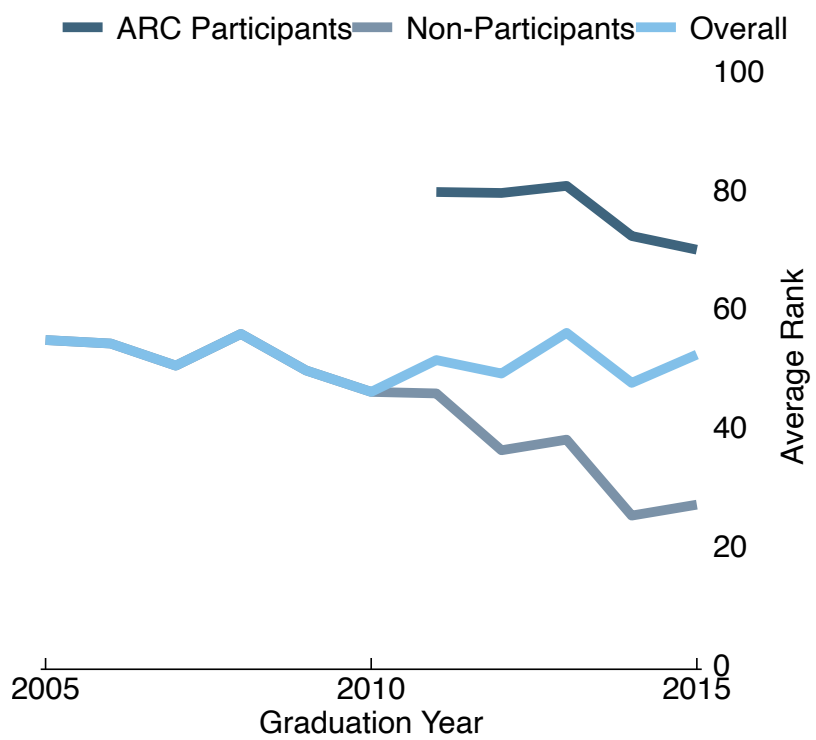

(a) Average Rank by RC participation over time - Recruiting Schools

- ARC Participants - Non-Participants - Overall

100

80

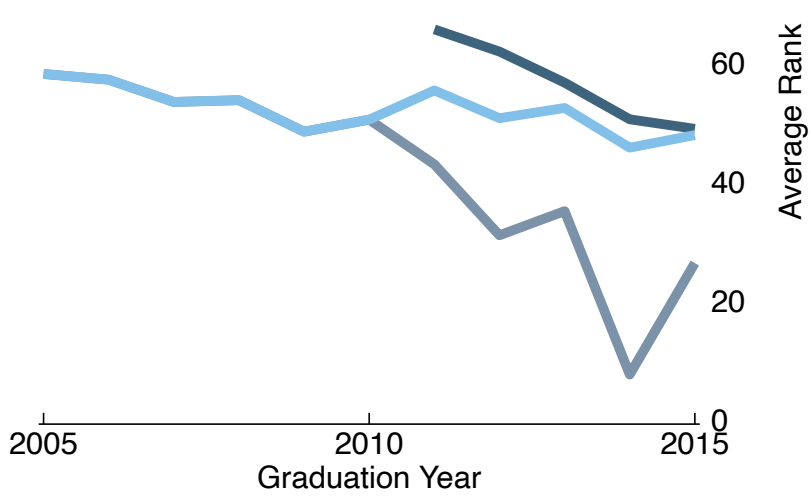

(b) Average Rank by RC participation over time - Degree Schools

Figure 2: This figure graphs the average rank of supplying and hiring universities by year and by participation in the rookie camp. Panel (a) plots the ranks for recruiting schools while panel (b) plots the ranks for degree schools. 


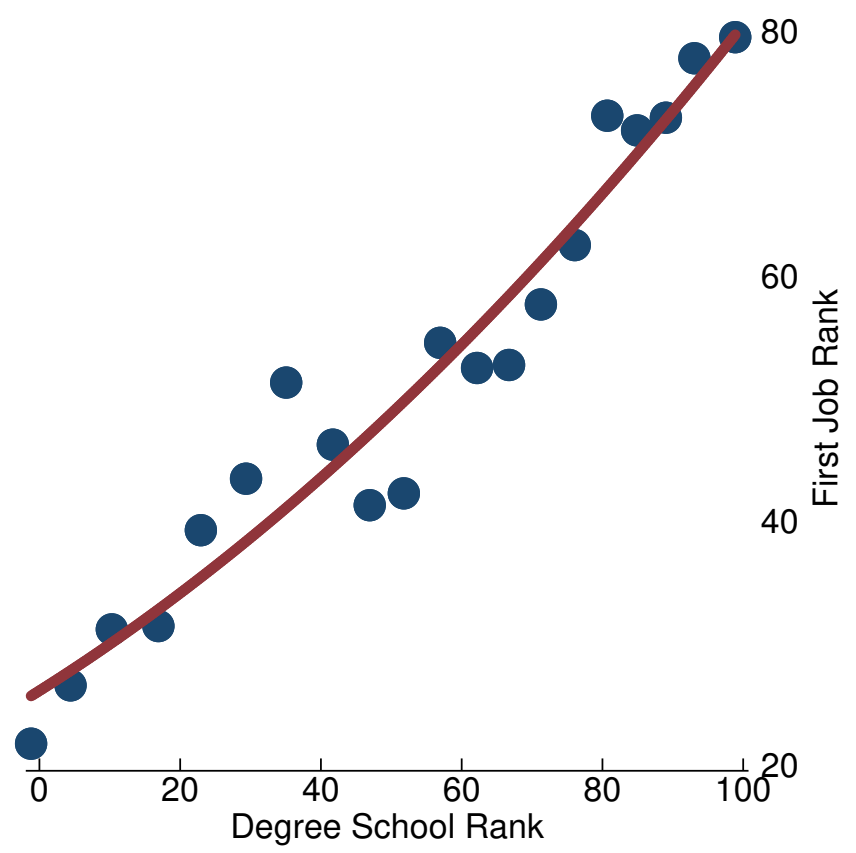

Figure 3: This figure plots the relation between the degree school's rank and the first placement rank. We also fit a line from a quadratic model using the full sample of placements. 


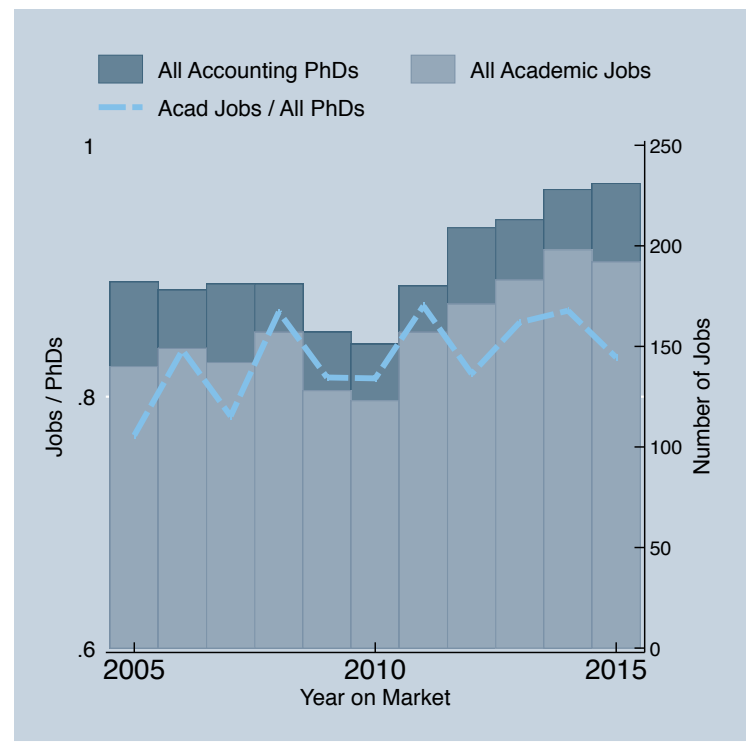

(a) Labor Market Tightness

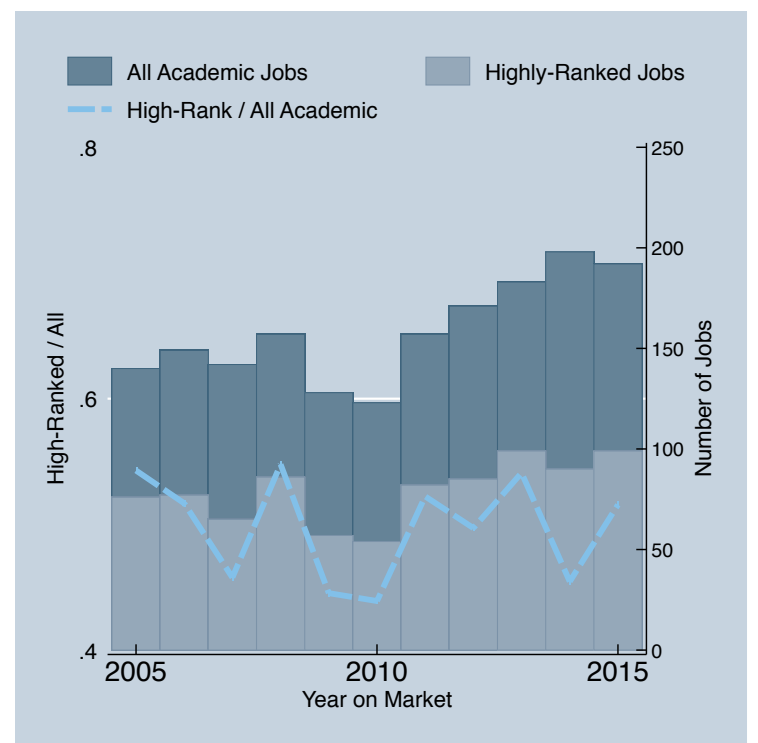

(b) Market for Highly Ranked Jobs

Figure 4: This figure graphs the labor market conditions in the academic market. In Panel (a), we graph the supply of accounting $\mathrm{PhDs}$, the number of PhDs that obtained an academic job, and the ratio of academic jobs to PhDs. In Panel (b) we examine the market for highly ranked jobs. We graph the number of academic jobs each year, the number of jobs that are in highly ranked schools, and the ratio of high-ranked jobs to total jobs in each of the years. 


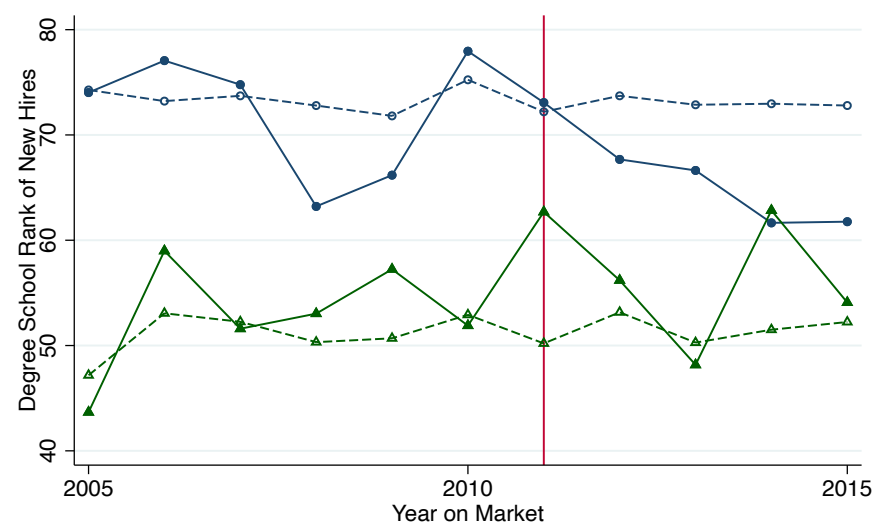

highly ranked employers: - - - - - - - predicted using 2005-07 hires —— observed lower-ranked employers: $\quad---\downarrow--$. predicted using 2005-07 hires $\longrightarrow$ observed

(a) Early adopters (2011-2013)

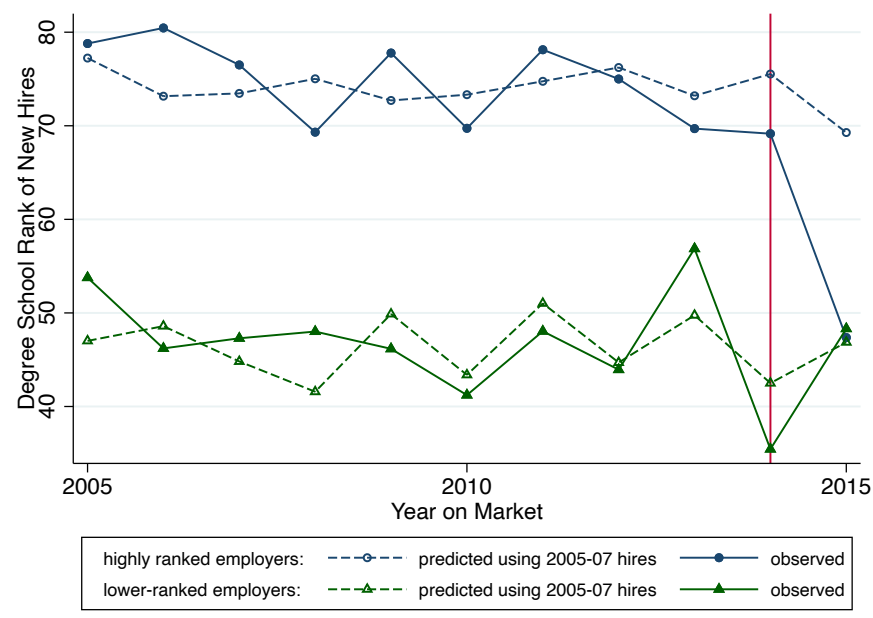

(b) Late adopters (2014-2015)

Figure 5: This figure plots the mean predicted rank and mean observed rank of degree programs from which universities hired each year, for all hiring schools that eventually attended the rookie camp. The sample is split into two groups based on the first year of the university's participation as a recruiter: "early adopters" (panel a) began participating between 2011 and 2013 and "late adopters" (panel b) began in 2014 or 2015 . Within each of these categories, recruiters are further grouped into "high-ranked" or "lower-ranked" based on their ranking relative to the sample median. 


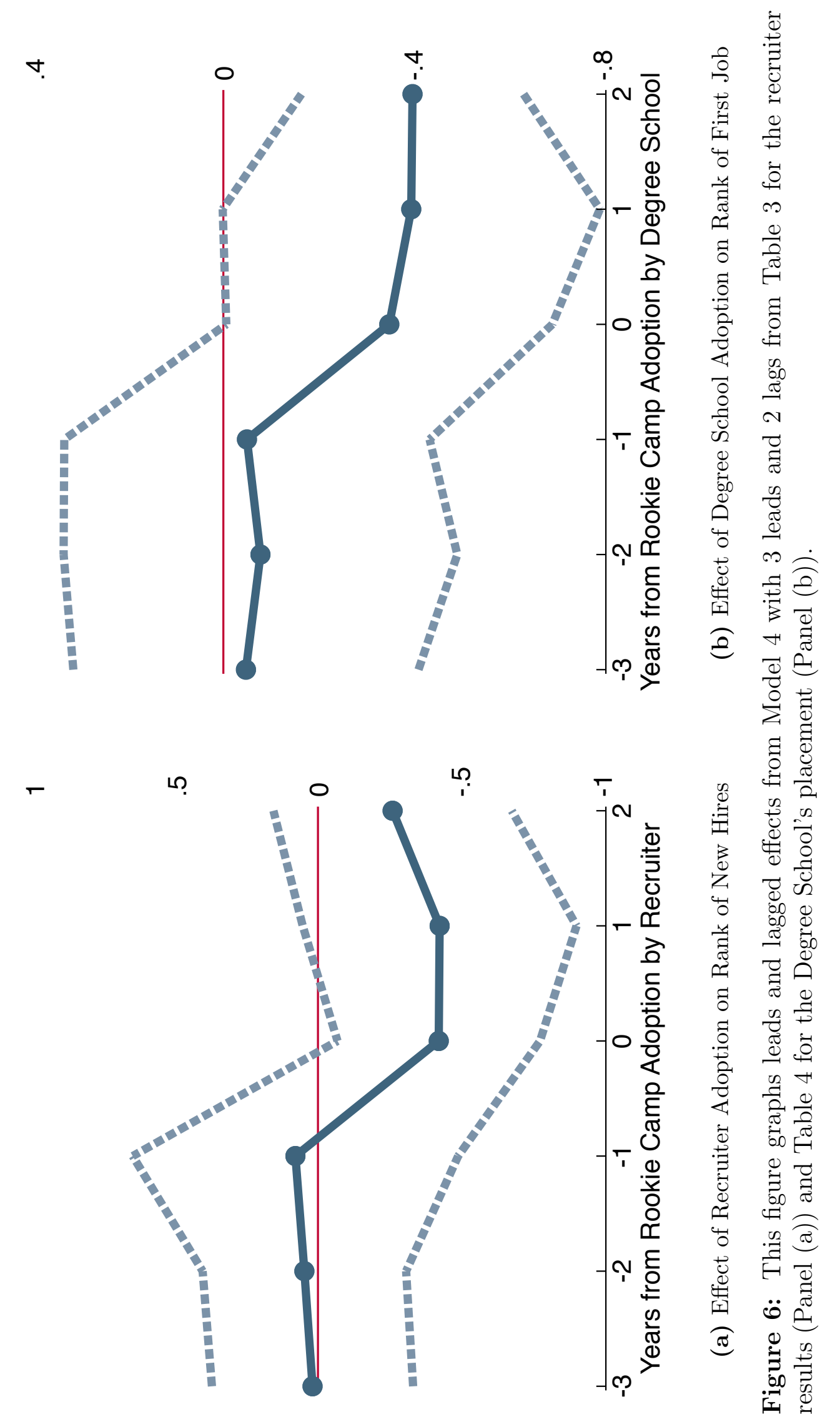




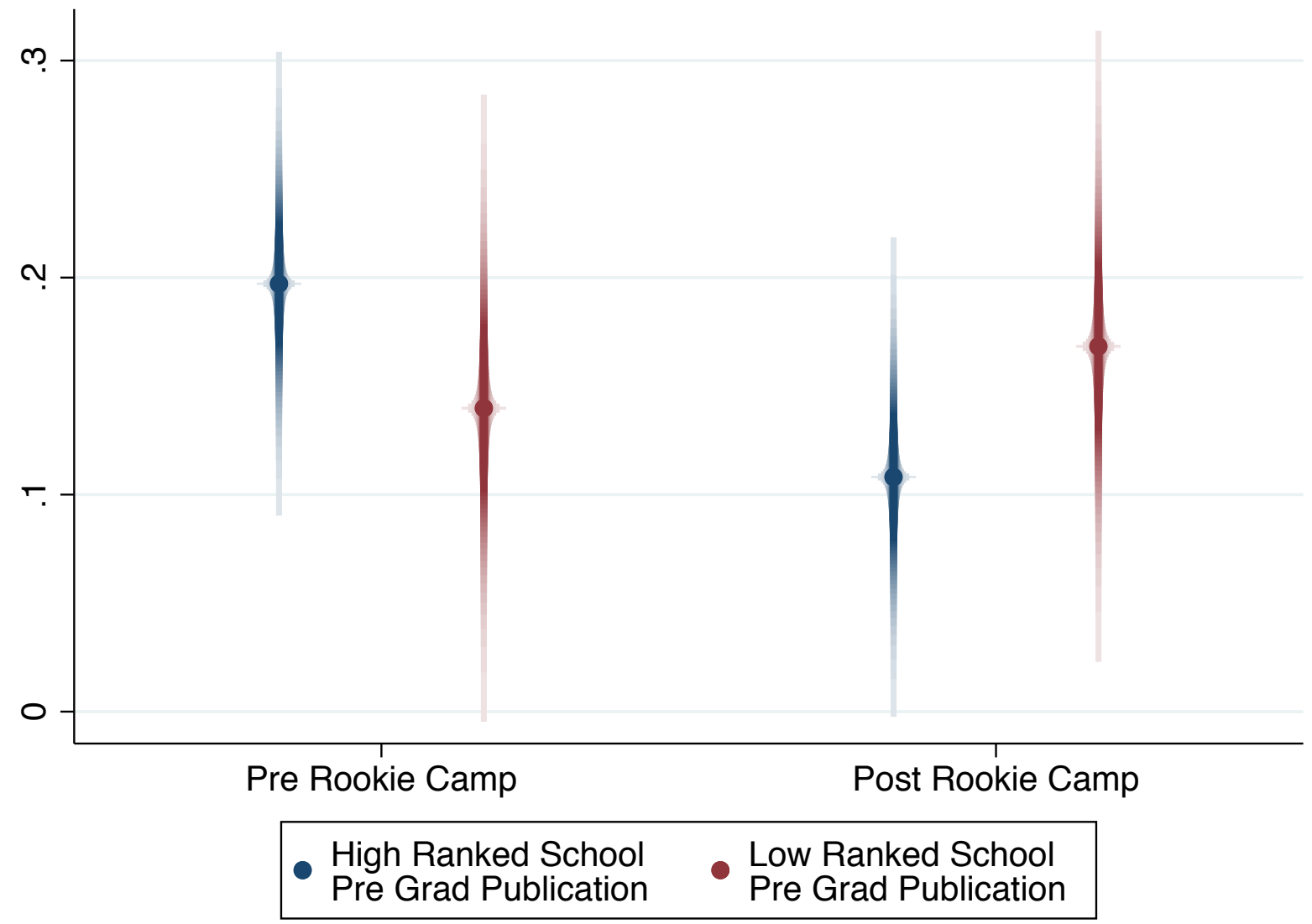

Figure 7: This figure graphs ARC's effect on the importance of a pre-graduation publication on the likelihood of placing at a high-ranked school for graduates from high-ranked schools and those from low-ranked schools. The variable Pre - Graduation Publication is defined as having a publication up until the graduation year. The estimates are generated from the second and the third specification of Table 5. 


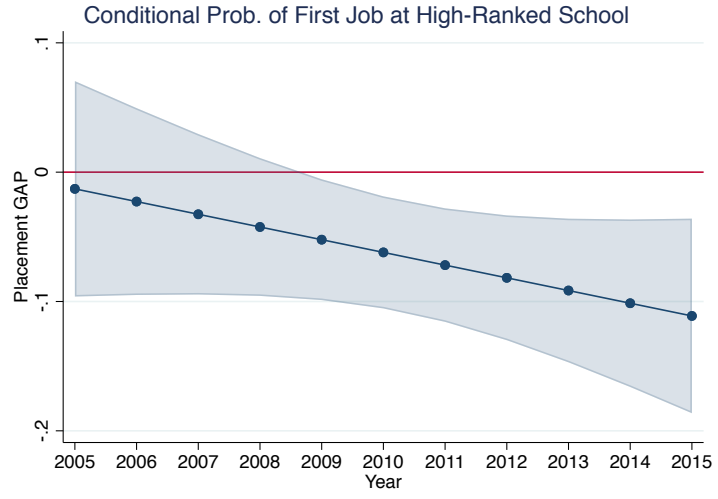

(a) Female (vs. Male)

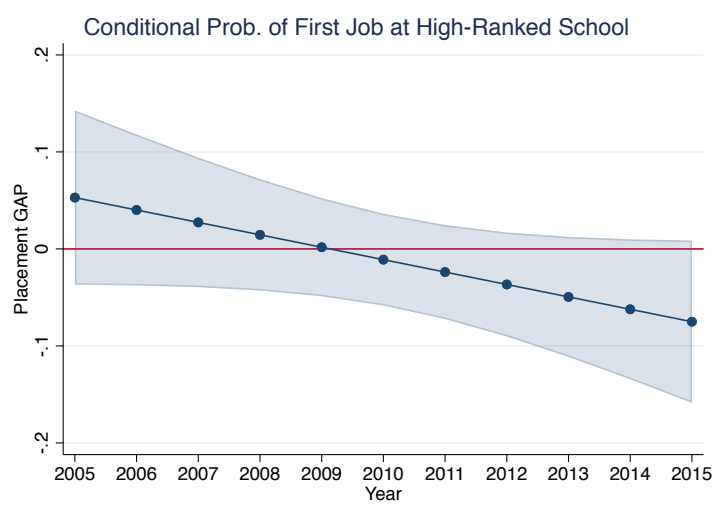

(c) API (vs. White)

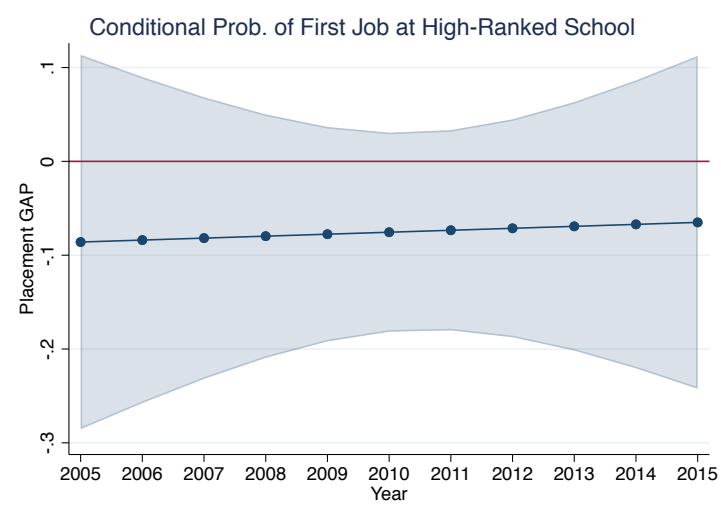

(b) Minority (vs. White)

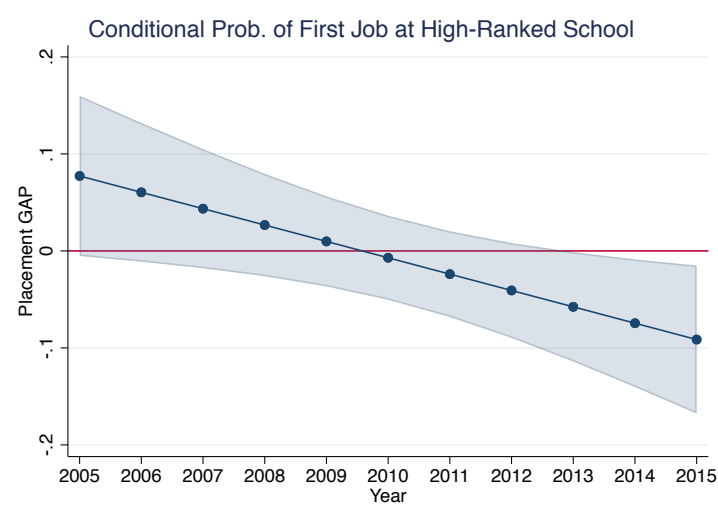

(d) Foreign (vs. Domestic)

Figure 8: This figure graphs the adjusted placement gap for various demographic groups. The estimates are constructed by estimating the likelihood of a high-ranked placement for each demographic group controlling for the quality of the individual's degree school. Panel (a) plots it for the female, Panel (b) provides it for the minority, while panels (c) provides it for API, and (d) provides it for foreign candidates. The bands in each panel provide the $95 \%$ confidence interval for the estimated likelihood. 


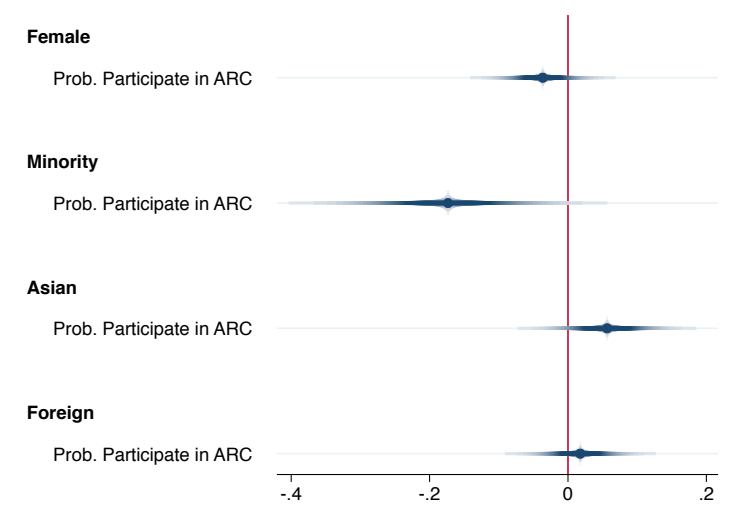

(a) $\mathrm{PR}($ Participation in ARC)

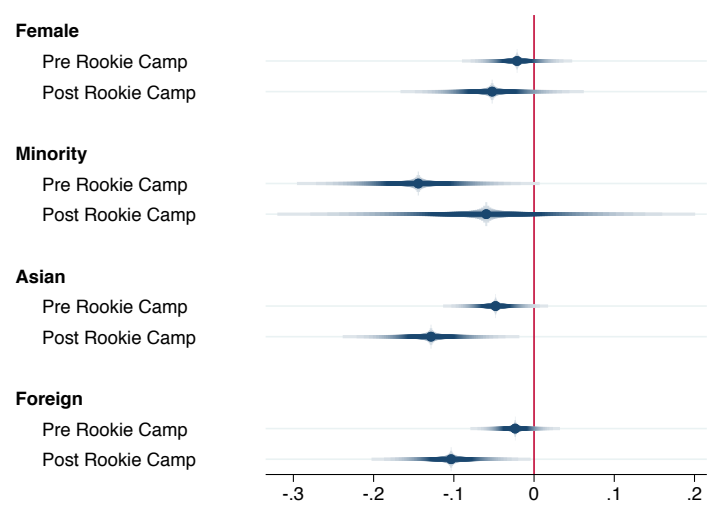

(b) $\operatorname{Pr}($ First Job at Highly-Ranked School)

Figure 9: This figure graphs both the likelihood of participating in the ARC and the likelihood of placing at a highly rank school. Panel (a) plots the likelihood of participation for each of the groups. The estimates are generated from Table A.4 (panel a). Panel (b) plots the likelihood of placing at a highly ranked first job by ARC participation for each of the groups. The estimates are generated from Table A.4 (panel b). The bands in each panel provide the $95 \%$ confidence interval for the estimated likelihood. 


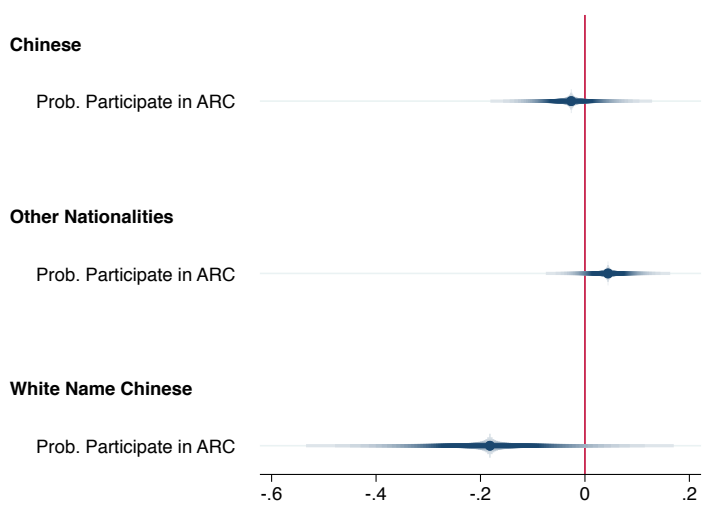

(a) $\operatorname{Pr}($ Participation in ARC)

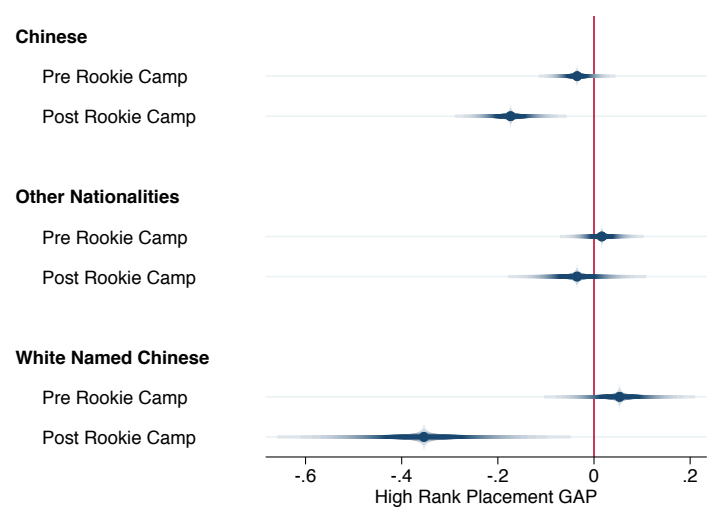

(b) $\operatorname{Pr}($ First Job at Highly-Ranked School)

Figure 10: This figure graphs both the likelihood of participating in the ARC and the likelihood of placing at a highly rank school for Asian subgroups. Panel (a) plots the likelihood of participation for each of the groups. The estimates are generated from Table A.5 (panel a). Panel (b) plots the likelihood of placing at a highly ranked first job by ARC participation for each of the groups relative to white individuals. The estimates are generated from Table A.5 (panel b). The bands in each panel provide the 95\% confidence interval for the estimated likelihood. 


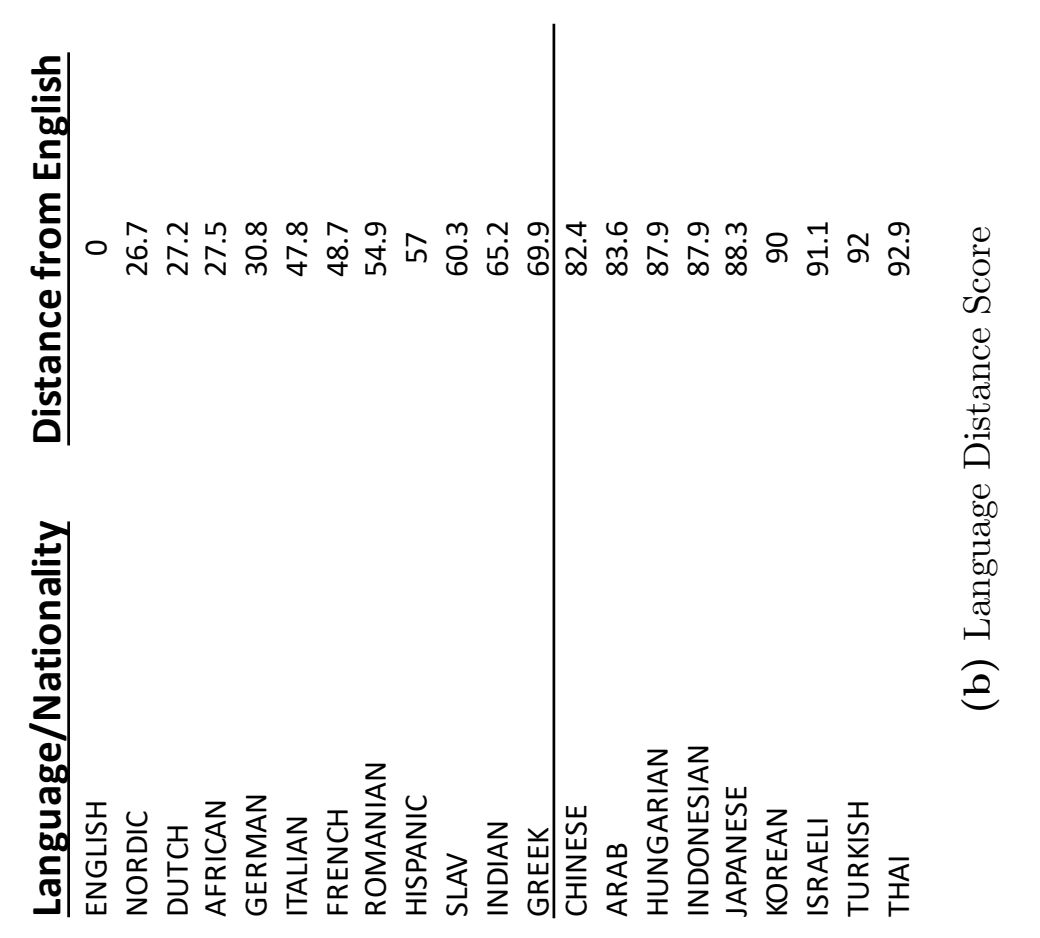

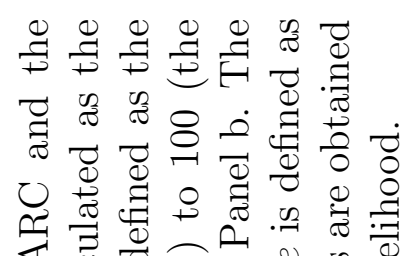

《

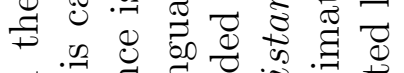

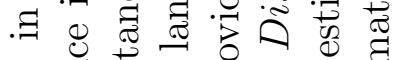
.

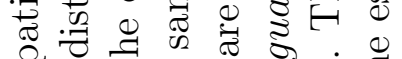
भ ज

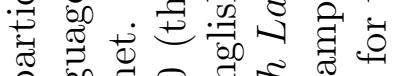

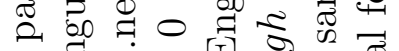
山ै.

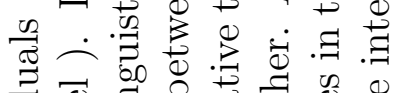

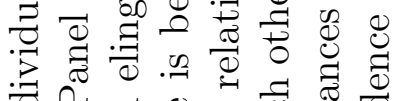
: 유 \&

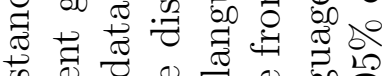

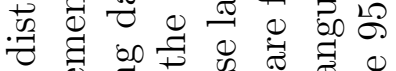

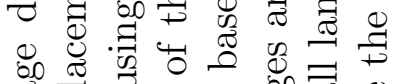
$\Xi \overrightarrow{2} \approx 0.00$ 20 0.7 . สี

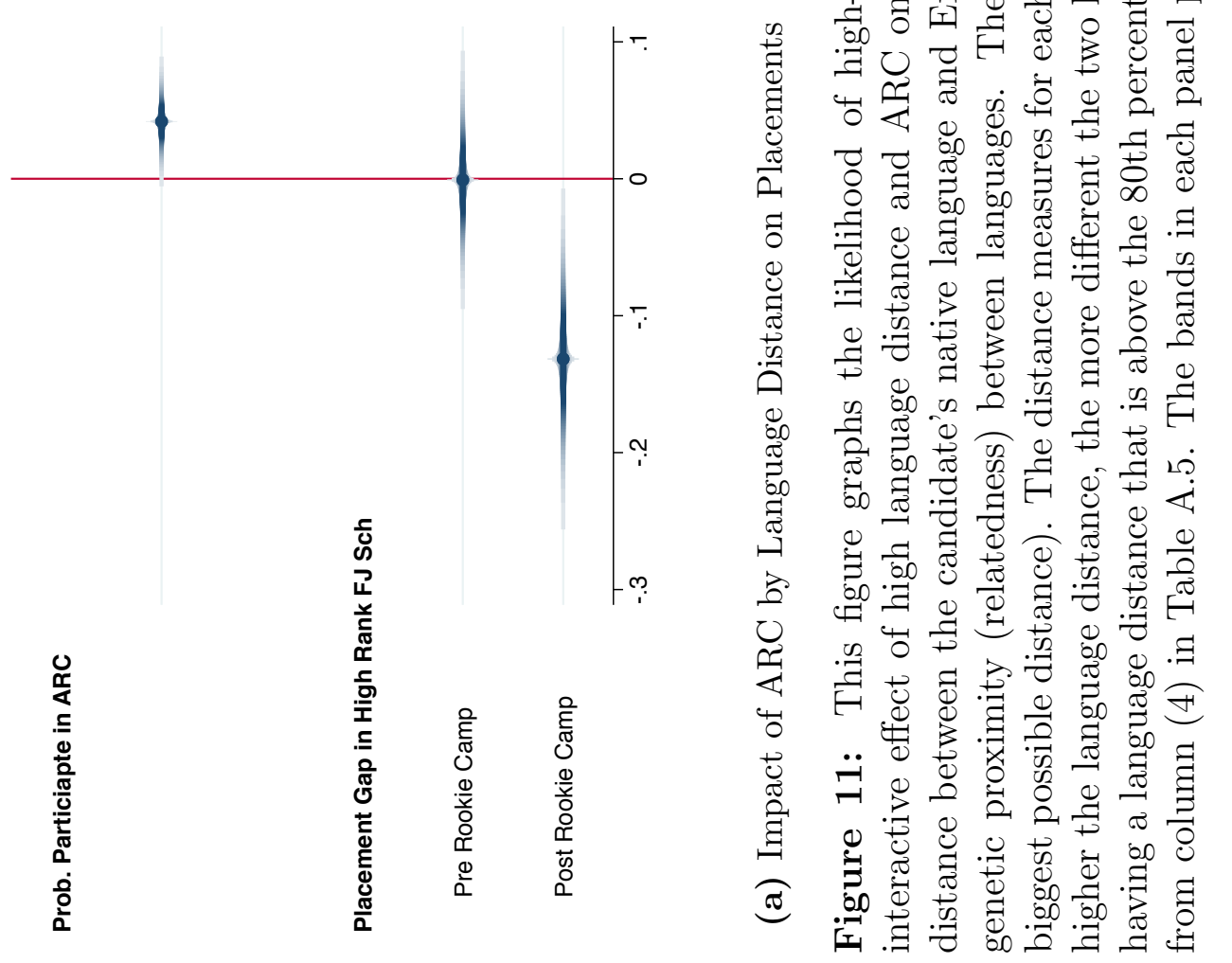




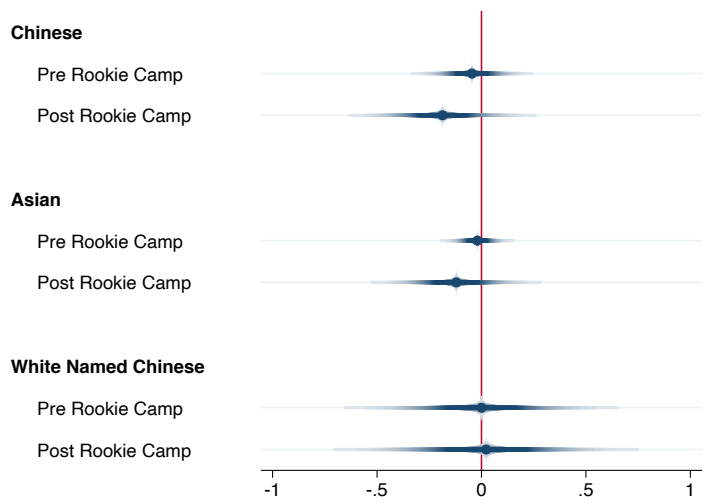

(a) Writing Typos

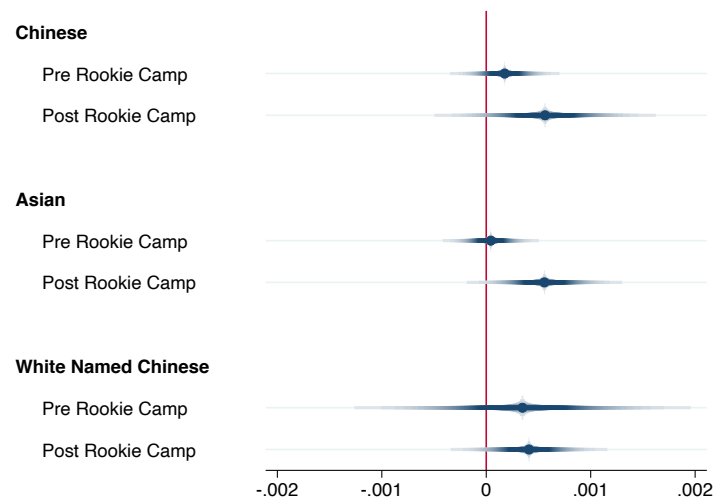

(b) Writing Complexity

Figure 12: This figure graphs the comparison of writing quality for various demographic groups against white candidates before as well as after ARC. Panel (a) uses the average number of typographical errors in individuals dissertation. Panel (b) uses the lexical richness measure of Mass; the index is based on a logarithmic function of the relation between the terms (types) and the total number of words in a text (tokens). The measure gives us a measure of the diversity of the writing. The estimates are generated the specifications in Table A.8. The bands in each panel provide the $95 \%$ confidence interval for the estimated likelihood. 
Table 1: Characteristics of New PhDs in Sample (2005-2015)

\begin{tabular}{|c|c|c|c|c|c|}
\hline \multirow[b]{2}{*}{ Candidate Characteristics } & \multicolumn{2}{|c|}{ Lower-Ranked Degree Schools } & \multicolumn{2}{|c|}{ Higher-Ranked Degree Schools } & \multirow[b]{2}{*}{ Total } \\
\hline & $2005-2010$ & $2011-2015$ & $2005-2010$ & $2011-2015$ & \\
\hline Female (\%) & $42.0 \%$ & $44.2 \%$ & $39.5 \%$ & $40.1 \%$ & $41.3 \%$ \\
\hline \multicolumn{6}{|l|}{ Race: } \\
\hline White (\%) & $64.5 \%$ & $65.1 \%$ & $66.2 \%$ & $68.0 \%$ & $66.1 \%$ \\
\hline Minority $(\%)$ & $5.4 \%$ & $5.7 \%$ & $3.1 \%$ & $3.6 \%$ & $4.3 \%$ \\
\hline Asian/Pacific Islander (\%) & $29.5 \%$ & $28.7 \%$ & $29.9 \%$ & $27.9 \%$ & $29.0 \%$ \\
\hline \multicolumn{6}{|l|}{ Nationality: } \\
\hline Anglo (\%) & $41.8 \%$ & $46.2 \%$ & $41.2 \%$ & $46.8 \%$ & $44.1 \%$ \\
\hline Chinese (\%) & $25.6 \%$ & $24.6 \%$ & $22.1 \%$ & $19.6 \%$ & $22.7 \%$ \\
\hline Other Asian (\%) & $8.0 \%$ & $7.9 \%$ & $8.6 \%$ & $9.5 \%$ & $8.6 \%$ \\
\hline Other European (\%) & $17.9 \%$ & $17.0 \%$ & $22.5 \%$ & $16.0 \%$ & $18.4 \%$ \\
\hline Other (e.g. Middle Eastern) (\%) & $6.0 \%$ & $3.2 \%$ & $5.1 \%$ & $6.9 \%$ & $5.3 \%$ \\
\hline Cohort size & 2.6 & 2.9 & 3.2 & 3.7 & 3.2 \\
\hline Participated in Rookie Camp (\%) & - & $39 \%$ & - & $60 \%$ & $26 \%$ \\
\hline First Job in Top-Rank School (\%) & $29 \%$ & $35 \%$ & $64 \%$ & $63 \%$ & $50 \%$ \\
\hline Predicted First Job School Rank & 33.5 & 33.4 & 64.5 & 63.0 & 50.5 \\
\hline Any publication $\%$ & $19.6 \%$ & $23.9 \%$ & $33.4 \%$ & $34.7 \%$ & $28.8 \%$ \\
\hline Top-5 journal \% & $6.3 \%$ & $10.6 \%$ & $21.1 \%$ & $22.8 \%$ & $16.1 \%$ \\
\hline Co-authored pub w/ advisor \% & $3.1 \%$ & $5.4 \%$ & $5.9 \%$ & $9.3 \%$ & $6.2 \%$ \\
\hline Percent Typos \% & $58.3 \%$ & $64.5 \%$ & $54.7 \%$ & $66.7 \%$ & $60.2 \%$ \\
\hline Writing Richness & 1.94 & 1.96 & 2.00 & 1.99 & 1.98 \\
\hline Number of placements & 352 & 407 & 488 & 494 & 1741 \\
\hline Number of degree schools & & 54 & & 45 & 99 \\
\hline
\end{tabular}

This table reports descriptive statistics on various candidate characteristics for the sample of 1741 new Ph.D. graduates in accounting. The first four columns show means for sub-groups based on whether the rank of one's degree school is below the sample median (Lower-Rank) or above it (Higher-Rank), and on whether the candidate entered the job market in the years before (2005-2010) or after (2011-2015) the rookie camp was introduced. 
Table 2: Characteristics of First Jobs by University Participation in the Rookie Camp as a Recruiter

\begin{tabular}{|c|c|c|c|c|c|}
\hline \multirow[b]{2}{*}{ University Characteristics } & \multicolumn{4}{|c|}{ Year University First Recruited in Rookie Camp } & \multirow[b]{2}{*}{ Total } \\
\hline & $\begin{array}{c}\text { Early adopters: } \\
\text { 2011-2013 }\end{array}$ & $\begin{array}{l}\text { Late adopters: } \\
2014-2015\end{array}$ & $\begin{array}{c}\text { Post-sample: } \\
\text { 2016-2017 }\end{array}$ & $\begin{array}{c}\text { Never } \\
\text { as of } 2018\end{array}$ & \\
\hline BYU Research Ranking & 79.3 & 61.8 & 46.5 & 23.3 & 51.4 \\
\hline Ranked above Median* & $87 \%$ & $62 \%$ & $39 \%$ & $15 \%$ & $50 \%$ \\
\hline Has PhD Program and is Located in US** (\%) & $70 \%$ & $57 \%$ & $41 \%$ & $11 \%$ & $42 \%$ \\
\hline Located in US $(\%)$ & $85 \%$ & $96 \%$ & $87 \%$ & $90 \%$ & $89 \%$ \\
\hline Number of placements & 602 & 336 & 99 & 704 & 1741 \\
\hline Number of universities & 88 & 65 & 31 & 303 & 487 \\
\hline
\end{tabular}

This table provides descriptive statistics for the 487 hiring universities in the sample. The first four columns show statistics for sub-samples that are defined based on the year the university first participated in the rookie camp as a recruiter. The final column shows characteristics for the full sample.

* The recruiter is ranked above the median of all placements in the sample, or roughly the 60 th percentile of recruiting universities.

** The recruiting university is one of the degree schools that produces a Ph.D. candidate in the analysis. 


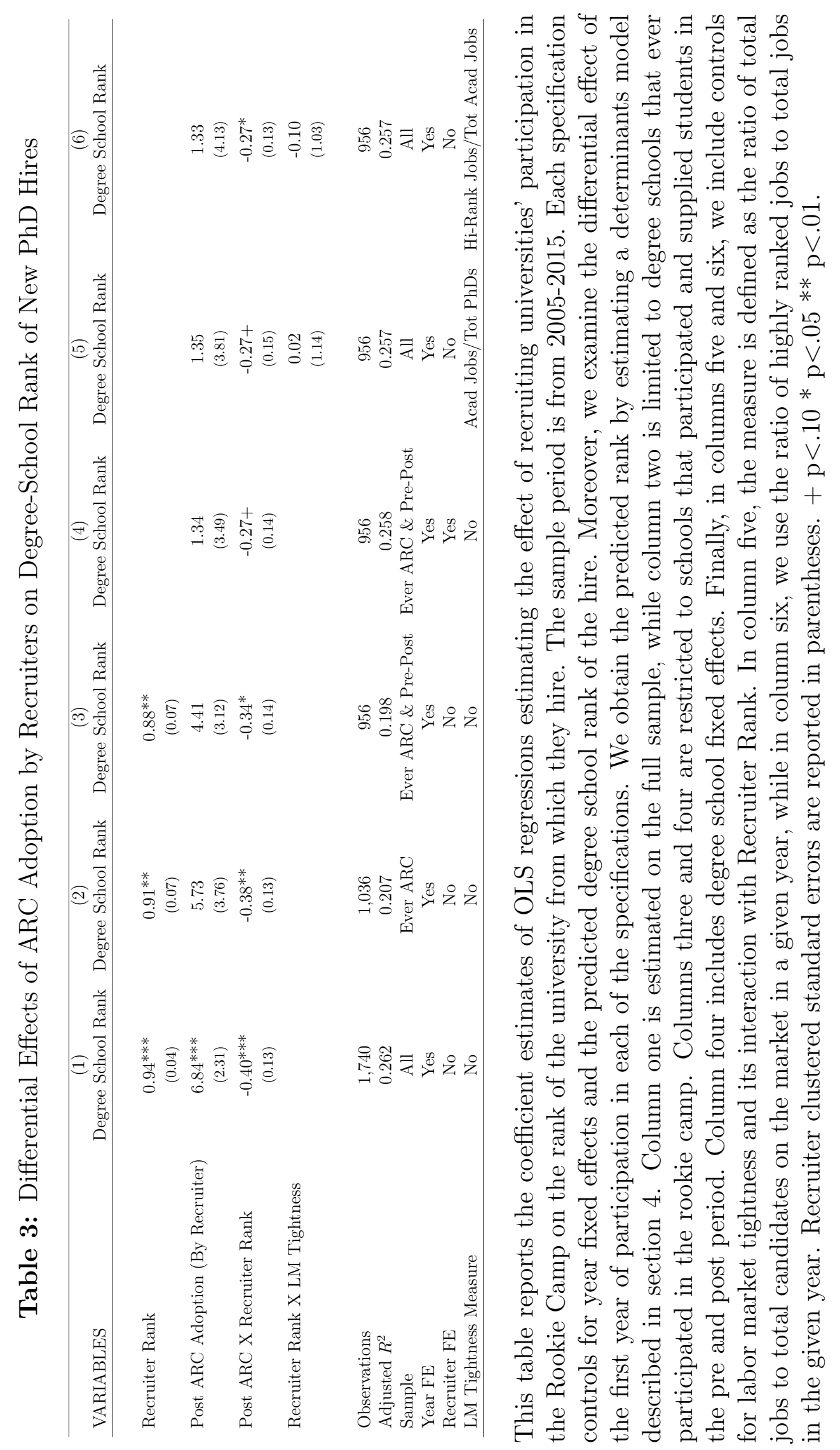




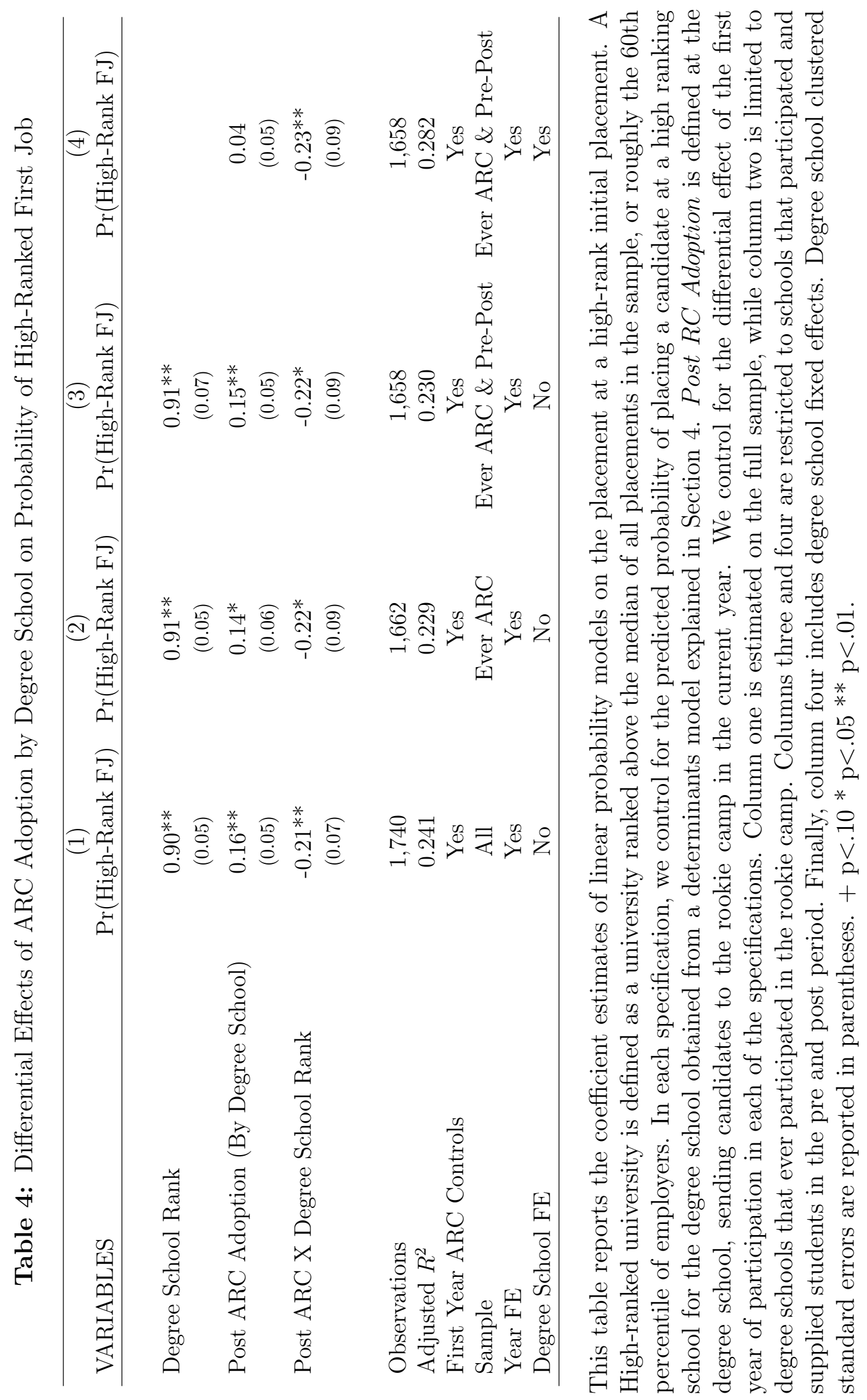


Table 5: Degree-School Based Models: Variation in Outcome Measures

\begin{tabular}{lccc}
\hline & $(1)$ & $(2)$ & $(3)$ \\
VARIABLES & First Job Rank & High-Rank First Job & First Job ARC Recruiter \\
\hline & & & 0.02 \\
Post ARC Adoption (By Degree School) & 1.78 & $(0.05)$ & $-0.24^{* *}$ \\
& $(3.76)$ & $-0.17^{*}$ & $(0.06)$ \\
Post ARC X Degree School Rank & -0.10 & $(0.07)$ & $(0.08)$ \\
& $(0.07)$ & & 1,658 \\
Observations & & 1,658 & 0.333 \\
Adjusted $R^{2}$ & 1,658 & 0.282 & Ever ARC \& Pre-Post \\
Sample & 0.323 & Yes \\
Year FE & DS Ever RC \& Pre-Post & Ever ARC \& Pre-Post & Yes \\
Degree School FE & Yes & Yes & Yes \\
\hline
\end{tabular}

This table replicates the supplier based degree school regressions from the previous table by varying the outcome measure. Column one is a linear probability model with the outcome being a binary measure of placement at a high-ranked university. Column two uses the average rank of the hiring school as the outcome measure to account for multiple placements from a degree school in a given year. Finally, column 3 used whether the hiring school participated at the rookie camp as the outcome. Each specification includes year and degree school fixed effects. Degree school clustered standard errors are reported in parentheses. + $\mathrm{p}<.10 * \mathrm{p}<.05 * * \mathrm{p}<.01$. 


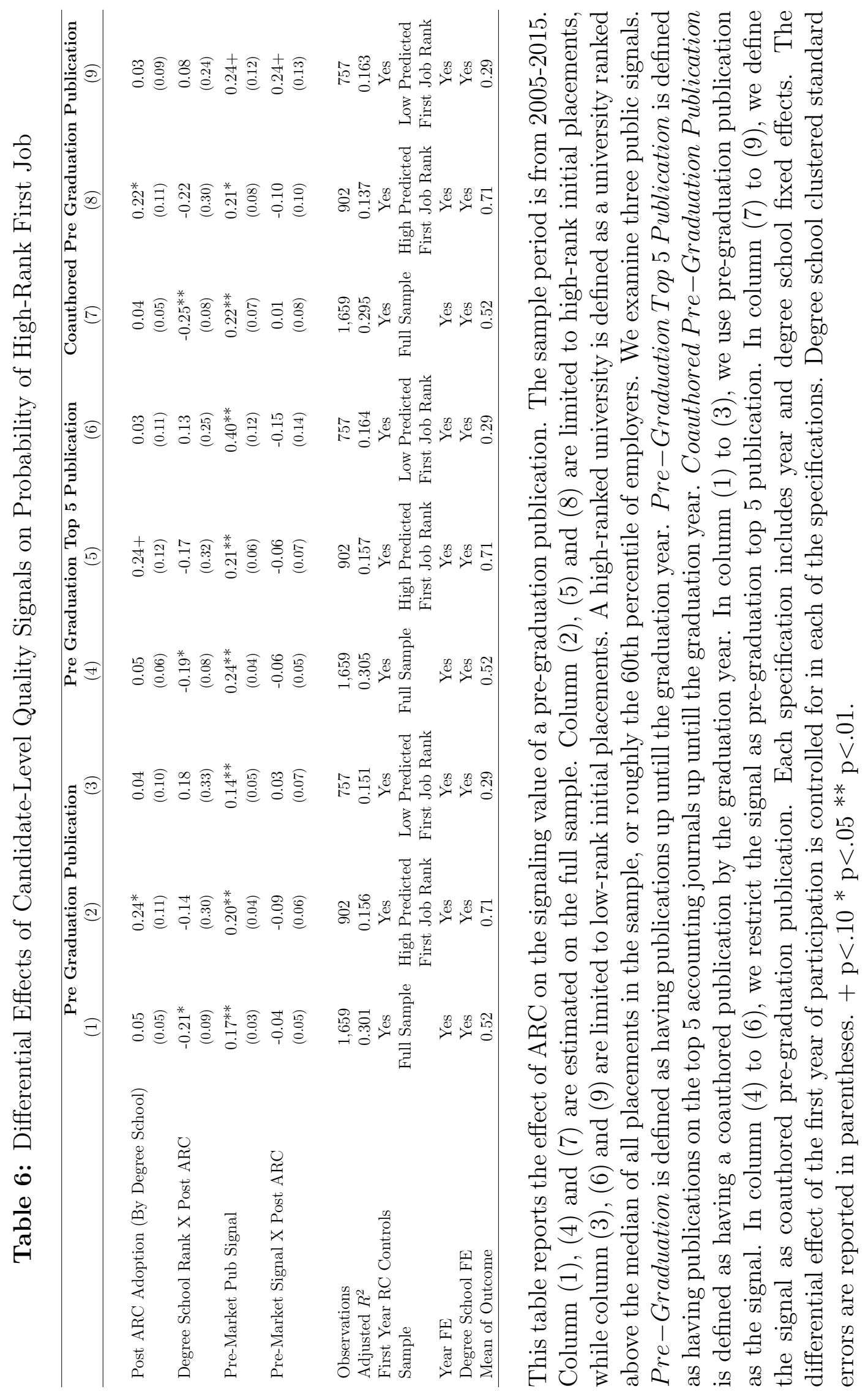


Table 7: The Role of Connections in Hiring

\begin{tabular}{|c|c|c|c|c|c|}
\hline VARIABLES & $\begin{array}{c}(1) \\
\operatorname{Pr}(\text { Hire })\end{array}$ & $\begin{array}{c}(2) \\
\operatorname{Pr}(\text { Hire }) \\
\end{array}$ & $\begin{array}{c}(3) \\
\operatorname{Pr}(\text { Hire }) \\
\end{array}$ & $\begin{array}{c}(4) \\
\operatorname{Pr}(\text { Hire }) \\
\end{array}$ & $\begin{array}{c}(5) \\
\operatorname{Pr}(\text { Hire }) \\
\end{array}$ \\
\hline Schools in Same Rank Decile & $\begin{array}{c}0.608^{* *} \\
(0.12)\end{array}$ & $\begin{array}{c}0.505^{* *} \\
(0.11)\end{array}$ & $\begin{array}{c}0.517^{* *} \\
(0.11)\end{array}$ & $\begin{array}{c}0.708^{* *} \\
(0.14)\end{array}$ & $\begin{array}{c}0.667^{* *} \\
(0.13)\end{array}$ \\
\hline Adviser has Connection with Recruiter & & $\begin{array}{c}5.207^{* *} \\
(0.46)\end{array}$ & $\begin{array}{c}5.033^{* *} \\
(0.46)\end{array}$ & $\begin{array}{c}5.746^{* *} \\
(0.58)\end{array}$ & $\begin{array}{c}4.798^{* *} \\
(0.49)\end{array}$ \\
\hline Log Distance between Schools & & & $\begin{array}{c}-0.685^{* *} \\
(0.06)\end{array}$ & $\begin{array}{c}-0.814^{* *} \\
(0.08)\end{array}$ & $\begin{array}{c}-0.765^{* *} \\
(0.07)\end{array}$ \\
\hline Post ARC Adoption & & & & $\begin{array}{c}-1.870^{* *} \\
(0.44)\end{array}$ & $\begin{array}{c}-2.226^{* *} \\
(0.35)\end{array}$ \\
\hline Adviser Connection X Post ARC & & & & $\begin{array}{c}-1.315^{*} \\
(0.64)\end{array}$ & $\begin{array}{l}0.777 \\
(0.60)\end{array}$ \\
\hline Same Rank Decile X Post ARC & & & & $\begin{array}{c}-0.486^{* *} \\
(0.17)\end{array}$ & $\begin{array}{c}-0.686^{* *} \\
(0.19)\end{array}$ \\
\hline Log Distance X Post ARC & & & & $\begin{array}{c}0.285^{* *} \\
(0.06)\end{array}$ & $\begin{array}{c}0.330^{* *} \\
(0.05)\end{array}$ \\
\hline Observations & 216,804 & 216,804 & 216,804 & 216,804 & 216,804 \\
\hline Adjusted $R^{2}$ & -0.002 & 0.006 & 0.009 & 0.010 & 0.010 \\
\hline First Year RC Controls & No & No & No & Yes & No \\
\hline Sample & All & All & All & All & All \\
\hline Year FE & Yes & Yes & Yes & Yes & Yes \\
\hline Degree School FE & Yes & Yes & Yes & Yes & Yes \\
\hline First Job School FE & Yes & Yes & Yes & Yes & Yes \\
\hline Source of Variation & - & - & - & Degree Schools & Recruiters \\
\hline Mean of Outcome & 0.791 & 0.791 & 0.791 & 0.791 & 0.791 \\
\hline
\end{tabular}

This table reports the coefficients of linear probability models on the job matches. The dependent variable takes on a value of one if a specific university hired the candidate in that year and zero on all the other potential hiring universities that year. The sample is constructed by crossing all universities that hire from another degree school in a given year with all the candidates that were hired by any sample university in that year. Schools in Same Rank Decile is an indicator for whether the degree school and recruiting school are in the same rank decile. Advisor has Connection takes on a value of one if the candidate's dissertation chair had a coauthor in the recruiting school. Log Distance between Schools is the log distance between the campuses of the degree school and recruiting school. Post ARC Adoption is defined as the degree school sending candidates to the rookie camp in the current or an earlier year in Column 4. In Column 5, Post ARC Adoption is defined as the recruiter school sending a recruiter to the rookie camp in the current or earlier year. All specifications include year, degree, and first job school fixed effects. The differential effect of the first year of participation is controlled in the specification (4). Standard errors are clustered at the degree school and are reported in parentheses. $+\mathrm{p}<.10 * \mathrm{p}<.05 * * \mathrm{p}<.01$. 
Table 8: The Effects of ARC on New Hire Productivity

\begin{tabular}{|c|c|c|c|c|}
\hline VARIABLES & $\begin{array}{c}\text { (1) } \\
\log (\text { Hire's \# pubs } 3 \text { yrs. out }+1)\end{array}$ & $\begin{array}{c}(2) \\
\log (\text { Hire's \# top-5's } 3 \text { yrs. out }+1)\end{array}$ & $\begin{array}{c}\text { (3) } \\
\log (\text { Hire's \# pubs } 3 \text { yrs. out }+1)\end{array}$ & $\begin{array}{c}(4) \\
\log (\text { Hire's \# top-5's } 3 \text { yrs. out }+1)\end{array}$ \\
\hline Post ARC Adoption (By Recruiter) & $\begin{array}{c}0.15^{* *} \\
(0.06)\end{array}$ & $\begin{array}{c}0.07+ \\
(0.04)\end{array}$ & $\begin{array}{l}0.10^{*} \\
(0.05)\end{array}$ & $\begin{array}{l}0.10^{*} \\
(0.04)\end{array}$ \\
\hline Post ARC X Recruiter Rank & $\begin{array}{r}-0.00 \\
(0.00)\end{array}$ & $\begin{array}{r}-0.00 \\
(0.00)\end{array}$ & $\begin{array}{r}-0.00 \\
(0.00)\end{array}$ & $\begin{array}{r}-0.00 \\
(0.00)\end{array}$ \\
\hline Recruiter Rank & $\begin{array}{c}0.01^{* *} \\
(0.00)\end{array}$ & $\begin{array}{c}0.01^{* *} \\
(0.00)\end{array}$ & & \\
\hline Observations & 1,036 & 1,036 & 956 & 956 \\
\hline Adjusted $R^{2}$ & 0.096 & 0.149 & 0.141 & 0.227 \\
\hline Sample & Pre-Post & Pre-Post & Ever ARC \& Pre-Post & Ever ARC \& Pre-Post \\
\hline Year FE & Yes & Yes & Yes & Yes \\
\hline Degree School FE & No & No & Yes & Yes \\
\hline Mean of dependend variable & 0.82 & 0.53 & 0.85 & 0.56 \\
\hline
\end{tabular}

This table reports the effect of ARC on the productivity of newly hired candidates. The dependent variables are two measures of productivity: the number of publications produced by the hire in the first three years of employment (Columns 1 and 3) and if the number published in a top 5 journal in the first three years (Columns 2 and 4). Models estimated as linear OLS models. Post ARC Adoption is defined as the degree school sending candidates to the rookie camp in the current or earlier year. Recruiter Rank is defined as the predicted rank of the first job placement of the candidate. All specifications include year fixed effects, while columns three and four include degree school fixed effects. Standard errors are clustered at the degree school and are reported in parentheses. $+\mathrm{p}<.10 * \mathrm{p}<.05 * * \mathrm{p}<.01$. 


\section{A Online Appendix: Does In-Person Screening Affect Who Gets Hired?}




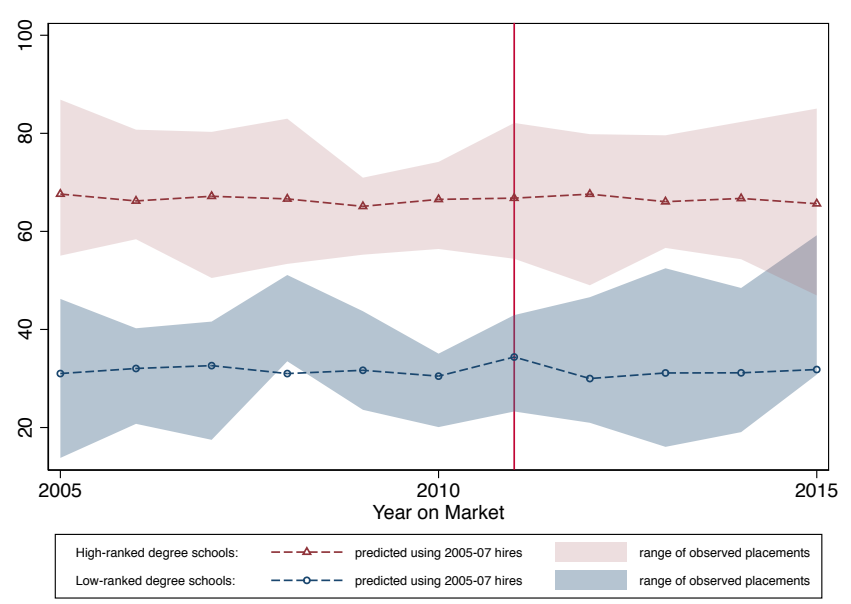

(a) First job rank of new PhD placements by degree school's predicted placement

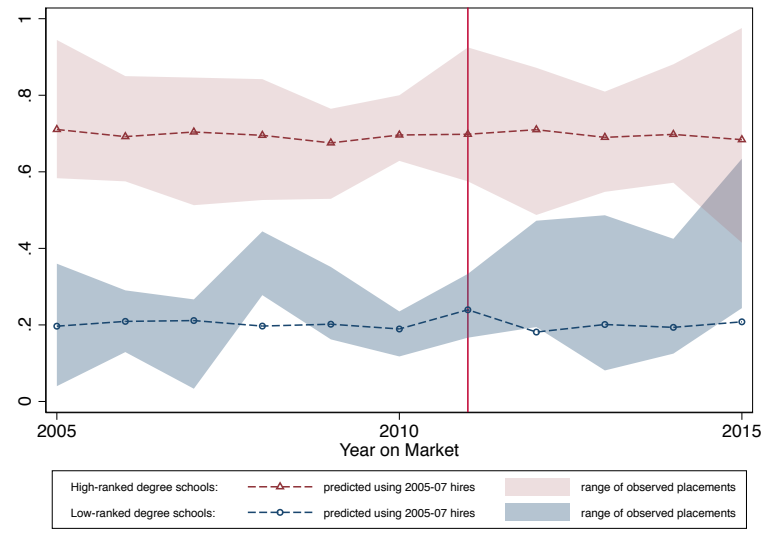

(b) Share of placements at top-ranked schools by degree school's predicted placement

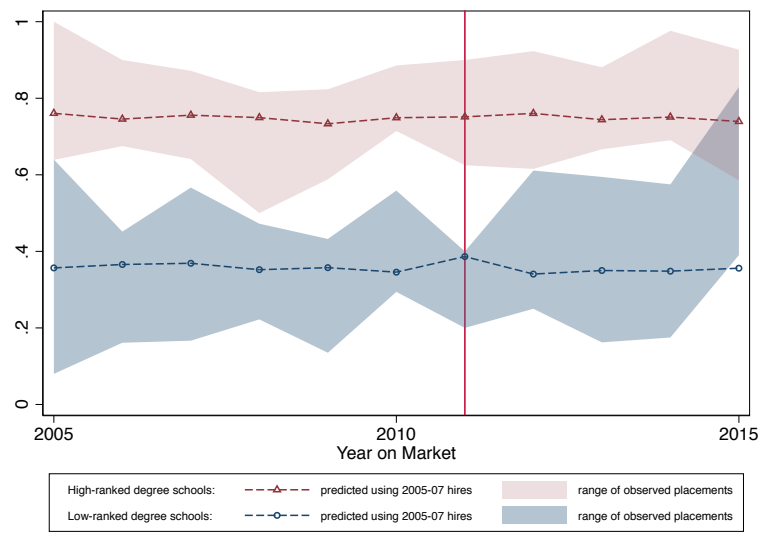

(c) Share of placements at eventual Rookie Camp recruiters by degree school's predicted placement

Figure A.1: This figure graphs the predicted rank of the placement against the actual placement rank by the rank of the supplying school. Because schools may produce more than one student per year overlay the range of placement ranks. This allows us to examine changes in the distribution of placements. In panel (a) we plot the first job ranks predicted and actual placements for high and low ranked schools ( defined above and below the median rank). In panel (b) we plot the share of placement at top-ranked schools for high and low ranked degree schools. Finally, panel (c) post the share of placements go to recruiting schools that eventually attend the rookie camp for high and low ranked universities. 


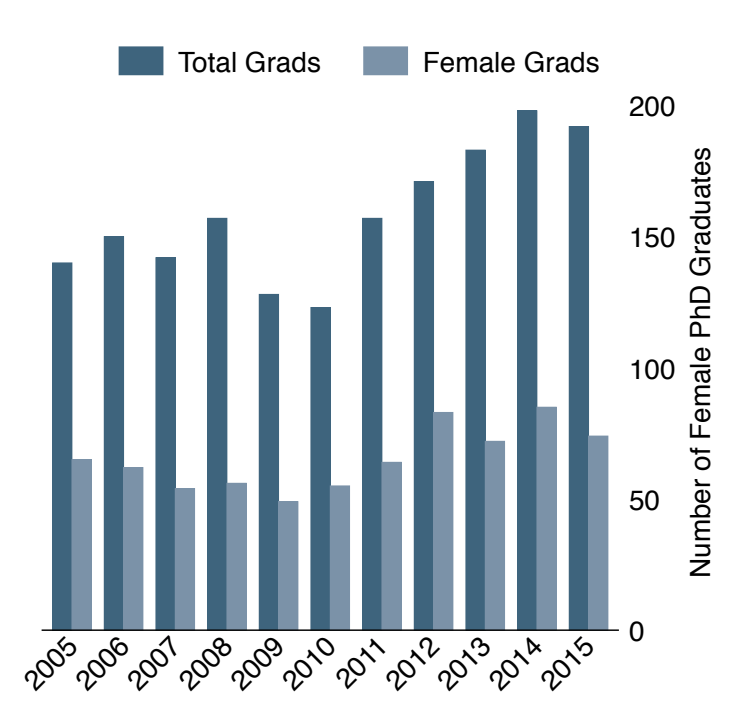

(a) Female Grads

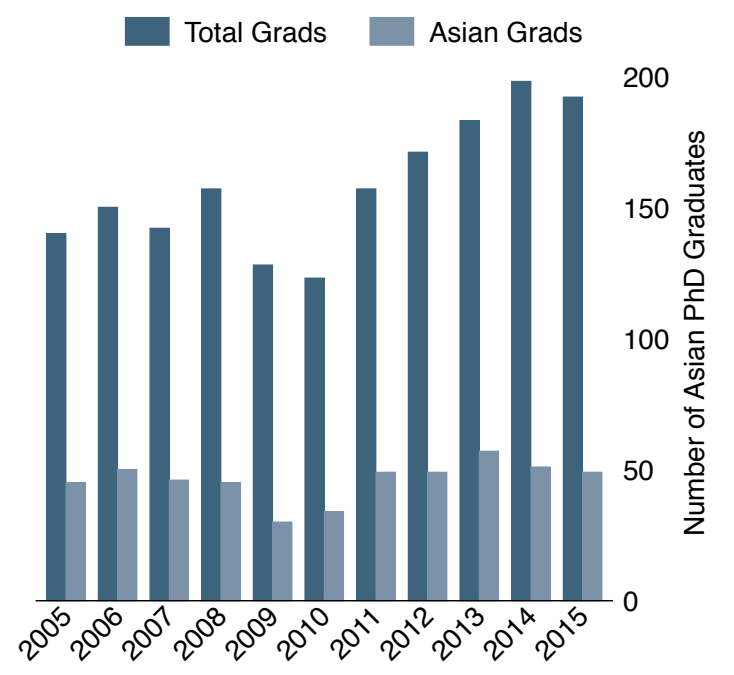

(c) Asian Grads

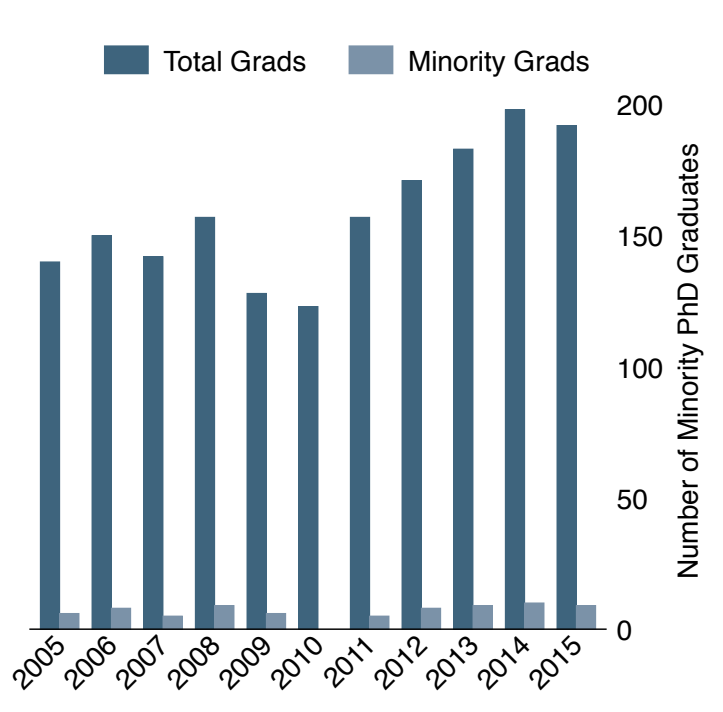

(b) Minority Grads

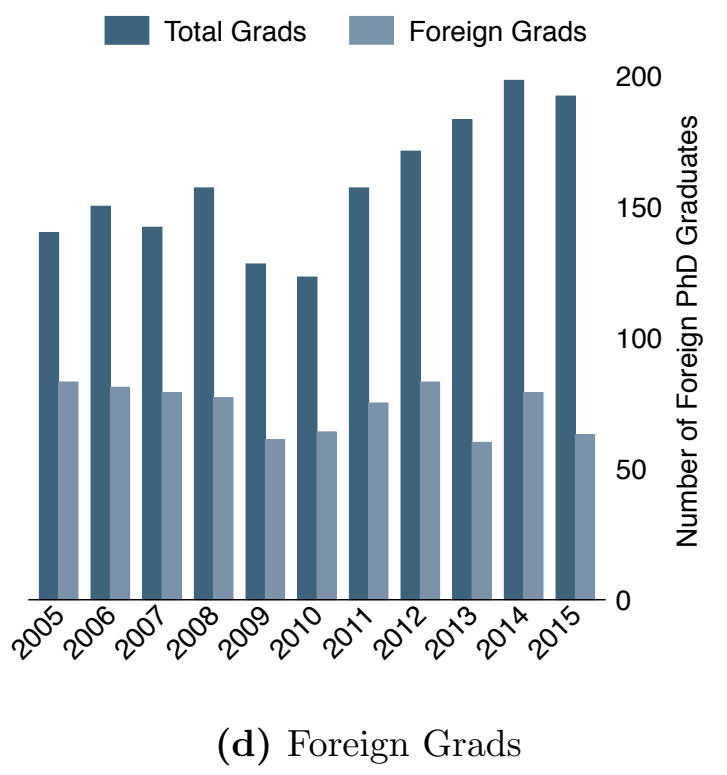

Figure A.2: This figure graphs the numbers of individual participants in the U.S. academic labor market for Ph.D. accountants by demographic groups over the sample years of 20052015. Panel (a) provides the number of new female Ph.D.s while panel (b) plots the number of new Ph.D.s that are minority, (c) and (d) do the same for Asian and foreign graduates. Each Panel also shows the number of Rookie Camp participants in each year. 

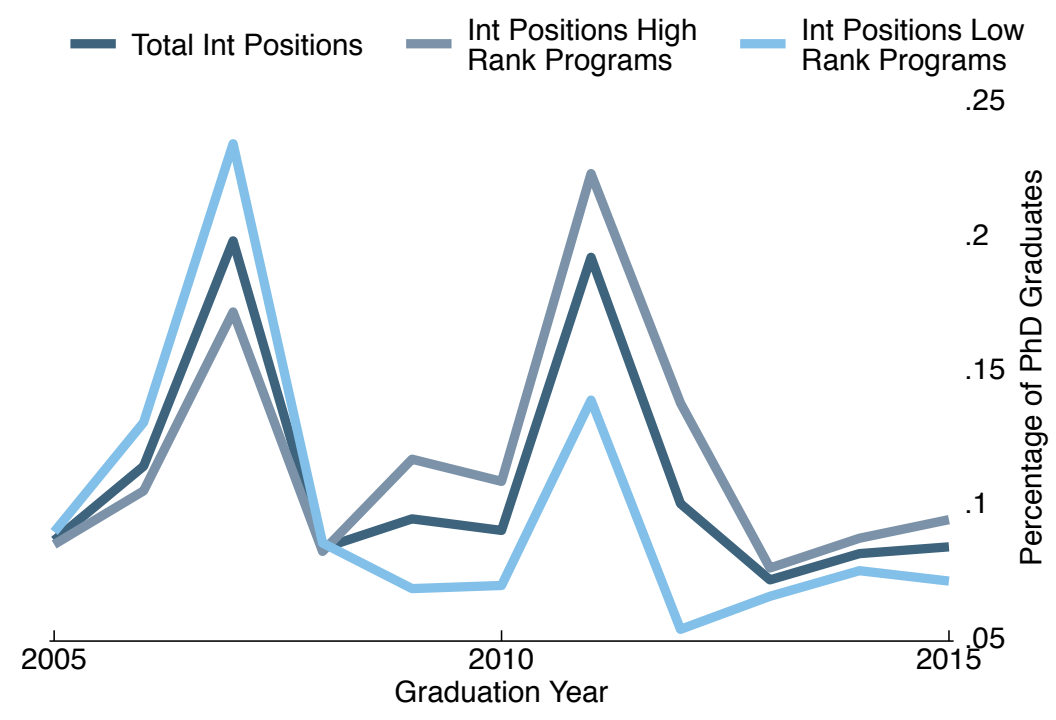

(a) International Placement by Rank of Degree School

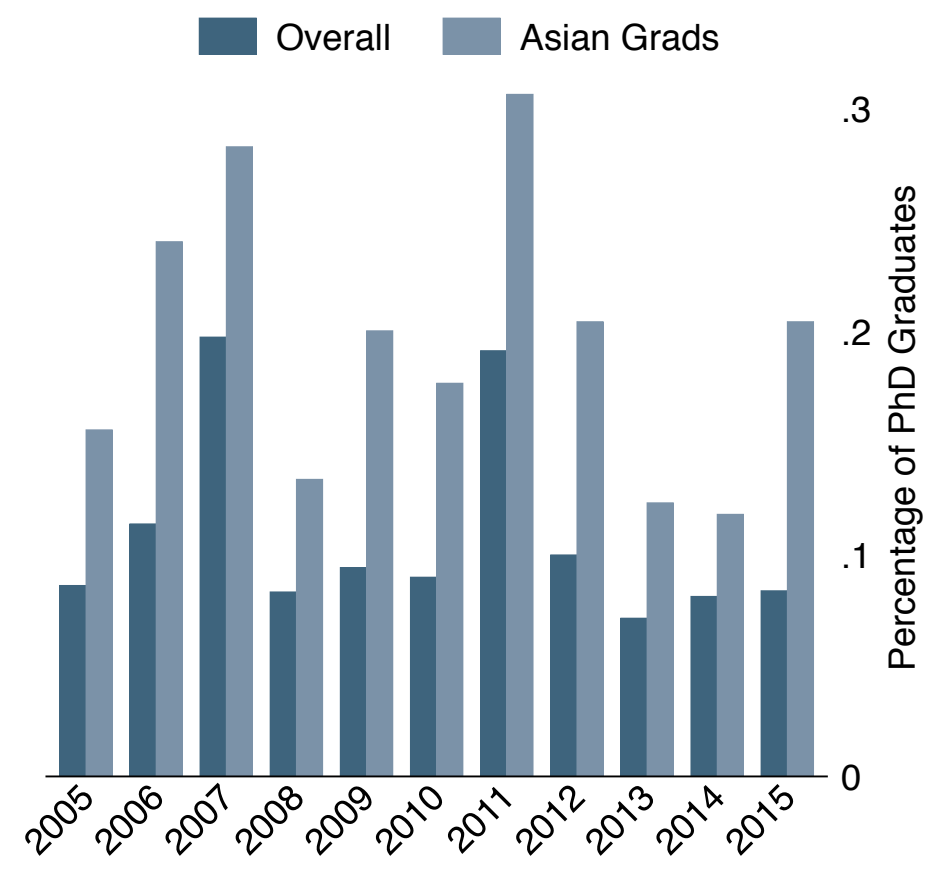

(b) International Placement by Candidate Ethnicity

Figure A.3: This figure graphs the number of Ph.D.s in accounting that took international positions by years. Panel (a) graphs the percentage of international positions obtained by year and rank of the degree program while in panel (b) we plot the percentage of graduates that go international for Asian candidates. 


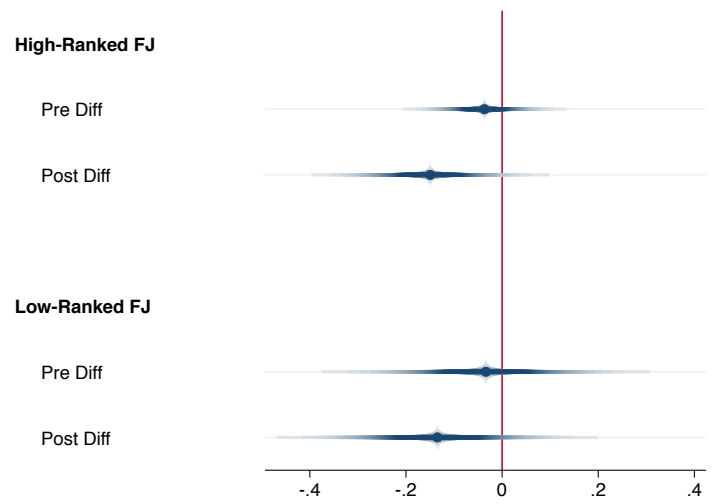

(a) Female (vs. male)

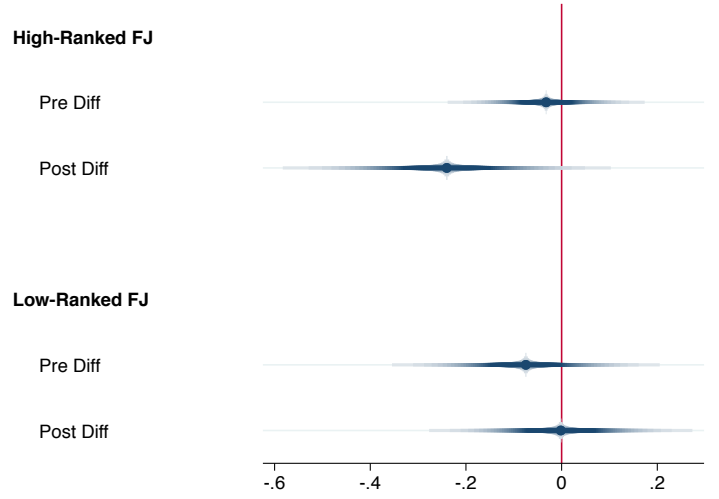

(c) API (vs. white)
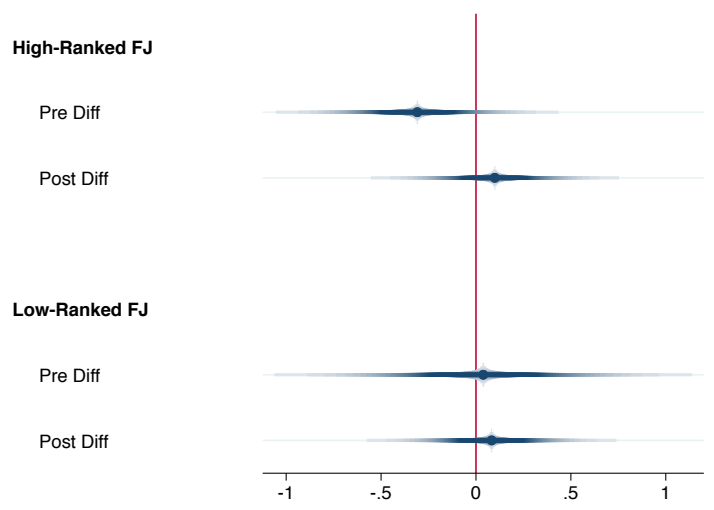

(b) Minority (vs. white)
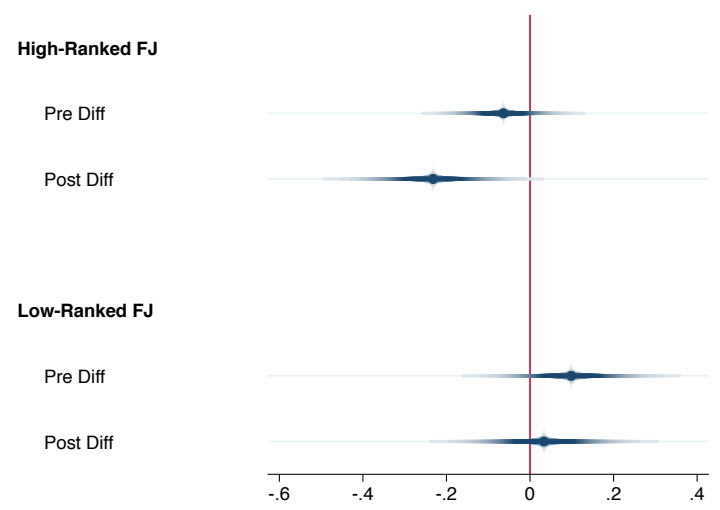

(d) Foreign (International + missing UG vs.domestic UG)

Figure A.4: This figure plots RC's effect on the differential signaling value of a pregraduation publication for each of the various demographic groups. We define the differential between groups as signaling value ${ }_{i}-$ signaling value $_{\text {basegroup }}$. Thus a coefficient of zero means no differential. The estimates are obtained from Table A.6. Panel (a) plots the differential for female and male while panels (b) plots the differential signaling value for minority and white, (c) and (d) do the same for Asian and foreign. The base groups are male for (a), white for (b) and (c) and domestic for (d). In addition, the effects are estimated separately for graduates from high-ranked schools and low-ranked schools in each panel. The bands in each panel provide the $95 \%$ confidence interval for the estimated likelihood. 


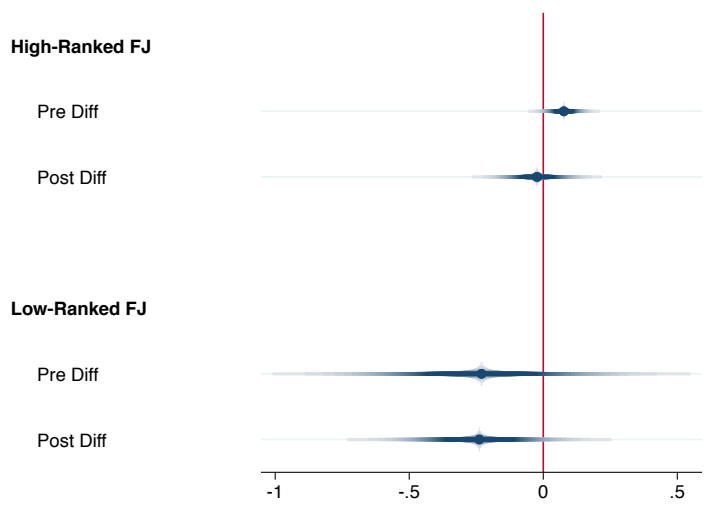

(a) Female (vs. male)

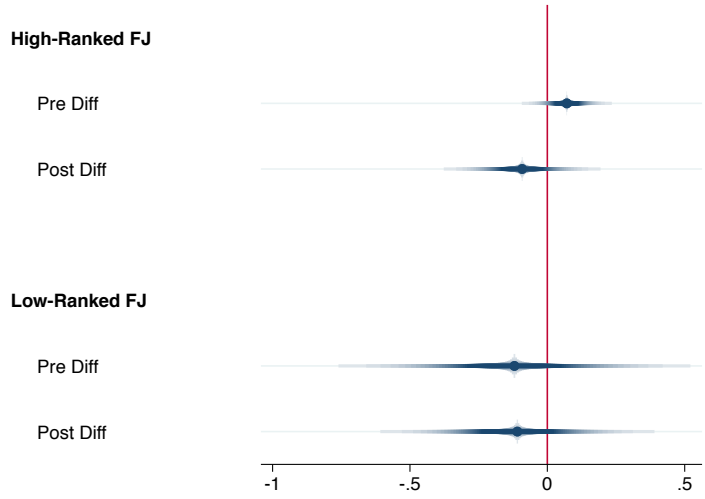

(c) API (vs. white)

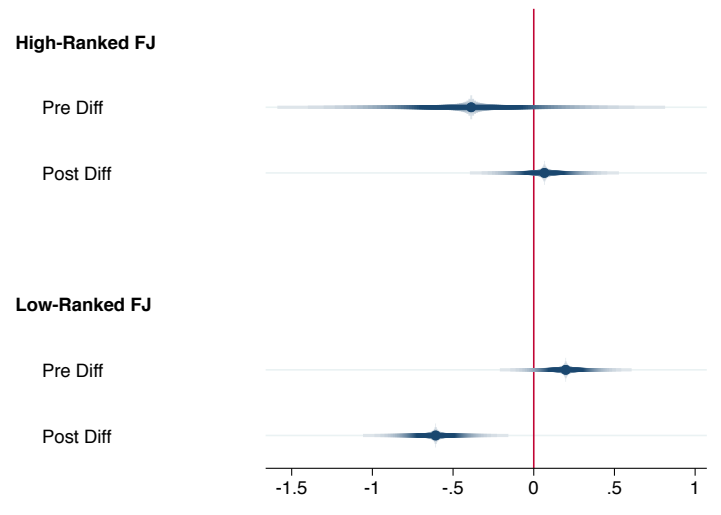

(b) Minority (vs. white)
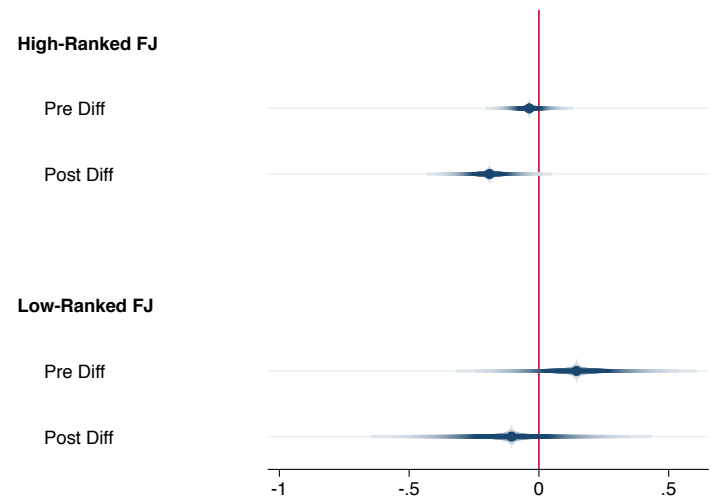

(d) Foreign (International + missing UG vs.domestic UG)

Figure A.5: This figure plots RC's effect on the differential signaling value of having pregraduation Top 5 publication for various demographic groups. We define the differential between groups as signaling value $_{i}-$ signaling value $_{\text {basegroup. }}$. Thus a coefficient of zero means no differential. The estimates are obtained from Table A.6. Panel (a) provides the placement gap between female and male while panels (b) plots the placement gap between minority and white, (c) and (d) do the same for Asian and foreign. In each panel, the effects are estimated separately for graduates from high-ranked schools and low-ranked schools. The bands in each panel provide the $95 \%$ confidence interval for the estimated likelihood. 


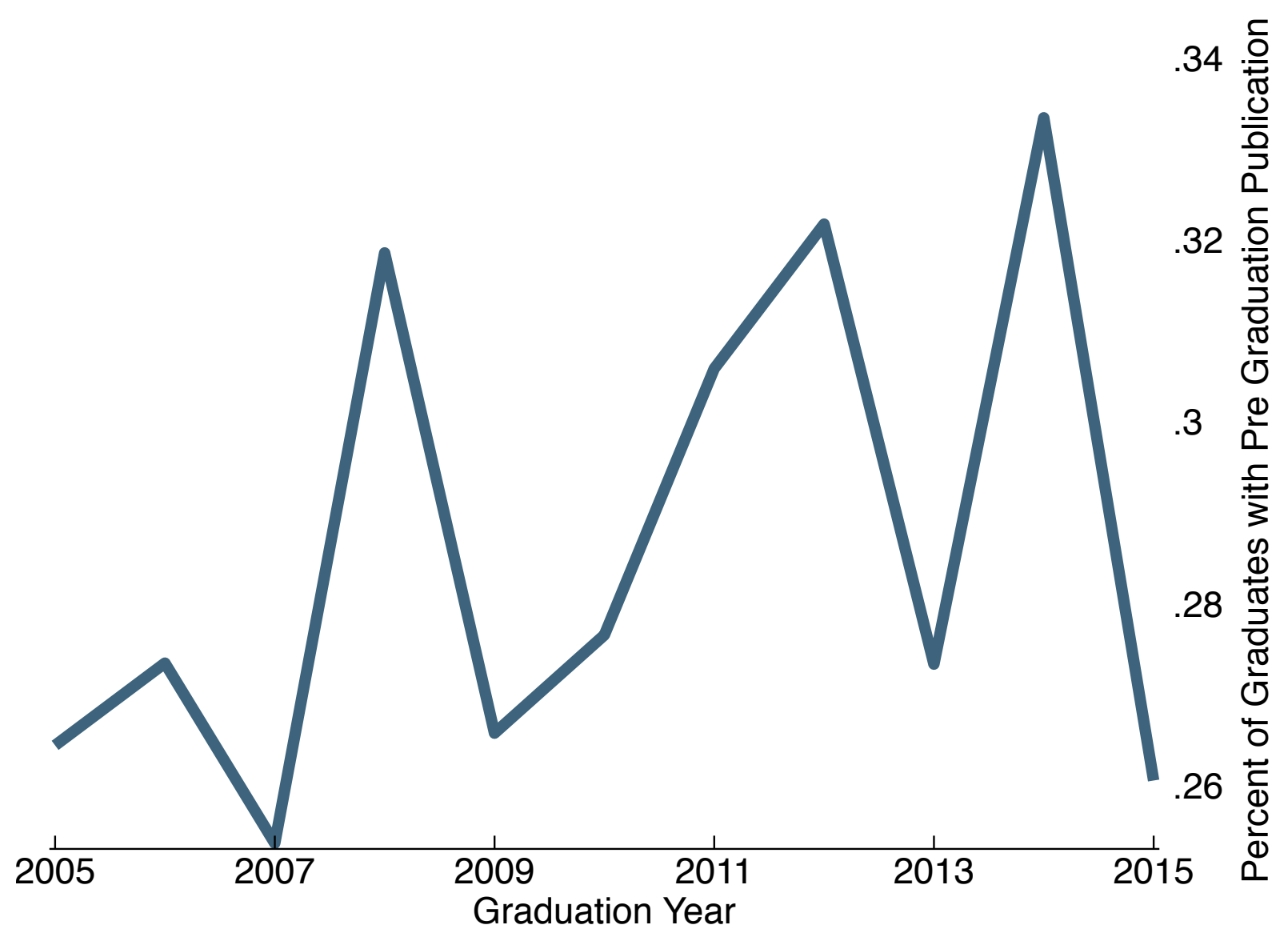

Figure A.6: Percentage of Graduates with a Pre-Graduation Publication. We define an individual having a pre-graduation publication if they had at least one publication by the year of their graduation from the Ph.D. program. 
Table A.1: DS or FJ Leads and Lags

\begin{tabular}{|c|c|c|}
\hline VARIABLES & $\begin{array}{c}(1) \\
\text { DS Rank }\end{array}$ & $\begin{array}{c}(2) \\
\text { FJ Rank }\end{array}$ \\
\hline Predicted School Rank & $\begin{array}{c}0.87^{* *} \\
(0.09)\end{array}$ & $\begin{array}{c}0.69^{* *} \\
(0.07)\end{array}$ \\
\hline Post RC Adoption & $\begin{array}{l}-1.87 \\
(5.53)\end{array}$ & $\begin{array}{c}4.47 \\
(5.15)\end{array}$ \\
\hline Predicted School Rank X Post RC & $\begin{array}{l}-0.42 \\
(0.32)\end{array}$ & $\begin{array}{r}-0.47+ \\
(0.24)\end{array}$ \\
\hline $\mathrm{RC}$ t-1 & $\begin{array}{c}2.48 \\
(6.01)\end{array}$ & $\begin{array}{c}4.52 \\
(5.63)\end{array}$ \\
\hline RC t-1 X Pred Rank & $\begin{array}{c}0.16 \\
(0.35)\end{array}$ & $\begin{array}{l}-0.02 \\
(0.22)\end{array}$ \\
\hline $\mathrm{RC}$ t-2 & $\begin{array}{c}3.04 \\
(4.95)\end{array}$ & $\begin{array}{c}0.95 \\
(4.76)\end{array}$ \\
\hline RC t-2 X Pred Rank & $\begin{array}{l}-0.19 \\
(0.23)\end{array}$ & $\begin{array}{c}0.20 \\
(0.21)\end{array}$ \\
\hline $\mathrm{RC}$ t-3 & $\begin{array}{c}0.46 \\
(4.35)\end{array}$ & $\begin{array}{c}6.21 \\
(5.29)\end{array}$ \\
\hline RC t-3 X Pred Rank & $\begin{array}{c}0.07 \\
(0.20)\end{array}$ & $\begin{array}{l}-0.12 \\
(0.19)\end{array}$ \\
\hline $\mathrm{RC} t+1$ & $\begin{array}{c}7.55 \\
(4.92)\end{array}$ & $\begin{array}{c}0.27 \\
(5.78)\end{array}$ \\
\hline $\mathrm{RC} \mathrm{t}+1 \mathrm{X}$ Pred Rank & $\begin{array}{l}-0.01 \\
(0.31)\end{array}$ & $\begin{array}{c}0.19 \\
(0.27)\end{array}$ \\
\hline $\mathrm{RC} t+2$ & $\begin{array}{l}-2.85 \\
(5.86)\end{array}$ & $\begin{array}{l}-2.94 \\
(3.96)\end{array}$ \\
\hline RC t+2 X Pred Rank & $\begin{array}{c}0.09 \\
(0.31)\end{array}$ & $\begin{array}{l}-0.04 \\
(0.19)\end{array}$ \\
\hline Observations & 957 & 957 \\
\hline Adjusted R-squared & 0.194 & 0.183 \\
\hline Sample & DS Ever RC and Pre-Post & FJ Ever RC and Pre-Post \\
\hline Year FE & Yes & Yes \\
\hline First Job School FE & No & No \\
\hline
\end{tabular}

This table reports the estimates of distributed lag models for the degree school rank (Model 1) and first job rank (Model 2). In each model we add leads and lags of the treatment variable to equation (1). The leads allows us to assess the assumption of no selection on unobservables by testing for differences in hiring patterns prior to ARC's implementation; while the lags allow us to test for dynamic effects. 
Table A.2: Conditional Placement Gaps by Gender, Race and Nationality Over Time

\begin{tabular}{lcccc}
\hline \multirow{2}{*}{ VARIABLES } & $(1)$ & $(2)$ & $(3)$ & $(4)$ \\
& Female & Minority & API & Foreign \\
\hline Year On Market (=Degree Year) & $0.01^{*}$ & $0.01^{*}$ & $0.01^{*}$ & $0.01^{* *}$ \\
& $(0.00)$ & $(0.00)$ & $(0.00)$ & $(0.00)$ \\
Dem & 19.69 & -4.28 & $25.72+$ & $32.45^{*}$ \\
& $(13.63)$ & $(32.01)$ & $(14.92)$ & $(13.66)$ \\
Dem X Year & -0.01 & 0.00 & $-0.01+$ & $-0.02^{*}$ \\
& $(0.01)$ & $(0.02)$ & $(0.01)$ & $(0.01)$ \\
Degree School Rank & $0.01^{* *}$ & $0.01^{* *}$ & $0.01^{* *}$ & $0.01^{* *}$ \\
& $(0.00)$ & $(0.00)$ & $(0.00)$ & $(0.00)$ \\
Observations & & & & \\
Adjusted $R^{2}$ & 1,741 & 1,225 & 1,655 & 1,741 \\
Sample & 0.189 & 0.193 & 0.191 & 0.187 \\
\hline
\end{tabular}

This table reports the conditional placement gaps by gender and ethnicity over time. The estimates are plotted in Figure 8. Standard errors are clustered at the degree school and are in parentheses. $+\mathrm{p}<.10 * \mathrm{p}<.05 * * \mathrm{p}<.01$. 
Table A.3: Robustness Test for Effect of Degree School's Adoption of ARC on The Probability of a High Rank Initial Placement

\begin{tabular}{|c|c|c|c|c|}
\hline VARIABLES & $\begin{array}{c}(1) \\
\operatorname{Pr}(\text { High-Rank FJ })\end{array}$ & $\begin{array}{c}(2) \\
\operatorname{Pr}(\text { High-Rank FJ) } \\
\end{array}$ & $\begin{array}{c}(3) \\
\operatorname{Pr}(\text { High-Rank FJ) } \\
\end{array}$ & $\begin{array}{c}(4) \\
\operatorname{Pr}(\text { High-Rank FJ) }\end{array}$ \\
\hline Post ARC Adoption (Degree School) & $\begin{array}{c}0.04 \\
(0.05)\end{array}$ & $\begin{array}{c}0.04 \\
(0.05)\end{array}$ & $\begin{array}{c}0.01 \\
(0.06)\end{array}$ & $\begin{array}{c}0.01 \\
(0.06)\end{array}$ \\
\hline Post ARC X Pr Hi-Rank FJ & $\begin{array}{c}-0.22^{* *} \\
(0.08)\end{array}$ & $\begin{array}{r}-0.22^{*} \\
(0.08)\end{array}$ & $\begin{array}{c}-0.19+ \\
(0.11)\end{array}$ & $\begin{array}{c}-0.20+ \\
(0.11)\end{array}$ \\
\hline Pre Graduation Publication & & $\begin{array}{c}0.17^{* *} \\
(0.03)\end{array}$ & & $\begin{array}{c}0.18^{* *} \\
(0.04)\end{array}$ \\
\hline Pre Graduation Publication X DS Post ARC & & $\begin{array}{c}-0.01 \\
(0.06)\end{array}$ & & $\begin{array}{c}0.00 \\
(0.06)\end{array}$ \\
\hline Elite Undergrad & & & $\begin{array}{r}-0.05 \\
(0.06)\end{array}$ & $\begin{array}{r}-0.04 \\
(0.06)\end{array}$ \\
\hline Elite UG X DS Post RC & & & $\begin{array}{c}0.09 \\
(0.11)\end{array}$ & $\begin{array}{c}0.10 \\
(0.11)\end{array}$ \\
\hline Observations & 1,659 & 1,659 & 1,431 & 1,431 \\
\hline Adjusted $R^{2}$ & 0.284 & 0.301 & 0.269 & 0.291 \\
\hline First Year RC Controls & Yes & Yes & Yes & Yes \\
\hline Sample & DS Ever ARC and Pre-Post & DS Ever ARC and Pre-Post & DS Ever ARC and Pre-Post & DS Ever ARC and Pre-Post \\
\hline Year FE & Yes & Yes & Yes & Yes \\
\hline Degree School FE & Yes & Yes & Yes & Yes \\
\hline
\end{tabular}

This table reports the robustness test for the effect of degree school's adoption of ARC on the placement at a high-rank initial placement. The estimates are obtained using linear probability models. The sample is restricted to schools that participated and supplied students in the pre and post period. A High-ranked university is defined as a university ranked above the median of all placements in the sample, or roughly the 60th percentile of employers. In each specification, we control for the predicted probability of placing a candidate at a high ranking school for the degree school obtained from a determinants model explained in Section 4. Post RC Adoption is defined at the degree school, sending candidates to the rookie camp in the current year. Pre Graduation Publication is an indicator variable that is one if an individual has a publication at the time of graduation and zero otherwise. Elite UG is an indicator for obtaining a Bachelor's degree from an elite college. All specifications include year and degree school fixed effects. We control for the differential effect of the first year of participation in each of the specifications. Degree school clustered standard errors are reported in parentheses. $+\mathrm{p}<.10 * \mathrm{p}<.05 * * \mathrm{p}<.01$. 
Table A.4: Estimated Effects of ARC on Placement Gaps by Gender and Ethnicity Panel A: First-stage effect of degree school "adoption" on individual participation in rookie camp

\begin{tabular}{|c|c|c|c|c|}
\hline VARIABLES & $\begin{array}{c}(1) \\
\text { Female } \\
\end{array}$ & $\begin{array}{c}(2) \\
\text { Minority }\end{array}$ & $\begin{array}{c}(3) \\
\text { Asian } \\
\end{array}$ & $\begin{array}{c}(4) \\
\text { Foreign }\end{array}$ \\
\hline Post RC Adoption (Degree School) & $\begin{array}{c}0.57^{* *} \\
(0.05)\end{array}$ & $\begin{array}{c}0.55^{* *} \\
(0.05)\end{array}$ & $\begin{array}{c}0.55^{* *} \\
(0.05)\end{array}$ & $\begin{array}{c}0.55^{* *} \\
(0.04)\end{array}$ \\
\hline Post RC X Pr Hi-Rank FJ & $\begin{array}{l}0.33^{* *} \\
(0.07)\end{array}$ & $\begin{array}{l}0.32^{* *} \\
(0.09)\end{array}$ & $\begin{array}{l}0.33^{* *} \\
(0.08)\end{array}$ & $\begin{array}{l}0.33^{* *} \\
(0.06)\end{array}$ \\
\hline Dem & $\begin{array}{c}-0.01 \\
(0.01)\end{array}$ & $\begin{array}{c}0.00 \\
(0.02)\end{array}$ & $\begin{array}{c}-0.02^{*} \\
(0.01)\end{array}$ & $\begin{array}{c}-0.02^{*} \\
(0.01)\end{array}$ \\
\hline Dem X Post RC & $\begin{array}{l}-0.03 \\
(0.04)\end{array}$ & $\begin{array}{r}-0.17+ \\
(0.10)\end{array}$ & $\begin{array}{c}0.07 \\
(0.06)\end{array}$ & $\begin{array}{c}0.04 \\
(0.04)\end{array}$ \\
\hline Observations & 1,659 & 1,161 & 1,579 & 1,659 \\
\hline Adjusted R-squared & 0.532 & 0.507 & 0.548 & 0.532 \\
\hline First Year RC Controls & Yes & Yes & Yes & Yes \\
\hline Sample & DS Ever RC and Pre-Post & DS Ever RC and Pre-Post & DS Ever RC and Pre-Post & DS Ever RC and Pre-Post \\
\hline Year FE & Yes & Yes & Yes & Yes \\
\hline Degree School FE & Yes & Yes & Yes & Yes \\
\hline
\end{tabular}

Panel B: Reduced-form effect of degree school "adoption" on probability of placing in a top ranked school

\begin{tabular}{|c|c|c|c|c|}
\hline VARIABLES & $\begin{array}{c}(1) \\
\text { Female }\end{array}$ & $\begin{array}{c}(2) \\
\text { Minority }\end{array}$ & $\begin{array}{c}(3) \\
\text { Asian }\end{array}$ & $\begin{array}{c}(4) \\
\text { Foreign }\end{array}$ \\
\hline Post RC Adoption (Degree School) & $\begin{array}{c}0.06 \\
(0.05)\end{array}$ & $\begin{array}{c}0.10 \\
(0.07)\end{array}$ & $\begin{array}{c}0.06 \\
(0.06)\end{array}$ & $\begin{array}{c}0.09 \\
(0.06)\end{array}$ \\
\hline Post RC X Pr Hi-Rank FJ & $\begin{array}{c}-0.13+ \\
(0.08)\end{array}$ & $\begin{array}{r}-0.17+ \\
(0.10)\end{array}$ & $\begin{array}{r}-0.15+ \\
(0.08)\end{array}$ & $\begin{array}{r}-0.14+ \\
(0.08)\end{array}$ \\
\hline Dem & $\begin{array}{c}-0.02 \\
(0.03)\end{array}$ & $\begin{array}{c}-0.14^{*} \\
(0.06)\end{array}$ & $\begin{array}{r}-0.05+ \\
(0.03)\end{array}$ & $\begin{array}{l}-0.03 \\
(0.03)\end{array}$ \\
\hline Dem X Post RC & $\begin{array}{l}-0.03 \\
(0.05)\end{array}$ & $\begin{array}{c}0.08 \\
(0.14)\end{array}$ & $\begin{array}{l}-0.08 \\
(0.05)\end{array}$ & $\begin{array}{c}-0.08+ \\
(0.05)\end{array}$ \\
\hline Has Top5 Pub & $\begin{array}{l}0.24^{* *} \\
(0.04)\end{array}$ & $\begin{array}{l}0.23^{* *} \\
(0.07)\end{array}$ & $\begin{array}{l}0.24^{* *} \\
(0.05)\end{array}$ & $\begin{array}{l}0.24^{* *} \\
(0.05)\end{array}$ \\
\hline Has Top5 Pub X DS Post RC & $\begin{array}{l}-0.03 \\
(0.06)\end{array}$ & $\begin{array}{c}-0.02 \\
(0.07)\end{array}$ & $\begin{array}{c}-0.03 \\
(0.06)\end{array}$ & $\begin{array}{c}-0.04 \\
(0.06)\end{array}$ \\
\hline Observations & 1,659 & 1,161 & 1,579 & 1,659 \\
\hline Adjusted R-squared & 0.306 & 0.295 & 0.309 & 0.307 \\
\hline First Year RC Controls & Yes & Yes & Yes & Yes \\
\hline Sample & DS Ever RC and Pre-Post & DS Ever RC and Pre-Post & DS Ever RC and Pre-Post & DS Ever RC and Pre-Post \\
\hline Year FE & Yes & Yes & Yes & Yes \\
\hline Degree School FE & Yes & Yes & Yes & Yes \\
\hline
\end{tabular}

This table reports the effect of ARC on placement gaps by gender and ethnicity. The estimates are plotted in Figure 9. The sample is restricted to schools that participated and supplied students in the pre and post period. All specifications include year and degree school fixed effects. We control for the differential effect of the first year of participation in each of the specifications. Standard errors are clustered at the degree school and are in parentheses. $+\mathrm{p}<.10 * \mathrm{p}<.05 * * \mathrm{p}<.01$. 
Table A.5: Estimated Effect of ARC on Placement Gaps for Chinese-sounding Names

Panel A: First-stage effect of degree school "adoption" on individual participation in rookie camp

\begin{tabular}{|c|c|c|c|c|}
\hline VARIABLES & $\begin{array}{c}(1) \\
\text { Chinese }\end{array}$ & $\begin{array}{c}(2) \\
\text { Other Nationalities }\end{array}$ & $\begin{array}{c}\text { (3) } \\
\text { White Name Chinese }\end{array}$ & $\begin{array}{c}(4) \\
\operatorname{Pr}(\mathrm{RC}) \\
\end{array}$ \\
\hline Post RC Adoption (Degree School) & $\begin{array}{c}0.54^{* *} \\
(0.05)\end{array}$ & $\begin{array}{c}0.56^{* *} \\
(0.04)\end{array}$ & $\begin{array}{c}0.53^{* *} \\
(0.06)\end{array}$ & \\
\hline Post RC X Pr Hi-Rank FJ & $\begin{array}{c}0.42^{* *} \\
(0.08)\end{array}$ & $\begin{array}{c}0.31^{* *} \\
(0.07)\end{array}$ & $\begin{array}{c}0.38^{* *} \\
(0.08)\end{array}$ & \\
\hline Dem & $\begin{array}{l}-0.02 \\
(0.01)\end{array}$ & $\begin{array}{l}0.00 \\
(0.01)\end{array}$ & $\begin{array}{l}-0.03 \\
(0.03)\end{array}$ & \\
\hline Dem X Post RC & $\begin{array}{l}-0.01 \\
(0.06)\end{array}$ & $\begin{array}{l}0.04 \\
(0.05)\end{array}$ & $\begin{array}{l}-0.15 \\
(0.13)\end{array}$ & \\
\hline Has Top 5 Pub & & & & $\begin{array}{l}0.03 \\
(0.02)\end{array}$ \\
\hline High Language Distance & & & & $\begin{array}{c}0.04^{*} \\
(0.02)\end{array}$ \\
\hline Observations & 1,111 & 1,278 & 779 & 1659 \\
\hline Adjusted $R^{2}$ & 0.541 & 0.524 & 0.511 & 0.466 \\
\hline First Year RC Controls & Yes & Yes & Yes & Yes \\
\hline Sample & DS Ever RC and Pre-Post & DS Ever RC and Pre-Post & DS Ever RC and Pre-Post & DS Ever RC and Pre-Post \\
\hline Year FE & Yes & Yes & Yes & Yes \\
\hline Degree School FE & Yes & Yes & Yes & Yes \\
\hline
\end{tabular}

Panel B: Reduced-form effect of degree school "adoption" on probability of placing in a top ranked school

\begin{tabular}{|c|c|c|c|c|}
\hline VARIABLES & $\begin{array}{c}(1) \\
\text { Chinese } \\
\end{array}$ & $\begin{array}{c}(2) \\
\text { Other Nationalities } \\
\end{array}$ & $\begin{array}{c}(3) \\
\text { White Named Chinese }\end{array}$ & $\begin{array}{c}(4) \\
\operatorname{Pr}(\text { High-Rank FJ) }\end{array}$ \\
\hline Post RC Adoption (Degree School) & $\begin{array}{c}0.11 \\
(0.06)\end{array}$ & $\begin{array}{l}0.09 \\
(0.07)\end{array}$ & $\begin{array}{c}0.14 \\
(0.09)\end{array}$ & $\begin{array}{r}0.10+ \\
(0.06)\end{array}$ \\
\hline Post RC X Pr Hi-Rank FJ & $\begin{array}{c}-0.26^{* *} \\
(0.09)\end{array}$ & $\begin{array}{c}-0.16+ \\
(0.09)\end{array}$ & $\begin{array}{c}-0.30^{* *} \\
(0.11)\end{array}$ & $\begin{array}{c}-0.13+ \\
(0.07)\end{array}$ \\
\hline Dem & $\begin{array}{l}-0.04 \\
(0.03)\end{array}$ & $\begin{array}{l}0.02 \\
(0.03)\end{array}$ & $\begin{array}{l}0.05 \\
(0.06)\end{array}$ & \\
\hline Dem_X_post & $\begin{array}{c}-0.14^{* *} \\
(0.05)\end{array}$ & $\begin{array}{l}-0.05 \\
(0.07)\end{array}$ & $\begin{array}{c}-0.41^{* *} \\
(0.15)\end{array}$ & \\
\hline Has Top5 Pub & $\begin{array}{c}0.25^{* *} \\
(0.04)\end{array}$ & $\begin{array}{c}0.20^{* *} \\
(0.06)\end{array}$ & $\begin{array}{c}0.20^{* *} \\
(0.07)\end{array}$ & $\begin{array}{c}0.24^{* *} \\
(0.05)\end{array}$ \\
\hline Has Top5 Pub X DS Post RC & $\begin{array}{l}-0.03 \\
(0.08)\end{array}$ & $\begin{array}{l}0.02 \\
(0.07)\end{array}$ & $\begin{array}{c}0.00 \\
(0.08)\end{array}$ & $\begin{array}{l}-0.04 \\
(0.06)\end{array}$ \\
\hline High Language Distance & & & & $\begin{array}{l}-0.00 \\
(0.03)\end{array}$ \\
\hline High Language Distance X DS Post RC & & & & $\begin{array}{c}-0.13^{* *} \\
(0.04)\end{array}$ \\
\hline Observations & 1,111 & 1,278 & 779 & 1,659 \\
\hline Adjusted $R^{2}$ & 0.322 & 0.283 & 0.298 & 0.308 \\
\hline First Year RC Controls & Yes & Yes & Yes & Yes \\
\hline Sample & DS Ever RC and Pre-Post & DS Ever RC and Pre-Post & DS Ever RC and Pre-Post & DS Ever RC and Pre-Post \\
\hline Year FE & Yes & Yes & Yes & Yes \\
\hline Degree School FE & Yes & Yes & Yes & Yes \\
\hline
\end{tabular}

This table reports the effect of ARC on placement gaps for Asian. The estimates are plotted in Figure 10. The sample is restricted to schools that participated and supplied students in the pre and post period. All specifications include year and degree school fixed effects. We control for the differential effect of the first year of participation in each of the specifications. Standard errors are clustered at the degree school and are in parentheses. $+\mathrm{p}<.10 * \mathrm{p}<.05$ $* * \mathrm{p}<.01$. 
Table A.6: ARC's Effect on the Importance of Pre-Graduation Publication for Various Demographic Groups

Panel A: Effect on Graduates from High-Ranked Schools

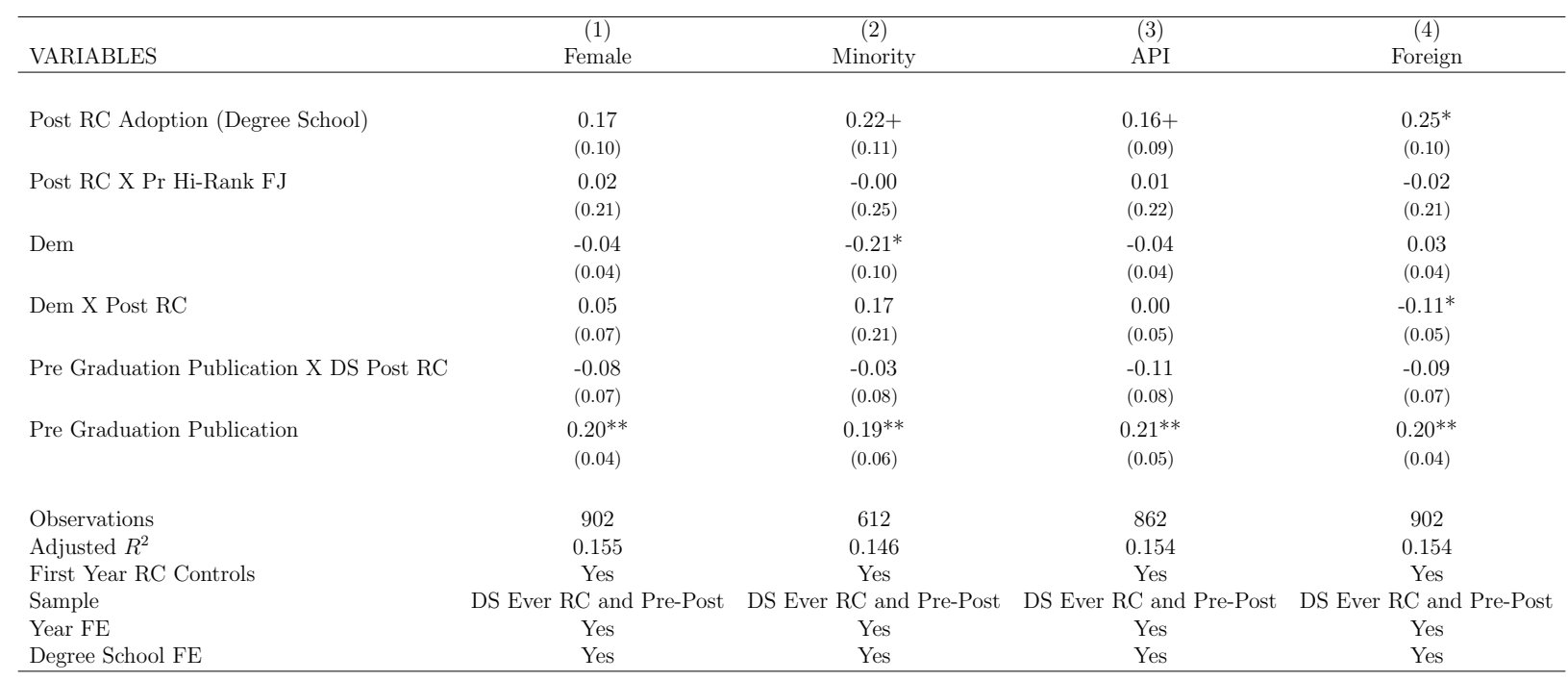

Panel B: Effect on Graduates from Low-Ranked Schools

\begin{tabular}{|c|c|c|c|c|}
\hline VARIABLES & $\begin{array}{c}(1) \\
\text { Female }\end{array}$ & $\begin{array}{c}(2) \\
\text { Minority }\end{array}$ & $\begin{array}{c}(3) \\
\text { API }\end{array}$ & $\begin{array}{c}(4) \\
\text { Foreign }\end{array}$ \\
\hline Post RC Adoption (Degree School) & $\begin{array}{c}0.06 \\
(0.10)\end{array}$ & $\begin{array}{c}0.09 \\
(0.11)\end{array}$ & $\begin{array}{c}0.02 \\
(0.11)\end{array}$ & $\begin{array}{c}0.03 \\
(0.10)\end{array}$ \\
\hline Post RC X Pr Hi-Rank FJ & $\begin{array}{c}0.10 \\
(0.27)\end{array}$ & $\begin{array}{l}-0.01 \\
(0.32)\end{array}$ & $\begin{array}{l}-0.06 \\
(0.29)\end{array}$ & $\begin{array}{c}0.07 \\
(0.26)\end{array}$ \\
\hline Dem & $\begin{array}{l}-0.02 \\
(0.04)\end{array}$ & $\begin{array}{l}-0.12 \\
(0.09)\end{array}$ & $\begin{array}{l}-0.05 \\
(0.04)\end{array}$ & $\begin{array}{c}-0.09^{*} \\
(0.03)\end{array}$ \\
\hline Dem X Post RC & $\begin{array}{l}-0.13 \\
(0.09)\end{array}$ & $\begin{array}{c}0.03 \\
(0.15)\end{array}$ & $\begin{array}{c}-0.22^{*} \\
(0.09)\end{array}$ & $\begin{array}{l}-0.06 \\
(0.07)\end{array}$ \\
\hline Pre Graduation Publication X DS Post RC & $\begin{array}{l}0.06 \\
(0.09)\end{array}$ & $\begin{array}{c}0.04 \\
(0.10)\end{array}$ & $\begin{array}{c}0.09 \\
(0.10)\end{array}$ & $\begin{array}{c}0.10 \\
(0.09)\end{array}$ \\
\hline Pre Graduation Publication & $\begin{array}{l}0.14^{*} \\
(0.06)\end{array}$ & $\begin{array}{l}0.16^{*} \\
(0.07)\end{array}$ & $\begin{array}{l}0.13^{*} \\
(0.06)\end{array}$ & $\begin{array}{l}0.12^{*} \\
(0.06)\end{array}$ \\
\hline $\begin{array}{l}\text { Observations } \\
\text { Adjusted } R^{2} \\
\text { First Year RC Controls } \\
\text { Sample } \\
\text { Year FE } \\
\text { Degree School FE }\end{array}$ & $\begin{array}{c}757 \\
0.156 \\
\text { Yes } \\
\text { DS Ever RC and Pre-Post } \\
\text { Yes } \\
\text { Yes }\end{array}$ & $\begin{array}{c}549 \\
0.166 \\
\text { Yes } \\
\text { DS Ever RC and Pre-Post } \\
\text { Yes } \\
\text { Yes }\end{array}$ & $\begin{array}{c}717 \\
0.165 \\
\text { Yes } \\
\text { DS Ever RC and Pre-Post } \\
\text { Yes } \\
\text { Yes }\end{array}$ & $\begin{array}{c}757 \\
0.161 \\
\text { Yes } \\
\text { DS Ever RC and Pre-Post } \\
\text { Yes } \\
\text { Yes }\end{array}$ \\
\hline
\end{tabular}

This table reports the importance of a pre-graduation publication on placement gaps. The estimates are plotted in Figure A.4. The sample is restricted to schools that participated and supplied students in the pre and post period. In panel A, the sample is further restricted to graduates from high-ranked schools while the sample is limited to graduates from lowranked schools in panel B. All specifications include year and degree school fixed effects. We control for the differential effect of the first year of participation in each of the specifications. Standard errors are clustered at the degree school and are in parentheses. $+\mathrm{p}<.10 * \mathrm{p}<.05$ $* * \mathrm{p}<.01$. 
Table A.7: ARC's Effect on the Importance of Pre-Graduation Top 5 Publication Pre Graduation for Various Demographic Groups

Panel A: Effect for Graduates from High-Ranked Schools

\begin{tabular}{|c|c|c|c|c|}
\hline VARIABLES & $\begin{array}{c}(1) \\
\text { Female }\end{array}$ & $\begin{array}{c}(2) \\
\text { Minority }\end{array}$ & $\begin{array}{c}(3) \\
\text { API }\end{array}$ & $\begin{array}{c}(4) \\
\text { Foreign }\end{array}$ \\
\hline Post RC Adoption (Degree School) & $\begin{array}{c}0.17+ \\
(0.10)\end{array}$ & $\begin{array}{c}0.24^{*} \\
(0.12)\end{array}$ & $\begin{array}{c}0.15+ \\
(0.09)\end{array}$ & $\begin{array}{c}0.24^{*} \\
(0.12)\end{array}$ \\
\hline Post RC X Pr Hi-Rank FJ & $\begin{array}{c}0.00 \\
(0.23)\end{array}$ & $\begin{array}{l}-0.06 \\
(0.25)\end{array}$ & $\begin{array}{l}-0.01 \\
(0.23)\end{array}$ & $\begin{array}{c}-0.04 \\
(0.23)\end{array}$ \\
\hline Dem & $\begin{array}{l}-0.03 \\
(0.04)\end{array}$ & $\begin{array}{c}-0.18^{*} \\
(0.09)\end{array}$ & $\begin{array}{l}-0.03 \\
(0.04)\end{array}$ & $\begin{array}{c}0.04 \\
(0.04)\end{array}$ \\
\hline Dem X Post RC & $\begin{array}{l}0.04 \\
(0.06)\end{array}$ & $\begin{array}{c}0.14 \\
(0.20)\end{array}$ & $\begin{array}{l}-0.01 \\
(0.06)\end{array}$ & $\begin{array}{c}-0.11+ \\
(0.06)\end{array}$ \\
\hline Has Top5 Pub & $\begin{array}{c}0.21^{* *} \\
(0.05)\end{array}$ & $\begin{array}{c}0.18^{* *} \\
(0.06)\end{array}$ & $\begin{array}{c}0.21^{* *} \\
(0.05)\end{array}$ & $\begin{array}{c}0.21^{* *} \\
(0.06)\end{array}$ \\
\hline Has Top5 Pub X DS Post RC & $\begin{array}{l}-0.04 \\
(0.07)\end{array}$ & $\begin{array}{c}0.00 \\
(0.07)\end{array}$ & $\begin{array}{l}-0.05 \\
(0.07)\end{array}$ & $\begin{array}{l}-0.06 \\
(0.06)\end{array}$ \\
\hline Observations & 902 & 612 & 862 & 902 \\
\hline Adjusted $R^{2}$ & 0.156 & 0.141 & 0.154 & 0.155 \\
\hline First Year RC Controls & Yes & Yes & Yes & Yes \\
\hline Sample & DS Ever RC and Pre-Post & DS Ever RC and Pre-Post & DS Ever RC and Pre-Post & DS Ever RC and Pre-Post \\
\hline Year FE & Yes & Yes & Yes & Yes \\
\hline Degree School FE & Yes & Yes & Yes & Yes \\
\hline
\end{tabular}

Panel B: Effect for Graduates from Low-Ranked Schools

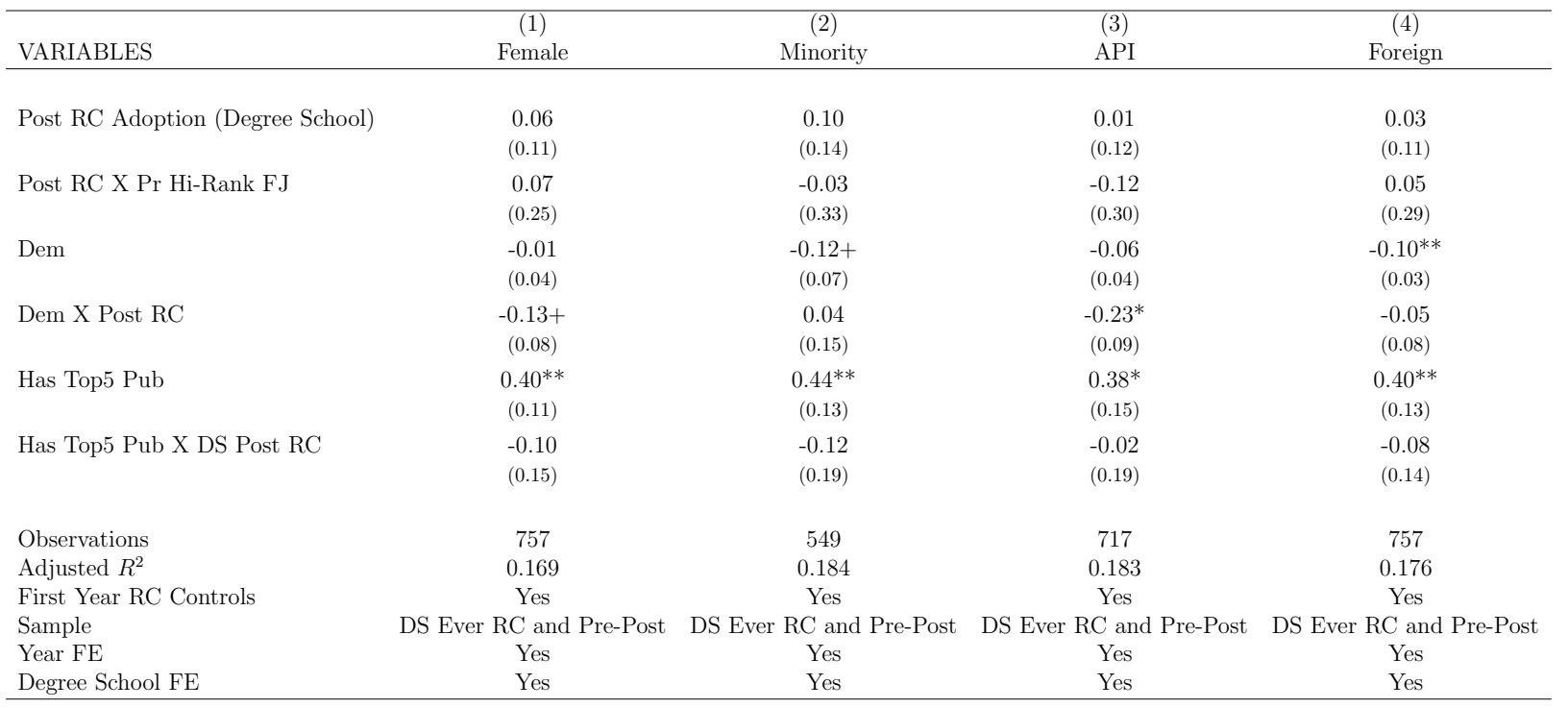

This table reports the importance of having top 5 publication pre graduation on placement gaps. The estimates are plotted in Figure A.5. The sample is restricted to schools that participated and supplied students in the pre and post period. In panel A, the sample is further restricted to graduates from high-ranked schools while the sample is limited to graduates from low-ranked schools in panel B. All specifications include year and degree school fixed effects. We control for the differential effect of the first year of participation in each of the specifications. Standard errors are clustered at the degree school and are in parentheses. $+\mathrm{p}<.10 * \mathrm{p}<.05 * * \mathrm{p}<.01$. 
Table A.8: Comparison of Writing Quality for Various Demographic Groups against White Candidates before and after ARC

Panel A: Writing Typos

\begin{tabular}{lccc}
\hline & $(1)$ & $(2)$ & $(3)$ \\
VARIABLES & API & Chinese & White Chinese Names \\
\hline & & & \\
Post ARC Adoption (By Degree School) & 0.23 & 0.35 & 0.11 \\
& $(0.30)$ & $(0.32)$ & $(0.22)$ \\
Post ARC X Degree School Rank & -0.29 & -0.21 & -0.17 \\
& $(0.28)$ & $(0.27)$ & $(0.22)$ \\
Dem & -0.02 & -0.05 & 0.00 \\
& $(0.09)$ & $(0.12)$ & $(0.24)$ \\
Dem X Post RC & -0.10 & -0.14 & 0.02 \\
& $(0.15)$ & $(0.17)$ & $(0.35)$ \\
Pre Graduation Top 5 Pub & 0.14 & 0.09 & -0.09 \\
& $(0.10)$ & $(0.09)$ & $(0.06)$ \\
Pre Graduation Top 5 Pub X Post ARC & -0.19 & -0.17 & -0.01 \\
& $(0.12)$ & $(0.14)$ & $(0.11)$ \\
Observations & & & \\
Adjusted $R^{2}$ & 538 & 492 & 323 \\
First Year RC Controls & 0.068 & 0.131 & 0.330 \\
Sample & Yes & Yes & Yes \\
Year FE & Yes & Yes & Ever ARC \& Pre-Post \\
Degree School FE & Yes & Yes & Yes \\
\hline
\end{tabular}

Panel B: Writing Compelxity

\begin{tabular}{lccc}
\hline & $(1)$ & $(2)$ & $(3)$ \\
VARIABLES & API & Chinese & White Chinese Names \\
\hline & & & \\
Post ARC Adoption (By Degree School) & 0.02 & 0.04 & 0.04 \\
& $(0.05)$ & $(0.05)$ & $(0.04)$ \\
Post ARC X Degree School Rank & 0.03 & -0.00 & -0.00 \\
& $(0.07)$ & $(0.08)$ & $(0.11)$ \\
Dem & 0.00 & 0.02 & 0.03 \\
& $(0.02)$ & $(0.02)$ & $0.06)$ \\
Dem X Post RC & 0.05 & 0.04 & 0.01 \\
& $(0.04)$ & $(0.05)$ & $(0.07)$ \\
Pre Graduation Top 5 Pub & -0.02 & -0.02 & -0.01 \\
& $(0.03)$ & $(0.02)$ & $(0.02)$ \\
Pre Graduation Top 5 Pub X Post ARC & 0.02 & 0.03 & 0.00 \\
& $(0.04)$ & $(0.04)$ & $(0.03)$ \\
Observations & & & \\
Adjusted $R^{2}$ & 538 & 492 & 323 \\
First Year RC Controls & 0.161 & 0.183 & 0.243 \\
Sample & Yes & Yes & Yes \\
Year FE & Yes & Yes & Ever ARC \& Pre-Post \\
Degree School FE & Yes & Yes & Yes \\
\hline
\end{tabular}

This table reports comparison of writing quality for various demographic groups against white candidates before as well as after ARC. The estimates are plotted in Figure 12 The sample is restricted to schools that participated and supplied students in the pre and post period. The dependent variable in Panel A is average number of typographical errors in individual dissertation. The dependent variable in Panel B is the lexcial richness measure of Mass; the index is based on a logarithmic function of the relation between the terms (types) and the total number of words in a text (tokens). The measure gives us a measure of the diversity of the writing. All specifications include year and degree school fixed effects. We control for the differential effect of the first year of participation in each of the specifications. Standard errors are clustered at the degree school and are in parentheses. $+\mathrm{p}<.10 * \mathrm{p}<.05 * * \mathrm{p}<.01$. 